\title{
Alchemisten und Goldmacher im 16. Jahrhundert in der Schweiz
}

\author{
Von Frieda Maria Huggenberg, Zürich
}

\section{Die Alchemie und ihre Anhänger im 16. Jahrhundert}

Das bewegte Cinquecento könnte in mancher Beziehung mit der Gegenwart verglichen werden. Nachdem sich die Wogen der Glaubensspaltung gelegt, fing der Dämon Gold die Menschheit zu beherrschen an, eine ungeheure Sucht nach Reichtum und Macht erfüllte Obrigkeit wie Bürger, hoch wie niedrig. Nocb wußte man wenig von Industrie und Technik, die Medizin steckte in ihren Anfängen, von der Chemie kannte man nichts Eigentliches, die Alchemie als ihre Vorgängerin aber übte seit ältesten Zeiten ihre Zauberkraft in den verschiedensten Formen aus. Um die Mitte des 16. Jahrhunderts nahm sie in allen Ländern einen neuen Aufschwung, besonders in Deutschland. Ihr huldigten die Mystiker wie die bedeutendsten Naturforscher des Zeitalters.

«L'Alchemie a souvent fait découvrir des grandes véritées sur le chemin de l'imagination. ${ }^{1}$

Für die einen Alchemisten war das Quecksilber, für die andern Erz, Eisen, Schwefel, Salz von höchster Bedeutung, je nachdem, was sie zu erforschen oder zu erzeugen hofften. «Gold sucht nach Gold, Silber nach Silber, Blei nach Blei », lautete die grundlegende Erkenntnis, die der Bergwerkingenieur Georg Thurzo aus Krakau den Fuggern in Augsburg vermittelte und sie bewog, Bergwerke zu kaufen und nach Erzen graben zu lassen ${ }^{2}$.

Die Frage der Metallverwandlung war von jeher ein brennendes Problem, wußte man doch lange Zeit nicht, daß Erze goldhaltig sind. Von allen Metallen kommen nur Gold, Silber, Kupfer und Quecksilber, aber auch diese nur ausnahmsweise, gediegen in der Erde vor. Durch Zusatz einer besondern Substanz versuchte die Alchemie die Verwandlung anderer Metalle in Gold zu bewirken. 1540 wurde der Schwefeläther entdeckt, und 1557 gelang Bartholomé de Medina durch Amalgamation die Gewinnung von Silber und Gold.

1 D. Diderot, Französischer Schriftsteller 1713 bis 1784.

2 E. Ortner, Das Weltreich der Fugger, Augsburg 1941, Bd.II, S. 78. 
Die Goldmacherkunst wurde als Geheimnis des ewigen Lebens, als Dienerin der Naturwissenschaft betrachtet. Man nahm an, das große Elexir, der sogenannte «Stein der Weisen», stärke und verjünge als Universalmittel den menschlichen Körper, er komme daher hauptsächlich für die Heilkunde in Betracht, während das kleine Elexir unedle Metalle in Silber verwandle. Der Stein der Weisen war für hochgebildete Männer eine absolute Wirklichkeit, dessen Erforschung die Gelehrten immer wieder anspornte.

Es müßte eine vielseitige und reizvolle Aufgabe sein, die Anregungen, Versuche, Förderungen, die im Laufe des 16. Jahrhunderts zur Entfaltung von Wissenschaft, Kunst, Kultur nur von den Alchemisten ausgegangen sind, verfolgen zu können. So darf die Alchemie keineswegs als Spielerei oder Scharlatanerie betrachtet und verurteilt werden. Sie mag oft in falsche und abwegige Bahnen geraten sein, aber als Vorstufe der Chemie wurde viel nützliche Arbeit geleistet.

«Die Bedeutung der Alchemie für die Entwicklungsgeschichte der Chemie liegt auf der Hand, ihre geistesgeschichtliche Bedeutung dagegen ist fast noch unbekannt.» ${ }^{3}$

In Paracelsus finden wir im 16. Jahrhundert den größten Vertreter der wissenschaftlichen Alchemie, und durch ihn gewann sie an Bedeutung. Aurelius Philippus Theophrastus Paragelsus Bombast von Hohenheim* wurde als Sohn des Arztes Wilhelm Bombast 1493 in der Nähe von Einsiedeln geboren. 1503 wurde sein Vater als Stadtarzt nach Villach in Kärnten berufen. In der Nähe befanden sich die Fuggerschen Bergwerke. Der aufgeweckte Knabe begleitete den Vater früh in die Gruben und wurde durch ihn mit Mineralogie, Botanik, Geochemie bekannt. Paracelsus bedeutete die Alchemie nie nur bloßes Suchen nach dem Stein der Weisen, sondern sein ganzes Streben ging darauf aus, Gesundheit und Krankheit des Körpers durch chemische Prozesse abklären zu können. Nach seiner Lehre beruht die Medizin auf vier Grundpfeilern: Philosophie, Astronomie, Alchemie, Ethos. Philosophie als Eingangstor zur Medizin; Astronomie: der wahre Weg zur Heilkunde liegt in den Sternen; Alchemie ist nötig, um die Heilmittel für die Krankheiten zuzubereiten; Ethos: der höchste Grad der Medizin ist Liebe und Barmherzigkeit - lautete die Auslegung von Paracelsus. Er war in seiner ganzen Lebensweise ein äußerst bescheidener

3 C. G. Jung, Paracelsus, Zürich und Leipzig 1951.

* Paracelsus starb am 24. September 1541 in Salzburg. Er war Naturphilosoph, Arzt, Astrolog, Gelehrter, Mystiker, Alchemist, Verfasser vieler Schriften. Durch den Herausgeber der zahlreichen Werke: Karl Sudhoff, gelangte Paracelsus erst in neuerer Zeit zur richtigen Anerkennung und werden seine großen Verdienste gewürdigt. 
Mensch, auf nichts anderes bedacht, als Kenntnisse und Wissen zu erweitern, um der leidenden Menschheit zu dienen.

«Tätiger Christ sein, heißt liebender Helfer sein. Ein Arzt mu $\beta$ Christ sein, der nicht nur für Heilung und Erhaltung des Körpers bedacht ist, sondern auch für die Seele sorgt. Gott ließ nie eine Krankheit kommen, der er nicht ihre Arznei verschrieben.» ${ }^{4}$

Er betrachtete als edelste Aufgabe der Alchemie die Erforschung der richtigen Zubereitung von Heilmitteln und der Wirkung derselben auf den Organismus. Erst in zweiter Linie befaßte er sich mit der künstlichen Hervorbringung edler Metalle.

«Viele haben sich in Alchimey geäußert. Wenn sie sagen, sie machen Gold und Silber, ist dies nicht ihr eigentliches Vorhaben, sondern allein das Verlangen zu traktieren, was Tugend und Kräfte der Arzney seien.» ${ }^{5}$

Paracelsus wußte um die Herstellung der Metallsalze, erkannte die Wirkung des Opiums, der ätherischen Öle, des Quecksilbers, die Verwendung der Nieswurz gegen die Wassersucht, einem Übel, unter welchem in frühern Zeiten viele litten. Er war der Begründer der modernen Pharmakologie und Psychiatrie, er unterschied die Heilquellen nach ihrer Art und ihrer Wirkung auf den menschlichen Organismus. Sein ungeheurer Fleiß und Wissensdurst trieb ihn von Land zu Land. Bald beschäftigte er sich als Arzt und Heiler, bald als Sprachlehrer und Gelehrter, dann wiederum als Geologe und Grubenarbeiter. So lernte er die Beziehungen zwischen den Lungenkrankheiten der Bergbauarbeiter und ihrem Berufe - insbesonders die Einwirkung der Grubengifte - kennen. Im 16. Jahrhundert wurden seine genialen Forschungen allerdings vielfach als Zauberkünste ausgelegt und oft mit Mißtrauen betrachtet. Aber wo wäre die Wissenschaft heute ohne die unermüdlichen Forschungen und Versuche eines Albrecht von Haller, eines Koch, Pasteur oder des Ehepaares Curie? Alle Erfindungen beruhen auf ausdauernder mühevoller Arbeit. Trotz dem häufigen Mißlingen ihrer Experimente erfüllte dieser Gedanke auch die alten Alchemisten, denn von dem eigentlichen Wesen der Chemie wußten sie ja noch nichts.

Paracelsus wirkte 1528 als Universitätsprofessor in Basel, wo ihn Bartholome Schobinger aus St. Gallen kennenlernte. Schobinger (1500 bis 1585) unterhielt weitgehende Beziehungen und stand als Handelsherr von Eisen, Stahl und Kupfer in enger Verbindung mit dem Hause Fugger in Augsburg. Einige Zeit war er der reichste Mann nicht nur von St. Gallen,

4 C. G. Jung, Psychologie und Alchemie, Zürich 1944, 1951.

5 J.Betschart, Theophrastus Paracelsus, Zürich 1941.

H.R. WoLf, Biographien zur Kulturgeschichte der Schweiz, Bd.III/1. 
sondern der ganzen Eidgenossenschaft. Von 1530 bis 1582 saß er im Rate, bekleidete mehrere städtische Ämter, unter andern dasjenige eines Münzprobierers. 1565 amtete er als Obmann der Münzkommission. Alle die Ämter dienten Schobinger hauptsächlich zur Förderung seiner Ambitionen, die auf wissenschaftlichem Gebiet lagen. Vorab interessierte er sich für Naturwissenschaft, pflegte aber auch eifrig Numismatik und verkehrte viel mit Altertumsforschern.

Schobinger wurde zu einem der treuesten Anhänger und Bewunderer von Paracelsus. Als sich dieser genötigt sah, wegen Differenzen mit dem Magistrat Basel zu verlassen, folgte Paracelsus der Einladung Schobingers nach St. Gallen. Dessen Schwiegervater, Christian Stauder, 1525 Bürgermeister, erkrankte 1531 schwer. Parạcelsus konnte ihm nur noch etwelche Erleichterung in dem bereits allzu vorgeschrittenen Leiden bringen. Bis zum Tode Stauders wohnte er in dessen Haus, nachher siedelte er zu Schobinger in das Haus «Zur Wahrheit» über. Im Schloß Horn richtete er dem sich leidenschaftlich Interessierenden ein größeres Laboratorium ein, eine seiner kleinen «kuchinen» in der «Wahrheit», in welcher Schobinger jederzeit eigene Versuche vornehmen konnte. An den Experimenten nahmen auch seine Brüder Hieronymus und Josef Schobinger sowie der Schwager Jаков Stauder, (1512-1584), Sohn von Christian, regen Anteil. In einem Briefe an Paracelsus schrieb Bartholome, wie glücklich und dankbar er sich fühle, durch den berühmten Meister persönlich in die Künste der Alchemie eingeführt worden zu sein, «dan ich bin von natur darzue erboren und von iugend uff biß uf dise stund dahin genaigt zu allen erlichen unnd nützlichen künsten.» Aus Dankbarkeit ließ Schobinger ein Bildnis von Paracelsus malen, welches lange in der Familie blieb, dann jedoch durch die Wechselschicksale der Nachkommen verlorenging.

Schobinger hinterließ eine für jene Zeit bedeutende Bibliothek deutscher und lateinischer Werke über Numismatik, Astrologie, Altertumskunde und besonders Alchemie*. Die Söhne und Enkel erbten fast alle seine Leidenschaft. David (1531-1599) vermehrte die alchemistische Bücherei und

* Besonders interessant gestaltete sich auch das Schicksal des jüngsten Sohnes Bartholome Schobingers. Er erbte nicht nur den Unternehmungsgeist des Vaters, sondern auch dessen Talente. Dieser ließ ihn an der Universität Augsburg studieren, wo er durch Magister Paningo in die Naturwissenschaften eingeführt wurde. Wahrscheinlich auf Anregung von Hieronymus SaILer, des verwandten Handelsherrn in Augsburg, erwarb er sich auch Kenntnisse im Bergbau und trat in die Handelsgesellschaft der Welser ein. Seine Reisen führten ihn in die Niederlande, wo er zwischen 1575 bis 1585 einen ausgedehnten Handel mit Webwaren betrieb. Am 16. September 1580 verheiratete er sich in 
stand diesbezüglich in regem Verkehr mit Professor Theodor Zwinger in Basel und Bürgermeister Johann Conrad Meyer in Schaffhausen ${ }^{6}$.

Antwerpen mit der Tochter des reichen Kaufherrn und Schöffen Markus Perez de VARoN. Die religiösen Unruhen aber nötigten das junge Ehepaar, nach Köln zu ziehen. Am 11. Juli 1584 kaufte Bartholome mit seiner Gattin die Burg Kalkofen mit dem dazu gehörigen Bauerngut «Eilf Gecken» nebst 166 Morgen Ackerland und Wiesen um 16000 holländische Gulden von Freiherrn Johann von Merode-Houffalize, Herr zu Frankenburg. Schobinger mußte demnach bereits über beträchtliche Mittel verfügen. Er errichtete eine Samtweberei mit 18 Webstühlen. Die von ihm beschäftigten Arbeiter wurden im Schloß verköstigt. Ein derartiges Unternehmen war für die Tuchstadt Aachen neu. Bald erhielten die dortigen Webmeister von Schobinger Aufträge zur Lieferung von Garnen und Seide. Die fertigen Erzeugnisse, sogenannter Bubensamt, auch Trippen benannt, fanden in Köln wie auf der Frankfurter Messe großen Absatz. Aber wiederum wurden die Religions- und Kriegsunruhen dem Unternehmen nachteilig. Am 25. August 1593 streckte der Schwager Martin Perez Bartholome 14000 Reichstaler vor. Doch die Geschäftssorgen ließen nicht nach. Jülich verhängte Sperren über Aachen, jeder Handelsverkehr wurde unmöglich. Im April sah sich Schobinger genötigt, den schönen Besitz Kalkofen seinen Schwägern Martin Perez und Baron Carolus de Billehé, Herr zu Verset und Hartelstein, um 50000 Brabanter Gulden zu überlassen. Er war gezwungen, mit seiner Familie das Aachener Gebiet zu meiden. In seiner Not stand ihm der Halbbruder Tobias Schobinger bei. Gemeinsam gründeten die Brüder mit Erlaubnis dẹs Herzogs von Jülich am 3. Juli 1608 im Kallbachtale auf dem Gebiete der Gemeinde Vessenack eine Glashütte und eine Seifensiederei. Der Herzog begrüßte das Unternehmen, da es für die Gegend Arbeit und Verdienst versprach, dabei bot das in den dortigen Wäldern reichlich vorhandene Holz einen großen Vorteil. Für die Bauten, die Tobias als Architekt ausführte, wurden ihnen drei Morgen Land an der Kalch zugewiesen.

Bartholome hatte offenbar in der Zwischenzeit das Gebiet tüchtig erforscht und verfolgte noch andere Absichten. In der Nähe befand sich nämlich eine Eisenerzgrube, die er als Alchemist sofort entdeckte und die ihm mehr eintrug als die Glashütte. Schobinger kehrte nie mehr in die Heimat zurück. Laut Bericht eines Neffen starb er am 17. Dezember 1631 im Alter von 83 Jahren in Heimbach. Seine Söhne Ludwig und Hans Bartholome besuchten die Schulen in Leyden und siedelten sich wie ihre Vettern in den Niederlanden an. Zwei Töchter von Bartholome vermählten sich nach St. Gallen: Anna * 1582 zu Köln, $\infty$ 1624 Johannes Brunner, Prediger, Barbara * 1592 zu Isäntorff, $\infty 1633$ Hermann Zollikofer [A. Schumacher, Kaufleute aus St. Gallen als Gründer von Simenskall in Mitteilungen des Geschichtsvereins Monschau, 21. Jahrgang, Nr. 1 194.9. Berechtigungsnachweis StA Düsseldorf Külich-Berg III 1246 (freundlịche Vermittlung durch Fräulein Frieda Schobinger)].

Von weitern Alchemisten in der Familie Schobinger sind zu nennen: Sebastian (1579-1652), Arzt, Bürgermeister; David (1594-1618); Heinrich (1602-1642); Jeremias (1625-1673); Bartholome (1610-1675); Joh. Caspar (1701-1763), alles direkte Nachkommen von Bartholome Schobinger I.

6 Stadtbibliothek St. Gallen, Nr.1/82, Nr.2/1448. Gefällige Mitteilung von Fräulein FriedA SсновіNGER aus dem Familienbuch der Schobinger. 


\section{Die alchemistischen Kreise}

Daran erkenn' ich den gelehrten Herrn!

Was ihr nicht tastet, steht euch meilenfern, Was ihr nicht faßt, das fehlt euch ganz und gar, Was ihr nicht rechnet, glaubt ihr, sei nicht wahr, Was ihr nicht wägt, hat für euch kein Gewicht, Was ihr nicht münzt, das, meint ihr, gelte nicht. (GoEthe, Faust II, 1, Mephistopheles)

Durch Paracelsus gewann die Alchemie im 16. Jahrhundert an Bedeutung. Ihre größten Beschützer fand sie in den Fürsten. Kaiser Rudolf II. von Österreich und Ungarn, die Markgrafen Georg und Joachim von Brandenburg, Herzog Julius von Braunschweig, der gelehrte Landgraf Moritz von Hessen-Kassel, Kurfürst August von Sachsen mit seiner Gemahlin Anna von Dänemark, Franz II. von Sachsen, Herzog Carl von Lothringen, die Herzoge von Württemberg und andere mehr unterhielten eigene Laboratorien und beschäftigten sich selbst stundenlang mit ernsten Studien. Es war nicht nur Zeitvertreib oder reine Sucht, sondern ein fortwährendes Suchen und Tasten auf den verschiedensten Gebieten?

«Eine dermaßen reiche Symbolik wie die Alchemie verdankt ihr Dasein stets einer zureichenden Ursache und niemals einer bloßen Laune oder phantastischen Spielerei. Zum mindesten drückt sich in ihr ein wesentliches Stück Seele aus.» ${ }^{8}$

Noch in der Barockzeit gab es sehr berühmte Alchemisten, zu denen auch GoEthe zählte. In Dichtung und Wahrheit hören wir von einer durch einen Alchemisten zubereiteten Arznei durch welche Goethe von schwerer Krankheit geheilt wurde. Seinen Faust läßt er ausrufen:

«Ich grüße dich, du einzige Phiole,

Die ich mit Andacht nun herunter hole, In dir verehr' ich Menschenwitz und Kunst,

Du Inbegriff der holden Schlummersäfte, Du Auszug aller tödlich feinen Kräfte, Erweise deinem Meister deine Kunst.» (Goethe, Faust I)

Die Alchemisten verfolgten drei Ziele: tiefste Erkenntnis der Naturkräfte, Ausnutzung derselben zur Förderung der Gesundheit, Streben nach sittlicher und geistiger Veredlung durch tätige Nächstenliebe. Tausende von Männern, mit allem Wissen der Zeit ausgerüstet, opferten ihr Vermögen

7 H. KорP, Alchemie in älterer und neuerer Zeit, Heidelberg 1886.

8 C. G.Jung, Psychologie und Alchemie, S.538. 
und setzten oft unter schwierigsten Verhältnissen alle ihre Kraft daran, neue Erkenntnisse zu sammeln. In allen Ländern bildeten sich kleine Gesellschaften oder Kränzchen, deren Mitglieder auf Grund von Beobachtungen und persönlichen Experimenten Austausch suchten. Die Verschiedenheit der Konfession übte keinen Einfluß. Wir finden sowohl unter sehr gläubigen Katholiken wie Protestanten überzeugte Anhänger der Lehre. Da die Ausdrucksweise der Alchemie aber vorwiegend in Zeichen bestand, wurde sie als Geheimlehre betrachtet und stets angefochten. Die Zusammenkünfte und Versuche fanden in aller Stille statt. Chemische Experimente waren ja noch verboten, mußten daher hinter verschlossenen Türen unternommen werden, weshalb sie im Rufe geheimnisvoller Vorgänge standen. Jede geschäftliche Ausbeutung der erlangten Kenntnisse war streng verboten. Die Mitglieder einer Gesellschaft wurden zu Stillschweigen verpflichtet, zu gegenseitiger Hilfe, für neue Alumnen hatten sie ihren Mitteln und ihrer Stellung entsprechend Bürgschaft zu leisten und für sie einzustehen, für Errichtung von Laboratorien, deren Ausstattung und für die Experimente gemeinsam aufzukommen. Trotz vieler Fehlschläge erfüllte diese Männer der Drang nach Erweiterung des Wissens mit immer neuen Hoffnungen. «Wer das Salz und dessen Lösung kennt, der kennt auch das Geheimnis der alten Weisen », lautete einer ihrer Grundsätze.

Warum unterließen die wirklichen Alchemisten alle Versuche zur Gewinnung von Gold? Jennings sieht die Antwort in folgenden Tatsachen:

«Sie wollten von ihren Kenntnissen nur Gebrauch auf den menschlichen Körper machen und sie nicht auf die niedrige Materie anwenden, weshalb sie Gold zu machen verachteten und verboten. Denen aber, die fragen mochten, was der Grund wäre, da 3 diese angeblich größten aller Philosophen sich selbst und ihre Freunde durch einen so schnellen und gründlichen Prozeß nicht reich machten, wurde geantwortet, sie möchten das nicht, sie seien zufrieden mit dem Besitz der Fähigkeit, sie lebten in der Vernunft, blieben zufrieden mit der Theorie und wiesen die Praxis ab. Sie waren so überwältigt und erstaunt über die unermeßliche Macht, die Gottes Gnade den Menschen gewährte, daß sie es verschmähten, Goldmacher für die Gierigen oder Helfershelfer von Betrügern zu werden. Würde diese Kunst wie eine andere ausgeübt, müßte der Mann, der solch stupendes Geheimnis erfunden, in der unersättlichen Gier der Leute, die ihn zum Goldmachen antreiben könnten, zum Opfer und Märtyrer werden. Solches Gold kann nur zerstören, aber niemals befriedigen, denn ,du kannst nicht Gott und dem Mammon dienen'. Dies wußten die alten Alchemisten nur zu gut.» (H. Jennings, Die Rosenkreuzer, Bd. II, S. 115 ff. und 204).

Paracelsus widmete sein Werk: De Gratubus et Compositionibus preceptorum seinem Freunde Christof Clauser, Arzt in Zürich. Dessen Sohn und Enkel, beides Goldschmiede, waren ebenfalls Alchemisten, wie auch 
Conrad Clauuser, der nach Luzern übersiedelte, dort einen ausgedehnten Handel und eine Apotheke mit Gewürz und andern Medizinstoffen gründete, die er hauptsächlich nach den Rezepten von Paracelsus herstellte. Er war einer der reichsten Eidgenossen, bekannt durch seine Orientreisen, und spielte eine große Rolle im öffentlichen Leben. Clauser blieb katholisch, erwarb das schöne Haus zum Kiel, in welchem er eine eigene Kapelle mit wertvollen Gemälden einrichtete. Der einzige Sohn, Anton, ebenfalls Apotheker, starb bereits 1568. So erbte die Tochter Anna das Haus, welches sie ihrem zweiten Gatten, Heinrich von Fleckenstein, testierte ${ }^{9}$.

In der Apotheke Clauser machte Rennward Cysat (1545-1614) die Lehre. Er blieb zwar nicht beim Apothekerberuf, sondern wurde luzernischer Stadtschreiber und Chronist, aber er beschäftigte sich fortwährend mit naturwissenschaftlichen Problemen, machte viel Experimente, wovon die Rezepte in den Observationes variae zeugen. Eifrig sammelte er Pflanzen, legte sich einen botanischen Garten auf der Musegg an, um stets neue Versuche zu Heilzwecken vornehmen zu können. Seine Beobachtungen tauschte er mit den ihm befreundeten Bürgermeister Meyer in Schaffhausen und den Ärzten Theodor Zwinger und Felix Platter in Basel aus, die ihm wiederum ihre Erfahrungen mitteilten. Gegenseitig sandten sie einander Traktätlein. Aus Neugierde unternahm Cysat auch Versuche in Goldgewinnung. Nach einem von Lothringen erhaltenen Rezept glaubte er in zehn Tagen auf hundert Kronen fünfundzwanzig gewonnen zu haben. Er teilte dies Meyer voller Freude mit und fügte bei, er finde diese Versuche besonders reizvoll. Aber Bürgermeister Meyer warnte ihn vor diesen Experimenten, die leicht zu einer Sucht und verhängnisvoll würden. Das Treiben der Scharlatane und Schwindler kritisierte Cysat mit scharfen Worten ${ }^{10}$.

Ein eifriger Alchemist in Luzern war der illegitime Sohn des Chronisten Diebold Schilling. Christof Schilling soll seinen Vater an Bildung und Talent übertroffen haben. Er war jedoch sehr jähzornig, eigensinnig und mißbrauchte sein Wissen. Da er eine von ihm verführte Magd vergiftete, wurde er verbannt. Später fand er im Kloster Engelberg Zuflucht und eine Freistatt. Durch seine vielfachen Kenntnisse genoß er die Gunst der größten Gelehrten ${ }^{11}$.

In Basel erkannte Johannes Huber, Professor der medizinischen Fakultät, früh den hohen Wert der ärztlichen Grundanschauungen von

${ }^{9}$ Gfr. Bd. 35/117, ZB LU: Bündebuch des Schultheißen Heinrich von Fleckenstein, Gefällige Mitteilung von Herrn Dr. M.Schinellmann, Luzern.

10 ZB LU: Cysat A 3, Observationes, 291, Coll. M 103.

11 Diebold Schilling, Chronik, S. 20 und 257. 
Paracelsus und brachte sie seinen Schülern bei. Unter diesen war es namentlich Professor Theodor Zwinger, der die Bedeutung der Alchemie für die Medizin erfaßte und mit seinem Sohn Jakob experimentierte. In Zwingers Verwandtschaft finden sich verschiedene Paracelsisten, auch auf Seite seiner Frau. Der Oheim Oporin führte ihn in die paracelsische Alchemie ein, Wilhelm Aragos, früherer Leibarzt des Königs von Frankreich, der sich seit 1585 in Basel niedergelassen, lehrte Vater und Sohn Zwinger weitere chemische Experimente, die auf der Grundlage der Erkenntnisse Hohenheims beruhten. Jakob Zwinger fuhr nach dem frühen Tod seines Vaters fort, paracelsische Arzneimittel herzustellen. Auch die mit Theodor Zwinger eng befreundeten Professoren Dr. iur. Basilius Amerbach und der berühmte Arzt Felix Platter interessierten sich für die Alchemie. Dieser betrieb zwar selbst nie Chemie. Auch war er gegen Paracelsus wegen dessen Auftreten und oft zerfahrenen und zornmütigen Wesens eingenommen. Er anerkannte jedoch sein umfassendes Wissen, seine vielseitigen Kenntnisse und befolgte mit der gleichen Hingabe die Lehre des PriesterArztes: Verständnis, Güte und Liebe sind die Grundlagen der ärztlichen Ethik. Felix Platter korrespondierte eifrig sowohl mit Meyer wie mit Cysat und tauschte mit letzterem öfters Rezepte aus. Mehr als der Sohn scheint sich der Vater Thomas Platter für Alchemie interessiert zu haben. In seiner Biographie berichtet er: «Es kam der Schreiber Rüest aus dem Emmental zu mir, ein Alchemist, wie auch D. Bonheri (?), der sich mit Destillieren abgibt. Rüest kennt eine Kunst, die ihm bei der Bilderstürmerei viel nützte. Er erfand ein Pulver, welches er an die vergüldeten Bilder spritzte, da fiel das Gold schön ab ohne Beschädigung und er hatte den Gewinn. Die Goldschmiede aber mußten es abschaben. Alchimey ist eine große Kunst, in die man sich vertiefen muß, um vieles lernen zu können.» ${ }^{12}$

Neben den Ärzten nennen wir in Basel noch Apotheker Hans HeInRIGH Ryhiner, Buchhändler MARx Russinger, welcher die einschlägige Literatur führte, den Sohn von Johannes Huber, Hans Rudolf, Bürgermeister zu Basel 1594. Eine große Rolle spielte auch der reiche Waffenhändler Hans Lux Iselin, der die Einrichtung des Laboratoriums auf Schloß Bellikon finanzierte, dann der Handelsherr Daniel Peyer von Schaffhausen, der sich in Basel eingebürgert hatte.

12 H.Boss, Thoma und Felix Platter, Leipzig 1878. J. Karcher, Felix Platter 1546 bis 1614, Basel 194.9. 
Überzeugter Anhänger von Paracelsus in Basel war Leonhard ThurnEYSEN. Als Sohn eines Goldschmieds geboren, half er in seiner Jugend dem Vater, benützte jedoch jede freie Minute zu Studien, besuchte Vorlesungen über Botanik, Heilkunde und half Professor Johannes Huber beim Kräutersammeln. Mehr und mehr vertiefte er sich durch seinen Lehrer und Gönner in die Lebren von Paracelsus. Leider war er sehr leichtsinnig, betrieb als Goldschmied unehrliche Geschäfte und mußte wiederholt bestraft werden. Er zog von Basel weg und wandte sich nach einem Aufenthalt in Deutschland nach England, um dort Gelegenheit zu finden, Paracelsus persönlich kennenzulernen. Sein Wissenshunger, auch die Sucht nach Reichtum, trieb ihn dann von Land zu Land. 1552 bis 1554 finden wir ihn als Söldner in den Niederlanden und Luxemburg, 1555 arbeitete er bei einem Goldschmied in Straßburg, hierauf in Konstanz. 1558 war er in Tirol und Kärnten; um die Bergwerke kennenzulernen, betätigte er sich als Grubenarbeiter. Durch die gewonnenen metallurgischen Kenntnisse stieg dann sein Ansehen rasch. Er legte für die Eberwaldschen Bergwerke selbst erfundene Schmelzöfen und Schwefelhütten an, die sich bewährten. Dadurch gewann er die Anerkennung der interessierten Kreise. Im Auftrag von Erzherzog Friedrich besuchte Thurneysen Schottland, Spanien, Portugal die Nordküste Afrikas und den Orient, um seine Studien und Kenntnisse zu erweitern. Er beherrschte achtundsechzig Fremdsprachen und viele europäische Dialekte. Nach seiner Rückkehr trat er als Arzt auf und hatte das Glück, die Gemahlin des Kurfürsten Johann Georg von Brandenburg heilen zu können. Er wurde zum Leibarzt ernannt und der Fürst stellte ihm für seine Experimente große Laboratorien zur Verfügung. Thurneysen befaßte sich auch mit Buchdruck und richtete 1574 im Grauen Hof zu Berlin eine eigene Druckerei nebst einer Schriftgießerei nach besonderm System ein. Er gab eine Menge Schriften sogar in orientalischer Sprache heraus. Auch die Teppichmanufaktur führte er ein. Der Briefwechsel Thurneysens mit allen Geistesgrößen der Zeit wird in der Berliner Staatsbibliothek aufbewahrt.

Aber dieser wahrscheinlich allzu vielseitige Mann, dessen Kenntnisse die Welt mit Staunen erfüllten, war eitel und genußsüchtig. Trotz den vorzüglichen Geschäften, der angesehenen Stellung verlor er durch übermäßigen Aufwand mit einer leichtsinnigen Frau sein ganzes Vermögen, verfiel wieder in Betrügereien und war genötigt, 1584 von Berlin zu flüchten. Von da an führte er ein sehr unstetes Leben. 1590 befand er sich in Solothurn, wo er eine Schrift über die Badordnung des Bades Attisholz und dessen Heilquelle 
verfaßte. Hier lernte Bürgermeister Meyer von Schaffhausen den seltsamen Mann, dessen naturwissenschaftliche Erfahrungen alle Alchemisten interessierten, durch den solothurnischen Staatsschreiber JAков von StaAL kennen. Nach einem Aufenthalt in Rom starb Thurneysen 1598 vollständig verarmt in einem Kloster in Köln ${ }^{13}$.

In Bern ward bereits im 14. Jahrhundert eifrig Alchemie betrieben. Der reiche Schultheiß Rudolf von Scharnachtal wurde durch Goldsucherei und Handelsspekulationen vollständig ruiniert. Wilhelm von Diesbach, ein Freund von Kunst und Wissenschaft, von seinen Zeitgenossen hoch geehrt, der zweiundvierzig Jahre treu im Dienste der Stadt Bern stand, durfte in der Herrschaft Trachselwald nach Gold graben lassen. Dadurch kam er so weit, daß bei seinem 1517 erfolgten Tod alles Hab und Gut in die Hände der Gläubiger fiel ${ }^{14}$. Und Ludwig von Diesbach gesteht in seinen hinterlassenen Schriften: «so hab ich ein groß gut in bergwercken verbuwen und desglychen in der Alchymei, daß Gott also geklaget seye. ${ }^{15}$

Das aber hinderte die Nachkommen keineswegs, sich immer wieder mit alchemistischen Studien zu beschäftigen. So finden sich im 16. Jahrhundert bei den Bernern höchste Magistraten, Ärzte, Apotheker, Goldschmiede unter den Alchemisten vertreten.

In St. Gallen nennen wir neben den Schobinger, Schlumpf, Stauder, Reutlinger namentlich Junker UlRich Zollikofer, auf Nengensberg und Karrersholz, Stadtammann zu St. Gallen 1597, ein leidenschaftlicher Adept, der sich jedoch hauptsächlich mit Goldgewinnung aus seinen Bergwerken beschäftigte.

Von bahnbrechender Bedeutung auf dem Gebiete der Naturwissenschaft war in Zürich der berühmte Stadtarzt und Gelehrte Conrad Gessner (1516 bis 1565), welcher ebenfalls in starker Beziehung zur Alchemie stand. In seinem Schreiben an den Augsburger Arzt Adolf Occo (1524-1606) berichtet er: «ich hab eine große Begierd, alle Kräfte für die einfachen Heilmittel sicher kennen zu lernen, um meinen Kranken und mir selbst helfen zu können. ${ }^{16}$ Sein Nachfolger, der bedeutende Mediziner HaNs Caspar Wolf, gab die Epistolae medicinales Gessners heraus und dedizierte sie Bürgermeister Johann Conrad Meyer in Schaffhausen als Aner-

13 Beiträge zur vaterländischen Geschichte, Basel, Bd.XI. Allgemeine deutsche Biographien, Bd. 38, 226.

14 StA BE: Ratsmanual 147, 75; Anselm Chronik, Bd. III, 258.

15 Archiv für Volkskunde, Bd. V, 233. Rueger Chronik, E 5 A 3.

16 H.R. Wolf, Biographien, Bd.I, 15. 
kennung für dessen wissenschaftliche Forschungen. Auch der Sohn, Havs Јаков Wolf, Stadtarzt, wie besonders der Neffe, Hans Ulrich Wolf, waren eifrige Alchemisten ${ }^{17}$. Unter den übrigen Vertretern in Zürich finden wir Johann Caspar Waser, Professor des Griechischen und Hebräischen am Carolinum, Stadtarzt Georg Keller mit seinen Brüdern Johannes Keller, Bürgermeister, und Goldschmied Felix Keller, Hans Jakob Fries, Professor der Philosophie und Theologie, Caspar und Hans LochMANN, mehrere Escher. Ein ganz hervorragender Alchemist war auch der Schwager der Brüder Keller, Hans Rudolf Bullinger, Sohn des Antistes. Er studierte Theologie, war 1560 Pfarrer zu Steckborn, 1565 zu Berg am Irchel, beschäftigte sich dann stark mit naturwissenschaftlichen Studien und hauptsächlich Alchemie für Heilzwecke. Dadurch geriet er in Schulden und wurde vom Rat als Pfarrer abgesetzt. Bullinger zog nach Bern, widmete sich ganz der Medizin, wurde Stadtarzt und bürgerte sich in Bern ein ${ }^{18}$.

Auf den Beobachtungen und Erfahrungen von Paracelsus und Geßner baute Raphael Egli, Pfarrer am Großmünster, genannt Iconius, auf. Nach seinen Studien am Carolinum hörte er Vorlesungen in Genf und Basel. Egli wirkte zuerst als Lehrer in Sondrio, wo er sich für den Abbau von Erzen zu interessieren begann. Nach Winterthur berufen, verheiratete er sich mit Susanna Schmidt, Tochter von Pfarrer und Mathematiker Sebastian Schmidt von Stein, ebenfalls ein Freund der Alchemie, wie auch Pfarrer und Chronist Josia Mahler. Egli erwarb mit dem Arzte Angelus Sala ein Bergwerk in Graubünden. Dieser verfügte über umfassende chemische Kenntnisse und kannte alle berühmten Alchemisten. 1592 kam Egli nach Zürich als Diakon am Großmünster, 1596 war er Archidiakon. Er beherrschte verschiedene Wissensgebiete, Philosophie, Sprachen, Musik, besonders Kirchengesang, beschäftigte sich mit Astrologie und namentlich Naturwissenschaft. 1593 führte er öffentliche theologische Disputationen ein zur Förderung der Kirche, gab auch ein Kirchengesangbuch heraus. Er war äußerst fleißig und voller Eifer für seine Kirche, jedoch nicht ohne einen starken Hang zum Mystischen. Der Wunsch nach Naturerkenntnis verfolgte ihn unablässig und wurde schließlich übermächtig, so daß er auf Abwege geriet, allerdings erst durch den verhängnisvollen Einfluß der Junkers Heinzel von Degerstein ${ }^{19}$. Die alchemistischen Beziehungen Eglis

17 Ebenda, Bd.IV, 306. Rueger Chronik E 5.

18 ZB ZH: Mscr. R I 165; Mscr. S. 152. O. FARnER, Briefe Bullingers.

19 ZB ZH: Mscr. J 306; Mscr. S. 158/98, 112, 125-130; S. 159/10, 19, 130. STA ZH: E II 450. H.R. Wolf, Biographien, Bd.IV, 306. J. WüLLI, Raphael Egli in Z.T. 1905, 154. 
mit den Katholiken wurden beanstandet, namentlich seine Freundschaft mit Pistorius. Dieser (1546-1608) genoß zwar als Wissenschafter einen hervorragenden Ruf. Er war mit allen Geistesgrößen befreundet, verwandt mit dem Altertumsforscher GotTFRIED von RAMingen, machte sich jedoch wegen seiner Unbeständigkeit und Untreue in Glaubenssachen sehr unbeliebt ${ }^{20}$.

Am wenigsten klar erscheint die Einstellung von Professor Hans WILhelm Stucki. Er vermittelte in Zürich die meisten Bekanntschaften unter den Alchemisten, führte die Heinzel ein, nahm an den Versammlungen und vielfach auch an Experimenten teil, bekannte sich jedoch nicht als Alchemist, trotzdem sein Schwiegersohn, Apotheker Hans Ulrich Wolf, einer der eifrigsten Anhänger der Lehre war.

Durch seine Freundschaft mit Tobias Schobinger, vor allem die Heirat mit dessen Base, der Nichte von Bartholome Schobinger, Helena Stauder, wurde Johann Conrad Meyer, Bürgermeister zu Schaff hausen, früh mit der Alchemie vertraut. Bereits Geßner schrieb an Occo, es sei schade, daß der junge Mann sich dem Studium der Rechtswissenschaft statt der Medizin widmen müsse, denn er sei überzeugt, daß er alle Hoffnungen auf einen hervorragenden Naturforscher und Arzt erfüllen würde. Meyer galt Ende des 16. Jahrhunderts als der bedeutendste wissenschaftliche Alchemist, der in beständigen Beziehungen mit Amerbach, Platter und Zwinger in Basel stand. Seine umfassenden Kenntnisse auf den verschiedensten Gebieten trugen ihm den Titel «der gelehrte Bürgermeister» ein. Mit seinen Vettern Benedicht Stokar und Felix Schmidt, den Stadtärzten Burgauer, Hagenbuch und Holzach, Junker Hans Im Thurn und anderen mehr gründete er zu Schaffhausen ein philosophisches Kränzchen, das viele Gelehrte von nah und fern herbeizog.

Dieser gedrängte Überblick über die Hauptvertreter der Alchemie in der zweiten Hälfte des 16. Jahrhunderts, soweit diese zu erfassen waren, zeigt, daß die meisten Persönlichkeiten aus wissenschaftlichen Kreisen hervorgingen. Viele hatten die Lehre vom Vater übernommen oder auch durch angeheiratete Frauen, jedenfalls erfüllte sie die Neigung zur Naturwissenschaft schon in frühester Jugend. Aus den meisten dieser Familien gingen in den nächsten Jahrhunderten berühmte Gelehrte, Mediziner, Erfinder, Chemiker hervor. Beispielsweise finden sich bei den Schobinger in neun Generationen zehn Ärzte, drei Apotheker, bei den Meyer zu Schaffhausen

20 Allgemeine deutsche Biographien, Bd. 26, 197. 
zwischen 1630 bis 1800 acht Apotheker, ein Arzt, vier Pfarrer, ein Goldschmied, viele bekannte Gelehrte und Staatsmänner, wobei nur die direkte Linie verfolgt wurde.

\section{Benutzte Literatur}

E.DarmstäDter, Die Alchemie, Berlin 1922.

M. GMeLIN, Geschichte der Chemie, Göttingen 1798.

D. Guthire, Die Entwicklung der Heilkunde, Zürich 1952.

H. Jennings, Die Rosenkreuzer, Berlin 1912.

E.Lippmann, Entstehung und Ausbreitung der Chemie, Berlin 1919.

E. Ortner, Das Weltreich der Fugger, Augsburg 1941.

L. Scheuermann, Die Fugger als Montanindustrielle in Tirol und Kärnten, Beitrag zur Wirtschaftsgeschichte des 16./17.Jahrhunderts (München 1938).

J.Strebel, Paracelsus Studien (Bern 1941).

J.Strebel, Neue Beiträge zur Ikonographie von Paracelsus in Gesnerus, Heft 1/2, 3/4. Jhrg. 1951.

L. WeIsz, Erzgewinnung im Klettgau in Studien zur Handels- und Industriegeschichte der Schweiz, Bd. II (Zürich 1938).

\section{Goldmacher und Scharlatane}

«Goldmachen wär die beste Kunst

Blieb nicht alle Mühe umsonst.

Wer sein Geld verlaboriert, Und seine Kunst im Rauch probiert, Dem wird gewiß der Weisen Stein

Das Grabmal seines Reichtums sein.»

(E. Lippmann, Entstehung und Ausbreitung der Alchemie, Bd. II, 36, Berlin 1919.)

Wenn im Jahrhundert der Aufklärung ein Cagliostro* Tausende zu betrügen vermochte, ein Syberg den Grafen Fugger um Millionen zu beschwindeln verstand, wie viel mehr Abenteurer mußte es im 16. Jahrhundert geben, die sich auf das Goldmachen verstanden. Noch befand man sich im Zeitalter des Aberglaubens, dem selbst hochgebildete Männer unterworfen waren, und zwar in einer Weise, die uns heute unverständlich erscheint. Falschmünzer und Schwindler hatten leichte Arbeit mit ihren Lockungen. Wie beim Spiel war der Reiz so groß, daß die meisten den Versprechungen Glauben schenkten, um dann alles zu verlieren.

* Cagliostro Graf Alexander, alias Giuseppe Balsano aus Palermo, einer der bekanntesten Hochstapler des 18. Jahrhunderts, der sich hauptsächlich auf die Kunst, Gold herzustellen, verlegte. 
«Gold zu machen oder andere Metalle in Gold umzuwandeln ist eine Kunst, die zwar mancher gesucht, aber keiner gefunden hat. Sie hat etwas sehr Reizendes und Geheimnisvolles, verführt die Wissenschafter, und daraus ziehen die Betrüger ihren Vorteil, wissend, wie groß die Begierde zu allen Zeiten nach Gold ist.» ${ }^{1}$

Gesteigertes Wohlleben, Sucht nach Reichtum, Ansehen, Macht, auch diplomatischer Verkehr wie religiöser Eifer erforderten große Summen. Viele Scharlatane benutzten die Leichtgläubigkeit der Menschen unter der Vorgabe, den "mercurius philosophorum», den Stein der Weisen, zu besitzen und damit die Goldmacherkunst zu verstehen. Die herrschenden Zustände im 16. Jahrhundert, die wirtschaftliche Lage, allgemeine Unzufriedenheit boten den besten Nährboden für das Gedeihen des Unfugs durch die Betrüger.

Immer wieder sahen sich die Obrigkeiten genötigt, Mandate zu strengen Vorgehen gegen Falschmünzer und Schwindler zu erlassen. Jede Münzstätte hatte ihre besondere Vorschrift. Eine Verordnung vom 9. September 1560 lautete: «Kein Ort darf die Stempel an Private leihen. Jeder Ort soll selber münzen. Der Münzmeister darf kein Silber auf eigene Rechnung kaufen und nur das ihm von der Obrigkeit zugestellte verarbeiten. Kein Münzmeister darf auf einer Schmiede mehr als mit fünf Gesellen münzen, damit der Silberverkauf nicht verteuert wird. Alle Fälschungen sind streng verboten. ${ }^{2}$

Die Ausbildung von Münzgesellen dauerte längere Zeit. Sie wurden vereidigt und unter strenge Aufsicht gestellt, doch gab es natürlich immer solche, die sich persönliche Vorteile zu verschaffen versuchten durch geheime Herstellung von minderwertigem Material, durch Nachguß von echten Stücken oder durch Anfertigung neuer Stempel. Beispielsweise wiesen die welschen Münzen einen geringern Gehalt auf, weshalb stets Versuche zu Fälschungen mit diesen vorgenommen wurden ${ }^{3}$.

Die zürcherische Obrigkeit nahm am 26. Mai 1591 zwei solcher Eigenmünzer gefangen, die als Krämer aus dem Mailändischen kamen. Auf der Folter gestanden sie, falsche Münzen in Umlauf gesetzt zu haben. Sie fälschten Berner und Walliser Kreuzer, konnten sie im Land herum beim Verkaufe ihrer Waren umtauschen, bis der Betrug in Zürich entdeckt wurde $^{4}$. Immer wieder gelangten Beschwerden an die Tagsatzung wegen

1 F.v. Stetten, Kunst-Gewerbe und Handelsgeschichte in Augsburg, Augsburg 1779.

2 A. Escher, Schweizerische Münz- und Geldgeschichte, Bern 1881.

3 L. Corragione, Münzgeschichte der Schweiz, Genf 1896.

4 EA Bd. VI, S. 263. 
dem vermehrten Herumziehen der fremden Händler, den Falschmünzern und Schwindlern. Jeder Ort wurde zu Maßnahmen gegen diese aufgefordert, damit das Volk nicht durch falsche Münzen geschädigt werde ${ }^{5}$.

In Zürich amtete in den achtziger Jahren Hans Peter Thomann als Münzmeister. Dieser hatte durch leichtsinniges Leben viele Schulden, von denen sein Vetter, Seckelmeister Thomans, keine Kenntnis erhalten durfte. Er sah sich daher immer wieder zur Aufnahme von Darlehen genötigt und gelangte mit der Bitte auch an Frau Nüscheler, deren Mann sich als Söldner im Tampiskrieg befand. Thoman versprach dem abwesenden Freund nach dessen Rückkehr zu einer guten Stellung im Münzamt zu verhelfen, sofern sie mit der Rückerstattung der zweihundert Gulden etwas Geduld üben wolle. Felix Nüscheler solle versuchen, sich in den Niederlanden noch einige Kenntnisse in der Goldmacherkunst anzueignen, dann sei er bald ein gemachter Mann ${ }^{6}$.

Nach seiner Rückkehr wurde Nüscheler denn auch in der Münzstätte angestellt mit einem wöchentlichen Gehalt von acht Gulden aus der Stadtkasse. Thomann fügte drei Gulden als Abzahlung für das Darlehen bei. Bürgschaft für Nüscheler leisteten seine Schwäger JАков MEISTER und Conrad Reutlinger, letzterer wiederholt wegen Schmuggels von Waren gebüßt. Die Schwäger halfen Nüscheler auf Grund seines Versprechens, ihnen durch seine erworbene Kunst bald das Dreifache zurückerstatten zu können. Thomann selbst versprach Nüscheler jede Hilfe, wie Zugang zu den Stempeln, sofern er ihm nur bald so viel Geld verschaffe, bis er seine Schulden abgezahlt, da er in beständiger Angst vor Entdeckung derselben durch den Seckelmeister lebe ${ }^{7}$. Um die Versuche zu fördern, entwendete Nüscheler mit vollem Wissen Thomanns Prägeplatten, eignete sich auch einen Stempel an und prägte nun zu Hause. Als dann ganz unerwartet eine Revision in der Münzstätte angesagt wurde, brachte das Ehepaar Nüscheler mit Thomann während der Nacht alles eilends in die Werkstatt zurück. Sie wurden jedoch vom Wächter entdeckt, der sofort Anzeige erstattete. Thomann und Nüscheler erhielten ihre Entlassung nebst Gefangenschaft und schwerer Buße ${ }^{8}$.

Auch der Bruder, Hans Jаков Nüscheler, der Medizin studieren sollte, hatte sich lange Zeit in der Fremde herumgetrieben und dabei sein Geld

5 EA Bd.V 1a, S.327.

6 StA ZH: A 27, 44.

7 Ebenda, B V 36, 323, 329, 476.

8 Ebenda, F III 45. 
vertan. Nach Zürich zurückgekehrt, vermochte er neben den Stadtärzten als bloßer Heilphysikus nicht eigentlich zu praktizieren. Er reichte daher bei der Obrigkeit das Gesuch ein, Kräuter destillieren zu dürfen, da er auf medizinischem Gebiet nicht genügend Auskommen finde, zudem vertreibe ihm seine geisteskranke Frau alle Patienten. Er mietete ein Häuschen außerhalb der Stadt, baute etliche Öfen ein und bereitete anfänglich hauptsächlich ätherische Öle, schrieb auch verschiedene Schriften über Destillation, heimlich aber gab er sich mehr und mehr mit der Goldmacherkunst ab ${ }^{9}$.

Die weitaus größte Anzahl dieser Scharlatane waren Männer, die längere Zeit als Offiziere und Söldner in fremden Kriegsdiensten standen. Sie hielten sich einige Zeit in den Niederlanden auf, trieben sich in Bergwerken herum, um nach Erzen zu suchen, in der Hoffnung, sich auf leichte Weise bereichern zu können. In die Heimat zurückgekehrt, versuchten sie gutgläubige Landsleute zu beeinflussen, machten sich wichtig mit ihrer Kenntnissen der Goldmacherkunst und verstanden durch ihr großartiges Leben zu täuschen. Die Zusammenkünfte der heimgekehrten Söldner fanden im "Rothen Haus» bei Wirt Jakòb Denzler statt. Hieher brachte Felix Nüscheler seinen Oberst Junker Caspar Krieg von Bellikon. Dieser hatte 1575 in Venedig die Münze geschlagen, dann sein Prägwerk an den Bündner Josef Bosniers in Plurs verkauft ${ }^{10}$. Er verstand sich also auf das "Handwerk», das ihm Geld einbringen mußte, denn er führte ein flottes Leben und befand sich mit seinen Brüdern Felix und Heinrich andauernd in Zahlungsschwierigkeiten. Lange Jahre verlangten viele zurückgekehrte Söldner vergebens ihren Sold, den Caspar Krieg nicht auszahlen konnte. Er mußte im Gegenteil noch Geld bei seiner Mannschaft entlehnen gegen schöne Versprechungen ${ }^{11}$. So verlegten sich die Brüder Krieg auf die Goldmacherkunst, für welche sich auch ihre Schwäger Hans Jаков und Wilpert Zoller interessierten. Zu Zusammenkünften und Experimenten war das abgelegene Schloß Bellikon vortrefflich geeignet.

Ob Bremgarten befand sich das Schlößchen Zuffikon, ein mittelalterliches Herrenhaus. Es befand sich im Besitze von Beat Flegkenstein aus Luzern, der mit einer Tochter des Schultheißen Bernhard Mutschly (Mutzly) in Bremgarten verheiratet war ${ }^{12}$. Fleckenstein hatte in Luzern öfters an den Experimenten von Apotheker Clauser und Cysat teilgenom-

9 Ebenda, A 27, 44, 161.

10 D. Fretz, Die Frühbeziehungen zwischen Zürich und Bergamo, S. 16, Zürich 1940.

11 STA ZH: A 369/2/4. Bd.VI 1, 11.

12 ZB LU: Rusconi: Viridarium. Gefällige Mitteilung v. Herrn Dr. M. Schnellmann, Luzern. 
men. Mit Hilfe der Gattin, später Sohn und Tochter, führte er die alchemistischen Versuche weiter. Als sich die Tochter Amalia mit Freiherr Johann Albrecht von Hohensax verheiratete, interessierte sich auch dieser mit seinem Bruder Johann Philipp. Dieser, zuerst in pfälzischem Hofdienst, dann in den Niederlanden Gouverneur von Geldern, hatte sich längst mit eingehenden alchemistischen Studien beschäftigt. Bürge für Caspar und Heinrich Krieg war der Schwyzer Hans Jаков Kyd, ebenso für die Darlehen, die Frau von Fleckenstein und ihre Tochter Amalia von Hohensax den Heinzel machten ${ }^{13}$. Der Vogt von Knonau fand wiederholt Anlaß, der Obrigkeit die Versammlung der Alchemisten sowohl auf Schloß Bellikon wie auf dem Albis anzuzeigen, doch das nützte nicht viel, denn viele Ratsherren fanden sich ebenfalls ein $!^{14}$

$\mathrm{Zu}$ der Junkerngesellschaft gehörten auch die Glarner Michael BäLdI und Fridolin (genannt Fridli) Freuler, die in einem recht sonderbaren Verhältnis zueinander standen. Bäldi war nämlich Oheim und zugleich Schwiegersohn von Freuler, ersterer Hauptmann, letzterer sein Lieutnant im Tampiskrieg. Aber beide hatten etwas Gemeinsames: ein rücksichtsloses, durchtriebenes Draufgängertum, gewinnsüchtige Naturen, die es mit der Ehre wenig genau nahmen und in unzählige Händel verstrickt waren. Davon legen die zahlreichen Prozesse wegen Nichtentrichtung des Soldes an die Mannschaft und vieler Affären beredtes Zeugnis ab. Als Bergwerkbesitzer hatte sich Bäldi früh für das Montanwesen interessiert. Längere Zeit hielt er sich nach Beendigung des Krieges mit Freuler in den Niederlanden und Lothringen auf, wo sie sich hauptsächlich Kenntnisse im Goldmachen anzueignen versuchten. $\mathrm{Zu}$ diesem $\mathrm{Zwecke}$ gingen sie auch an den württembergischen Hof und nach Prag, Stätten, wo die Goldmacherkunst besonders betrieben wurde. Freuler besaß eine glänzende Überredungsgabe und versprach Interessenten Einführung in die «Kunst». So gewann er unter andern auch Frau von Fleckenstein sowie Philipp von Hohensax, welcher ihm dreihundert Kronen bezahlte und ihn nochmals nach Lothringen begleitete ${ }^{15}$. Wir finden den Glarner in zahlreiche Unterschlagungen und Betrügereien verwickelt, hauptsächlich zusammen mit Caspar Krieg. Überall verstanden sie mit ihren Versprechen Darlehen aus den Leichtgläubigen herauszuholen, die sie nie zurückerstatten konnten ${ }^{16}$.

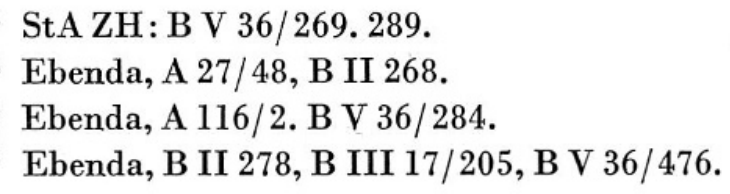


Bäldi bestrebte sich inzwischen, die Magistratenwürde zu erlangen. Der Glarner JАKов Kundert verfaßte 1598 ein Pasquill auf ihn, das ihn kennzeichnet:

«Der Bäldj far umben in dem land und trolle uf das Amman-ambt ist das nit ein freflichen list, daß ein söllicher Alchemmist darff treiben wis und bärden, daß er sollt Ammann werden.

Er gat tröllen uf sollichen sachen, er kan aus kupfer gold machen, Zu Paris hat er auch thun spalten, da hand si in für die flügen gehalten,

Man muß uns stellen ein Ammann für augen, dem man fry frölich dörffe glauben, Nit ein sölichen Alchenmist, was er seit, doch alles erheit und erlogen ist,

Pfud Bäldj, gang müßig solcher sachen, dänn ein solch futen mann, wänn wir nit zum

Hast vil übrig geld im hus, zal hübschli dini arme kriegslüt drus, Ammann machen.

Du bringst din vetter Fridlj in das spil, daß er landsbuwmeister werden will

Wir aber wend ein alten erbaren man, was wollten wir mit einem schnudderlig auch han, Wir finden wol fromme lüt im land, bei dir und Fridlj aber wärs ein Schand ». ${ }^{17}$

Aber Bäldj wurde dennoch Landammann, denn durch den Ämterkauf mit «Trölen» oder «Gutzen» (Gelage und Geschenke) gelang der Stimmenfang, und Bäldj besaß genügend Ehrgeiz, um vor nichts zurückzuschrecken.

In Bern verstand der Goldschmied Sebastian Marchstein 1599 den Rat von seiner Goldkunst zu überzeugen und die Erlaubnis zur Prägung von Dukaten zu erhalten. Aber auch seine Versprechungen erwiesen sich als Humbug. Er wurde gefangengenommen und besaß 1603 nichts mehr, nachdem er 1590 für sein Vermögen $200 \vec{t}$ versteuern konnte ${ }^{18}$.

Ähnlich erging es Goldschmied Hans StüLz in Schaffhausen, der trotz allen Vorkommnissen noch nach 1600 bei Versuchen, Silber herzustellen, ertappt und schwer gebüßt wurde ${ }^{19}$. Felix Bluntschli, des Wirtes «Zum Schwert» in Zürich Sohn, hatte sich als Apotheker in Schaffhausen eingebürgert. Mit seinem Schwager Ludwig Löw aus Lindau gehörte er ebenfalls zu den Schwarzkünstlern. Ihnen half GEorg BECK, welcher einige Zeit als Goldarbeiter in Feldkirch tätig gewesen war ${ }^{20}$. Der schlimmste Betrüger war der Schaffhauser HANs JАков Ochs. Als Söldner hatte er sich mit den Glarnern überall herumgetrieben, blieb längere Zeit in Lothringen und kam von dort in die Dienste des Goldschmieds Ulrich Muelich zu Freiburg im

17 IHV Glarus, Heft XVI, Jahrgang 1879.

18 Schweizer Künstler-Lexikon, Bd. III, 324. Gefällige genealogische Mitteilung von Herrn Dr. OEHLER, Bern.

19 StA ZH : B V 36/476.

20 Ebenda, A 27/160. 
Breisgau. Ochs war ein geschickter Handlanger und wurde von Muelich an den württembergischen Hof mitgenommen, wo dieser oft in den Laboratorien arbeitete. Als guter Beobachter eignete sich Ochs bald die erforderlichen Kenntnisse an, um sich als Goldmacher ausgeben zu können. Nach Schaffhausen zurückgekehrt, fand er eine Anstellung bei dem Salzhändler Hans Caspar Spleiss. Dieser geriet durch eine Unvorsichtigkeit in Schulden. Spleiß war ein ehrlicher und tätiger Salzagent, das Versehen bereitete ihm Kummer, und in seiner Besorgnis ließ er sich verleiten, durch Ochs im geheimen Salz zu verkaufen. Schon am nächsten Tag wurde er dieser Verfehlung reuig und bekannte dem Richter die Schuld. Ochs, der wegen dieses Geständnisses zornig wurde und Spleiß der Feigheit bezichtigte, wurde entlassen, nicht ohne noch einige Säcke Salz zu unterschlagen und sie auf eigene Rechnung zu verkaufen. Wegen Betrügereien mußte er fliehen und begab sich wieder nach Württemberg ${ }^{21}$.

Die meisten der Genannten sind als Scharlatane zu betrachten und dürfen nicht zu den eigentlichen Alchemisten gezählt werden. Ihr einziges Bestreben galt der Gewinnung von Gold. Alle aber waren Helfer und Trabanten der Heinzel von Degerstein.

\section{Benutzte Literatur}

J. MiedeL, Goldmacher in Memmingen in Geschichtsblätter Memmingen, Jahrgang 1932, Nr. 2.

L. WeIsz, Goldmacher auf Schloß Elgg in Studien zur Handels- und Industriegeschichte der Schweiz, Bd. I, Zürich 1938.

\section{Die Heinzel von Degerstein auf Schloß Elgg}

Unter den evangelischen Flüchtlingen, die im 16. Jahrhundert Zuflucht in der Schweiz suchten, befanden sich die Brüder Johann Heinrich und Johann Ludwig Heinzel von Degerstein. Ihre Vorfahren gehörten den reichen Handelsgesellschaften in Augsburg an, wo sie mit den vornehmsten Geschlechtern aliiert waren*.

21 StA ZH: A 252/2.

* Ursprünglich stammten die Heinzel von dem Schlößchen Degerstein in der Nähe von Lindau. HaNs HeINZEL (Haintzel) versuchte die sanktgallischen und schellenbergischen Lehen, die seine Vorfahren seit 1332 zusammengekauft, zu einem Territorium mit selbständigem Gebiet zu gestalten. Dank dem Eingreifen der Stadt Lindau glückte ihm dies nicht. Seine Söhne zogen nach Memmingen, Augsburg und Ulm und nannten sich hinfort Heinzel von Degerstein (K. Wolfarth, Geschichte der Stadt Lindau am Bodensee, Bd. I, 168). Ob der erste berühmte Koch, HeInzelin von Zürich, der beim Grafen von Hohenzollern Küchenmeister war und von diesem in den Adelsstand erhoben wurde 
Der jüngste der sechs Brüder, Johann Peter, bekannt als vorzüglicher Wissenschafter, sammelte Altertümer und Wappen, stand in regem Verkehr mit Gottfried von Ramingen und Junker Hans von Schellenberg, durch welche er Pfarrer und Chronist Johann Jаков Rueger* in Schaffhausen kennenlernte. Der Zürcher Hans CASPAR WASER war sein Hauslehrer und begleitete ihn an die verschiedenen Universitäten. Auch seine Brüder genossen eine wissenschaftliche Ausbildung in Tübingen ${ }^{1}$. Der zweitälteste Bruder, JонANn Baptist, wurde als Haupt der evangelischen Bewegung in Augsburg bei Rückkehr der Stadt zum alten Glauben ausgewiesen. Er ließ sich im Ulm nieder, wo Johann JaKob und JoHanN Friedrich Heinzel bei Handelsgesellschaften beteiligt waren, was ihnen durch nahe Verwandtschaft mit den Welsern nicht schwer fiel ${ }^{2}$.

Der älteste dieser Brüder, Johann Heinrigh, saß 1580 im Rat zu Augsburg und amtete als Kirchenpfleger. Er geriet jedoch bald in verschiedene Konflikte, zeigte sich widerspenstig und wurde deshalb 1583 all seiner Ämter enthoben. Er begab sich nach Ulm und verfaßte dort trotz den Warnungen seiner Brüder ein ehrenrühriges Pasquill gegen den Stadtpfleger Rechlinger und den Ratsadvokaten D. Tradeln zu Augsburg. Dies empörte den Rat, der Erzherzog Ferdinand ersuchte, den Aufwiegler gefangenzunehmen. Wie seine Brüder verfügte Heinrich Heinzel über eine umfassende humanistische Bildung. Er hatte Philosophie und Geschichte studiert, wandte sich dann aber mehr der Naturwissenschaft zu. Sein besonderes Intresse galt der Mineralogie und der Erzgewinnung. In Augsburg gehörte er zum Kreise der Alchemisten **. Zu verschiedenen Malen erhielt er

$(\dagger 1298)$ ein Vorfahre dieser Heinzel war, ist nicht bekannt. Jedenfalls wiesen die beiden Junker, mit denen wir uns zu beschäftigen haben, gerne auf ihre ursprüngliche Herkunft aus der Schweiz.

Ihr Vater, Johann Baptist Heinzel, studierte mit Johann Conrad Ulmer zu Schaffhausen in Basel und Wittenberg. Er war ein bedeutender Gelehrter und Staatsmann, saß im Rate und Stadtgericht zu Augsburg und machte sich durch Förderung der evangelischen Lehre besonders verdient. Mit seinem Bruder Paul, Astronom, schenkte er dem evangelischen Kollegium verschiedene Stiftungen. Er war eifriger Altertumsforscher und Historiker, wie sein jüngster Sohn (s. dazu Stammtafel).

* Rueger, Johann JaKob, 1548 bis 1606, $\infty$ 7.2.1570 Rahel Oechslin, T. v. Blasius und Anna Brümsi VDM, Pfarrer am Münster zu Schaffhausen, berühmter Chronist und Altertumsforscher.

** Und wahrscheinlich dem Bund der Rosenkreuzer an.

1 H. Hemelink, Die Matrikel der Universität Tübingen, Jahre 1571 und 1575, Stuttgart und Berlin 1906.

2 K. Wolfarth, Geschichte der Stadt Lindau am Bodensee, Bd. I, S. 168, Lindau 1909. 
Verweise wegen unerlaubten Experimenten. Umsonst warnte ihn sein väterlicher Freund und Hausarzt Adolf Occo. Dieser bemühte sich wohl um die wissenschaftliche Alchemie zu Heilzwecken, verwarf jedoch die Versuche seines Kollegen Dr. Daniel Keller zur Gewinnung von Gold. In Augsburg, der goldenen Stadt, waren aber auch die Fugger, Welser und ihre Gesellschafter an Geld knapp geworden, so daß sich mehr als einer mit der «Kunst» beschäftigte. So richtete Markus FugGer in seinem Haus am Weinplatz für Dr. Daniel Keller ein eigenes Laboratorium ein, mit dem Versprechen, ihm den vierten Teil des Gewinnes zu geben, sofern er aus jeder Mark Silber eine Unze Gold ziehen könne. Keller mußte sich verpflichten, während der Versuche in Fuggers Haus zu bleiben und mit niemanden als seinem Auftraggeber zu verkehren. Nun war Keller keineswegs ein Scharlatan, sondern ein tüchtiger Chirurg und Wissenschafter. Er hatte seine Kenntnisse an den Universitäten in Italien erweitert und war mit verschiedenen Alchemisten bekanntgeworden. Die Experimente reizten ihn zu persönlichen Versuchen. Er machte Markus Fugger sofort darauf aufmerksam, daß er seinen Wünschen kaum entsprechen könne. Fugger ließ aber nicht ab mit Drängen und wollte persönlich mithelfen. Als sich jedoch nach drei Wochen, trotz dem Kostenaufwand keine wirklichen Ergebnisse zeigten, wurde der Auftraggeber ungeduldig und Keller verließ sein Haus ${ }^{3,4}$.

Durch Keller erhielt Heinrich Heinzel eine Empfehlung an Graf MarTINENGo*. Sehr wahrscheinlich gab diese Reise nach Venedig den ersten

3 P. von Stetten, Geschichte der adeligen Geschlechter in Augsburg, S. 226.

4 P. von Stetten, Kunst-, Gewerbe- und Handwerksgeschichte Augsburg, S. 242, Augsburg 1791. Hochzeitsbüchlein, hg. von DF. WARnEcKe. O. AlBerTI, Württembergisches Adelsund Wappenbuch, Stuttgart 1889 bis 1898. A. Westermann, Die Heinzel von Degerstein und Memmingen in Memminger Geschichtsblätter, Nr. 5, Jahrgang 1922.

* Graf Marcantonio Martinengo di Villa chiara nahm im venezianischen Heer eine hervorragende Stellung ein und war eine durchaus einwandfreie Persönlichkeit. Aber auch er hatte eine Schwäche für die Goldkunst. Wie so mancher andere lieh er einem Betrüger seine Unterstützung, der sein volles Vertrauen zu gewinnen vermochte. Es war dies Marco Bragandino (er hieß eigentlich Mamugnâ), der zwischen 1540 bis 1550 auf der Insel Zypern geboren war. Er gab vor, aus Quecksilber Gold machen zu können. Einzelne Proben gelangen ihm, denn er hatte bereits einen Ruf als Goldkünstler, als er zu Graf Martinengo kam. Dieser wohnte einem Versuche in Brescia bei und gab ihm einen Geleitbrief nach Venedig mit dem gewonnenen Goldstängelchen. Der Graf gab dieses mit einem Pfund an und schätzte den Wert auf 1062,29 Goldmark. Trotz wiederholten Proben gelangen jedoch die Experimente in Venedig nicht. Bragandino erklärte, er sei allzusehr bedrängt worden. Der Graf, welcher zur Rechenschaft vorgeladen und eine beträchtliche Menge Quecksilber zur Verfügung gestellt hatte, fand, man müsse den 
Anstoß zu Heinzels Leidenschaft und späterem Verhalten. In seiner Stellung und unter andern Verhältnissen wäre er wohl kaum ausschließlich der Goldsucht verfallen. Als Vertriebener und Flüchtling entbehrte er das frühere standesgemäße Junkernwohlleben und suchte sich nun auf jede Art Mittel zu verschaffen. So wurde er zur Triebfeder des ganzen Unglücks, indem er in Zürich und auf Schloß Elgg die Hauptstätten der Goldmacherei errichtete.

Verschiedene Beziehungen verbanden die Heinzel mit Zürich und namentlich mit Stein am Rhein, hauptsächlich durch die Verwandtschaft ihrer Frauen. Drei Brüder Heinzel heirateten die reichen Schwestern NeIdHaRdT* . Felix Schмidt in Stein lernte die Heinzel anläßlich seines Aufenthaltes in Augsburg kennen. Der Vater seiner zweiten Gattin, Hans Martin Hux, stand in regem Handelsverkehr mit den Neidhart und Stebenhaber, war auch durch die Herwart mit letztern verwandt. Die vierte Gattin Schmidts, Elisabeth Hürus, war aber eine Base zweiten Grades der Brüder Heinzel ${ }^{6}$. Diese Verwandtschaft wußten sie reichlich auszunützen.

1597 wurde Schmidt von Bürgermeister Keller** zu einer eingehenden Berichterstattung über alle ihm bekannten Tatsachen aufgefordert, da

Mann ruhig allein arbeiten lassen. Es benötige viel Zeit, um die richtigen Lösungen zu finden. Als jedoch Wochen und Monate vergingen und trotz aller Mittel das Gold, das Venedig so sehr benötigte, nicht erzielt wurde, fing der Graf selbst zu zweifeln an. Als militärischer Beschützer zog er sich zurück, privat unterstützte er jedoch Bragandino weiter, auf Grund der in Brescia gelungenen Versuche. Bragandino, dem es offenbar heiß wurde, wollte nun noch Erfahrungen in den Niederlanden und in Deutschland sammeln. Der Goldmacher fand glänzende Aufnahme bei Herzog Wilhelm V. und dessen Bruder, dem Erzbischof in Köln, beides leidenschaftliche Alchemisten. Es gelang dem Schwindler, eine ganze Reihe hoher Persönlichkeiten zu betrügen. Unter diesen befand sich auch der Nürnberger Handelsherr Willibald Im Hof, ein Verwandter der Mutter von Heinrich Heinzel. Schließlich kamen die Betrügereien doch zutage. Bragandino wurde am 25. April 1591 zu München hingerichtet. Zu seinen Experimenten verwendete er legiertes Gold, das er aus gestohlenen Schmuckstücken oder Münzen gewann, ein Rezept, welches bereits der Spanier RaImund Lullus (1234-1315) angewandt hatte. Aber wirkliches Feingold wurde nie erreicht ${ }^{5}$.

* Jaков Neidhart, der Vetter ihres verstorbenen Vaters, Gabriel NeidhaRt, amtete als Probst zu Wagenhausen. Ein Verwandter der Mutter, Hans Stebenhaber, besaß ein Gut in der Nähe von Öhningen, bei welchem sie öfters weilte.

** Schmid war durch seine Mutter Elisabeth Stokar sowohl mit Keller wie mit Stucki verwandt. Die erste Frau von Hans Balthasar Keller (1501-1554), Margaretha Schaller, war die Nichte der Mutter von Felix Schmid.

5 Ivo Striedinger, Der Goldmacher Marco Bragandino in Archivalische Zeitschrift, hg. vom bayerischen Hauptstaatsarchiv, Beiheft, III. Jahrgang, 1928.

6 Persönliche Nachforschungen in den Archiven Augsburg, Memmingen, Konstanz. 
die Junker Heinzel durch seine Empfehlung nach Zürich gekommen waren*.

Das sehr umfangreiche Dokument beginnt (ohne Überschrift u. Datum)**: «Grundtliche warhafte und summarische zellung der gantzen handlung und ansprachen so die Junkeren und frouwen zu Ellgöuw gegen mir, unnd ich, Felix Schmidt, Burger zu Stain, gegen inen hab, us welchem sich klarlich befinden würd, daß sy nit allein von mir allerdings usgerichtet unnd bezahlt, sonder daß ich noch ein fürtreffliche große summen gelts by inen zu fordern unnd zu suchen hab.

Des alten fründschaft eingedenk will ich den Wunsch zu entsprechen versuchen und den Edlen und Gestrengen Herren Bürgermeister und Räten der löblichen Stadt Zürich als meinen vielgeliebten Herren und Oberen alles wahrheitsgetreu berichten, was ich weiß und miterlebt habe. Wie Euch bekannt, mußte sich Junker Hans Heinrich Heinzel von Degerstein wegen seiner Umtriebe in Augsburg betreffend des neuen Calenders und einem von $\mathrm{ihm}$ in Ulm verfaßten Pasquill flüchten. Er wurde in einem Dorfe arretiert, zuerst nach Weißenhorn, dann nach Kintzburg auf das fürstliche Schloß gebracht und dort wochenlang von Wächtern in Verwahrung gehalten. Durch Bestechung eines desselben gelang es ihm eines Nachts, zu entfliehen. Aber im Reiche war er nirgends mehr sicher. Er sah seine einzige Rettung bei uns in Stain. Zu unserer Bestürzung erschien er eines Nachts vollständig erschöpft und halb verhungert. Als alten Freund und Verwandten meiner Frau hatten wir christliches Mitleid mit ihm, gewährten ihm gerne Asyl und pflegten ihn mit aller Liebe. Ich verständigte sofort meinen Vetter Johannes Keller in Zürich von dieser Aufnahme, auch daß Heinrich mich bat, seine Familie zu holen. In Anbetracht seiner Verhältnisse wollte ich diese Bitte gerne erfüllen. Als bekanntem Handelsmann gelang es mir, unter eigener Lebensgefahr seine Frau und Verronika nebst so viel Kleinodien, Kupfer und Zinngeschirr, als ich in den mit meinem Handelszeichen versehenen Ballen versorgen konnte, nach Stain zu bringen. Nach langer Fahrt kamen wir glücklich zu Hause an, gerade recht, um am 2. April 1585 das Tauffest meines dritten Knaben feiern zu können. Heinrich war voller Freude und Dankbarkeit. Mein Sohn sollte unbedingt seinen Namen erhalten und er wollte Gevatter stehen, wie später in Stammheim 1591 und 1593 bei zwei

* Dank einem Zufallsfund ist es möglich, jeweilen an geeigneter Stelle Auszüge zu geben. Der lange, umständliche Bericht wurde gekürzt und mit Ausnahme besonders betonter Stellen (in Klammern gehalten) möglichst der heutigen Schriftform angepaßt.

** Wahrscheinlich die Kopie. 
weitern Knaben. Hätte ich in die Zukunft blicken können, würde ich gerne auf diese Patenschaft verzichtet haben!

Natürlich fehlte es Heinrich bald an flüssigem Geld, obschon er keine Auslagen für Nahrung und Wohnung hatte. So ersuchte er mich, seine Schwiegermutter, die seit Jahren mit mir befreundet, und die noch über ein großes Vermögen verfügte, nebst dem Bruder Ludwig Heinzel und dessen Frau zu holen. Da Ludwig auch in Ungnade gefallen und beobachtet wurde, war diese Fahrt mit sehr viel Schwierigkeiten und Strapazen verbunden. Obschon wir nur des Nachts reisen konnten und ich sie tagsüber verborgen hielt, mußte ich doch in steter Besorgnis leben, verraten und arretiert zu werden. Während meines langen Aufenthaltes teils in meinem Haus zum Schwarzen Horn in Stain, teils auf meinem Gut Klingenried im thurgauischen Gebiet, fing sich Heinrich für meinen Handel zu interessieren an. In Anbetracht, daß zwei seiner Brüder in großen Handelshäusern beteiligt seien, schlug er mir eine Kommanditgesellschaft vor. Wir könnten in Ulm ein Zweiggeschäft gründen, da er und Ludwig nun nach Verdienst trachten müßten. Der Antrag paßte mir in Berücksichtigung meiner sanktgallischen Verwandtschaft und den Vettern Stokar gar nicht. Aber Heinrich sprach von Vorteilen auch für diese, ließ nicht locker und bedrängte mich stets von neuem. Dann fing Frau Neidhart an, dieses Gesuch zu unterstützen und offerierte mir schließlich eine Einlage von 12000 Gulden, sofern ich anläßlich meiner Reisen ihr Vermögen in die Schweiz bringen könne. Die Brüder wollten einen Schmuck verkaufen und 500 Gulden hinzugeben unter dem Vorbehalt, alle Geschäfte müßten auf meinen Namen gehen. Niemand solle von ihrer Beteiligung wissen. Ich hätte jedes Jahr eine Gewinn- und Verlustrechnung aufzustellen, $6 \%$ falle zu meinen Gunsten, die übrigen an die Junker.

Weder mir noch meiner Frau paßte dieser Antrag. Schließlich willigte ich ein und versuchte ihre Befürchtungen und meine eigenen Bedenken zu beschwichtigen im Hinblick auf die unglückliche Lage der beiden Familien.

In dieser Zeit besuchte uns mein Schwager Thomas Gutenson, der das Bergwerk zu Eisenbach von seinem Vater übernommen hatte. Sofort drehten sich alle Gespräche nur mehr um Alchemie und besonders Metallgewinnung. Heinrich ließ sich durch Caspar Waser, der mit Peter Heinzel in Basel weilte, neueste Schriften über Alchemie besorgen. Kurz vor seinem Tode besuchten sie auch noch unsern alten lieben Verwandten Bartholome Schobinger in St. Gallen, um mit ihm über seine Erfahrungen sprechen zu können. Schließlich richteten sie während meiner Abwesenheit in aller 
Heimlichkeit einen Raum in Klingenried für Experimente ein. Thomas verschaffte die benötigten Materialien, und nun pröbelten sie oft tagelang. Die Sache wurde später durch meinen Pächter Hans Tumeli verraten, da der Knecht Hans Schiegg falsche Münzen in der Umgebung Stains in Umlauf bringen mußte. Von diesen Machenschaften erhielt ich zufolge Abwesenheit erst nachträglich Kenntnis.

Nach der Abreise von Thomas wurde es Heinrich zu langweilig in unserer kleinen Stadt. Wie Ihr wißt, begleitete ich die Brüder selbst nach Zürich, um sie Eurem Schutz und Schirm zu empfehlen. Frau Neidhart blieb mit ihren Töchtern und der Enkelin noch bei uns.

Ich hatte die Junker bei meinen Vettern in Schaffhausen eingeführt. Heinrich ritt oft dahin, um an den Zusammenkünften der philosophischen Gesellschaft teilzunehmen. Von dem vielseitigen Wissen und namentlich den Forschungen meines Vetters und lieben Freundes Johann Conrad Meyer war er begeistert und begleitete ihn öfters nach Schloß Randegg. Er verstand es vorzüglich, mit seiner Gelehrsamkeit für ihn günstige Beziehungen zu knüpfen und durfte sich dadurch ja auch bei Euch weitgehendster Protektion erfreuen. Als die Brüder passende Unterkunft in Eurer Stadt gefunden, fuhr ich ihre Frauen mit allem, was sie ins Land gebracht, nach Zürich. Bei der Abreise gaben sie den Dienstboten keinen Heller, trotzdem sie diese so viel in Anspruch genommen hatten. Dies empörte meine Elsbeth sehr. Ich tröstete sie mit der Aussicht, nun wieder mehr Ruhe im Hause zu haben.

Im September begab ich mich nach Ulm und Nürnberg, um laut Abmachung für die eingelegte Summe Waren einzukaufen, namentlich Nördlinger Loden, Leinwand und Nürnberger Waren, die man bei uns wenig kannte. Zuerst brachte ich Frau Neidhart mit Veronika nach Ulm, wo uns die Brüder Hans Jakob und Friedrich Heinzel nicht besonders freundlich empfingen. Sie äußerten ihre Bedenken wegen der Handelsgesellschaft. Die Zeit sei nicht günstig zu einem Warenaustausch - sie wünschten sich zu keinen Verbindungen zu verpflichten, Heinrich und auch Ludwig hätten ihnen bereits genügend Unannehmlichkeiten bereitet und ihre Stellungen erschwert. Hans Jakob gedenke auch nicht in Ulm zu bleiben. Ich fand ihr Verhalten nach all dem, was ich für die Brüder riskiert hatte, reichlich sonderbar. Aber weder meine Vettern Stokar noch ich selbst waren auf ihre Vermittlung angewiesen. Ich hatte meine guten Agenten und machte mir keine allzu großen Sorgen betreffend Absatz. Bald darauf setzte jedoch die Teuerung ein, Zoll- und Frachtspesen stiegen beständig. Eine Fuhr von Zink, Kupfer und Draht wurde einem meiner Angestellten geraubt. In 
Frankreich war wegen der savoyischen Unruhen kein Absatz möglich. Auch mein Vetter Stokar klagte über die schlechte Geschäftslage. Für mich entstand durch den Einkauf dieser Waren, die keinen Anklang bei uns fanden, ein Verlust von mehreren Tausend Gulden. Die Junker ärgerten sich, reklamierten ihren Gewinnanteil - den Verlust wollten sie nicht tragen helfen. Heinrich kam eines Tages nach Stain und erklärte, sie seien nicht zu Kaufleuten qualifiziert. Es sei besser, ich betreibe den Handel wieder allein und erstatte ihnen ihre Einlage. Umsonst wies ich ihm die Belege für die in seinem Auftrag eingekauften Waren vor, erinnerte ihn an die getroffenen Abmachungen, auch da $\beta$ der Vorschlag einer Kommanditgesellschaft von seiner Seite aus ergangen sei und ich nur ungern eingewilligt hätte. Es nützte nichts. Mit der Erklärung: 'Ich bin kein Handelsmann und verstehe nichts von Geschäften - ich fordere nur unser Geld zurück ${ }^{6}$ wies er alle meine Vorstellungen ab. Meine arme Elsbeth nannte ihn vor Erregung einen unverschämten Erpresser. Er lachte über seine ,liebe temperamentvolle Frau Base'. Ich selbst war zu betroffen über die Unverfrorenheit eines so gelehrten Mannes und litt innerlich um der Freundschaft willen. Da mir kein bares Geld zur Verfügung stand, gab ich ihm eines meiner Güter als Unterpfand, verlangte jedoch den in Doppel ausgeführten Handelsvertrag mit dem Schein der Einlage zurück. Er versprach, ihn beim nächsten Besuch mitzubringen, fand jedoch jedesmal eine Ausrede.»?

Ja, wenn zu Sol sich Luna fein gesellt
Zum Silber Gold, dann ist es heitre Welt (GoETHE, Faust II, 1)

Die Heinzel verstanden allerdings rasch sich die Gunst der zürcherischen Obrigkeit und reicher Patrizierkreise zu gewinnen. Trotzdem die Schweizer stets als vorsichtig, mißtrauisch und nüchtern bezeichnet werden, ließen sie sich doch zu allen Zeiten leicht von ausländischer Bildung und einer gewissen Überlegenheit beeinflussen. Und die Junker Heinzel besaßen nicht nur Bildung, Geist und Weltgewandtheit, sondern auch liebenswürdige Umgangsformen. Jedenfalls wurde ihnen großes Vertrauen entgegengebracht.

Schmidt war nicht der einzige, der sich täuschen ließ. Als angesehener Mann verfügte er über viele Beziehungen, die den Heinzel zustatten kamen. Er war eng befreundet mit Amtmann Heinrich Thomann, der drei seiner Kinder aus der Taufe hob, ebenso mit Seckelmeister Gerold Escher. In geschäftlicher Beziehung stand er mit den Brüdern THürING und HaNs

7 ZB ZH: Mscr., S. 279, Nr. 210, ausführliches Konzept in Privatbesitz. 
Heinrich Lochmann, dem Pannerherrn. Diese interessierten sich lebhaft sowohl für Bergbau wie Alchemie*8.

Laut einem Brief an WASER unterhielt Heinzel wahrscheinlich durch Vermittlung Schmidts bereits 1586 persönliche Beziehungen mit Pannerherrn Lochmann. Jedenfalls dürfte ihm Schloß Elgg nicht unbekannt gewesen sein. Nach dem plötzlichen Hinschied des Pannerherrn drängten die Erben zu raschem Verkauf der Güter. Aber es zeigten sich wenig ernsthafte Bewerber für die Herrschaft Elgg. Obgleich im Rat Bedenken gegen die Abgabe an Ausländer geäußert wurden, blieb Zürich schließlich nichts anderes übrig, als die von den Lochmannschen Erben vorgeschlagenen Interessenten, die Junker Heinzel von Degerstein, zu genehmigen. Bürgschaft übernahmen unter andern mehr Apotheker Hans Ulrich Wolf und Felix Schmidt. $\mathrm{Da}$ auch die Stokar und Johann Conrad Meyer in Schaffhausen beteiligt waren, geht aus einem Schreiben Heinzels an Stucki hervor**9.

Die Übernahme durch die Heinzel wurde durch den Umstand begünstigt, daß der Verwandte der Schwiegermutter, Junker Hans Heinrich FunK von Memmingen ${ }^{+}$, seit 1579 bei Lochmann als Statthalter und Stellvertreter des oft abwesenden Gerichtsherrn amtete ${ }^{10}$.

Die Verhältnisse schienen demnach für die Heinzel günstig. Wahrscheinlich hegte Heinrich die größte Hoffnung auf das Bergwerk am Gon-

* Ihr Vater hatte ihnen das Bergwerk am Gonzen hinterlassen. Als Hans HeINRICH von DEN Hinwyl am 20. September 1576 die Herrschaft Elgg übernahm, wurde dieser das Bergwerk einverleibt. Der älteste Bruder, Heinrich Lochmann, übernahm die Schaffnerei in Flums. Auf einer Reise nach Italien erkrankte der Pannerherr und starb am 2. Juni 1589 zu Padua, ohne Kinder zu hinterlassen. Sein ebenso geschäftstüchtiger Bruder ThüRING war ihm bereits $1576 \mathrm{im}$ Tode vorausgegangen. Die Erben wollten sich weder mit den erworbenen Gütern Schloß Vufflens (Bezirk Morges), der Baronie Aubonne, noch mit der Herrschaft Elgg und dem Bergwerk befassen. Es zeigte sich, daß die Verhältnisse des Pannerherrn keineswegs so glänzend waren, wie angenommen worden. Die Geschwister trachteten daher nach schnellem Verkauf der kostspieligen Herrschaften. 1592 konnten sie Aubonne an François Villain verkaufen, mit welchem sie jedoch jahrelang, wie auch mit den Stokar, prozedierten. Letztere gehörten mit Niklaus Falkner und dessen Neffe Offrion Merian, in Basel, zu den Hauptgläubigern des Pannerherrn.

** Nähere Angaben über die Höhe dieser Beteiligungen ließen sich nicht finden. Jedenfalls erhielten die Lochmannschen Erben trotz ihres Prozesses mit den Verwandten der Heinzel die zweite Hälfte des Kaufpreises nie.

+ Funk Hans Heinrich, Junker von Memmingen, Statthalter der Herrschaft, $\infty$ 1) 14.12. 1580 Beatrix von Hinwyl, 2) 24.8.1612 Anna Meiß, $\uparrow$ Elgg 12.11.1620.

8 StA ZH: A 27,160, A 92, 1.

9 Ebenda, A 116,2.

10 Ebenda, A 116,2, Gemeindearchiv Elgg IV A t 6 a. 
zen*. Laut Kaufbrief vom 5. März 1590 betrug der Preis für die Herrschaft Elgg 68000 Gulden. Eine Anzahlung von 30000 Gulden hatte sofort zu erfolgen, 15500 Gulden waren, innerhalb sechs Jahren, mit $5 \%$ verzinsbar zu entrichten, 12000 Gulden nebst 600 Gulden Zins bis 1. Mai 1600. Frau Neidhart hinterlegte beim Obmannamt die Summe von 12000 Gulden. Durch Vermittlung von Münzmeister Hans Jakob Wegerich in Chur, eines alten Bekannten der Neidhart, konnte eine Anleihe von 9100 Gulden bei Samuel Verzaska in Basel aufgenommen werden. Wegerich übernahm die Bürgschaft und verpflichtete sich für regelmäßige Abzahlung innert drei Jahren besorgt zu sein. Der Bruder Hans Jakob Heinzel gab ein Darlehen von 15000 Gulden, forderte jedoch $5 \%$ Zins, was der Rat ausschlug und nur die üblichen $3 \%$ bewilligte ${ }^{11}$.

Bald herrschte auf Schloß Elgg ein feudales, fröhliches Leben und Treiben. Die Junker fühlten sich in ihrem Element, hielten ein gastfreundliches Haus, genossen den Ruf hoher Bildung und gedachten, Förderer der Kunst und Wissenschaft in der Eidgenossenschaft zu werden. So wurde Schloß Elgg bald der Sammelpunkt nicht nur der bedeutendsten Gelehrten, sondern auch der reichen Handelsherren von Zürich, St. Gallen, Wil, Schaffhausen. Zur Begutachtung des Bergwerkes ließen die Junker fremde Bergbausachverständige kommen und suchten Verbindung mit allen bekannten Alchemisten ${ }^{12}$. Heinrich Heinzel wurde in Zürich namentlich von Professor Wilhelm Stucki protegiert und durch ihn in die Patrizier- und Gelehrtenkreise eingeführt. So lernte er auch Pfarrer Raphael Egli kennen, zu dessen Verhängnis.

Anläßlich der Durchreise von Frankreich nach Venedig machte Giondano Bruno **, genannt der Nolaner, 1591 einen Aufenthalt in Zürich. 1548 in Nola geboren, führte der einstige Dominikanermönch, der wegen seiner allzu freimütigen Ansichten aus seiner Heimat fliehen mußte, ein sehr unstetes Leben. Er hielt sich in Spanien, Frankreich, England und Deutschland auf, betätigte sich als praktischer Naturphilosoph und Alchemist, wurde 1588

* Das Bergwerk dürfte kaum sehr ertragreich gewesen sein, denn in der Zeit zwischen 1547 bis 1654 wechselte der Besitz achtmal.

** Bruno wurde am 20. Januar 1600 degradiert, exkommuniziert und am 17. Februar verbrannt. Er teilte dasselbe Schicksal wie sein Landsmann Bragandino ${ }^{13}$.

11 Ebenda, A 27,160.

12 ZB ZH: Mscr., S. 279, 28.

13 Valentin Gitermann, Der Prozeß des Giardano Bruno. E. Spundi, Verbannt von Gottes Gnaden, Lebensroman des G. Bruno. 
als Förderer des böhmischen Bergwerkwesens zu Kaiser Rudolf II. nach Prag berufen, nachher zu Herzog Julius von Braunschweig, beides bekannte Freunde der Goldmacherei. Stucki vermittelte die Bekanntschaft Brunos mit Heinzel und Egli, die bald vollständig unter seinem Bann standen und dessen begeisterte Schüler wurden. Während sich Egli bis anhin mit Apotheker Hans Ulrich Wolf hauptsächlich mit chemischen Fragen und Experimenten zur Gewinnung von Heilmitteln beschäftigt hatte, wurde er nun in ein anderes Fahrwasser gezogen. Brunos Hauptinteresse galt der Auffindung der Materie, durch welche unedles Metall in edles verwandelt werden könnte. Diese Frage beschäftigte auch Heinrich Heinzel unaufhörlich. Voll Freude teilte er Hans Caspar Waser in Basel mit: «Endlich, endlich habe ich den rechten Mann gefunden, der dieselben Interessen mit mir teilt. Bald werden alle Schwierigkeiten behoben sein, was Du dann auch spüren sollst.» ${ }^{9}$ Der berühmte Naturforscher wurde also nach Schloß Elgg eingeladen. Dort errichtete er ein Laboratorium, und nun wurde mit Leidenschaft experimentiert. Eifrig studierte man die 1590 erschienenen Schriften von Gaston de Claves, einem überzeugten Verfechter der Alchemie in Frankreich. Heinzel wandte alles auf, um Bruno zu gefallen, welcher mehrere Monate in Elgg und Zürich zubrachte. Allerdings konnte er trotz vielen Versuchen keine bestimmten Resultate erzielen, machte hingegen stets große Versprechungen. Als er sich 1592 nach Mailand begab, dedizierte er Heinzel seine Schrift. Sehr wahrscheinlich begleitete ihn Heinzel zu Graf Martinengo.

Bei all diesem Betrieb vergaßen die Heinzel vollständig ihre Pflichten als Gerichtsherren. Sogar die Einstellung eines von der Gemeinde vorgeschlagenen Vogtes wurde vernachlässigt. Alle Amtsgeschäfte wurden dem Weibel Hans Stadelmann überlassen, bis dieser sich weigerte, länger eine unliebsame Doppelstellung zu versehen. Trotz wiederholter Mahnung bekümmerte sich keiner der Brüder um das Tun und Lassen noch um die Wohlfahrt der Bürgerschaft. Versäumte Gerichtsfälle, fortwährende Unannehmlichkeiten in der Gemeinde gaben zu vielen Klagen Anlaß ${ }^{14}$.

Sowohl Einrichtungen wie Experimente aber erforderten Geld und immer wieder Geld. Bereits am 16. März 1591 beklagt sich Heinzel in einem Schreiben an Stucki, die Lochmannschen Erben bedrängten ihn in unerhörter Weise und verlangten pünktliche Abzahlung. Dies sei ihm nicht möglich, da es schwer halte, Darlehen aufzunehmen, indem man sich

14 Gemeindearchiv Elgg III A t 4 und V A t I 3. 
gegenüber Fremden sehr mißtrauisch zeige. Flüssige Mittel besitze er keine und seine Schwiegermutter wolle nicht mehr aushelfen ${ }^{15}$. Natürlich wandte er sich auch an Bürgermeister Meyer, welcher ihm bereits 1588 eine Summe vorgestreckt hatte. Am 28. Oktober 1591 berichtet Heinzel an Stucki: «M. (Meyer) hat mir geschrieben, es sei ihm momentan unmöglich, mir die durch Eure Bürgschaft versprochenen 1000 Gulden zur Verfügung zu stellen. Er hoffe, dies werde auf Dezember möglich werden. Auch verlange er freundschaftshalber keinen Zins dafür.» Im November bittet er Stucki inständig, Meyer zu erinnern: «Ich fürcht' und spür's, M. führt mich am Narrenspiel herum. Ich glaub', er hat schlechten Bericht von Augsburg erhalten. Fortunato (Felix Schmidt) tut sein Möglichstes, aber er ist durch den von Sulz bereits stark belastet.» Die von Bürgermeister Meyer versprochene Summe gelangte im Laufe des Dezembers durch Stucki an Heinzel. Stucki warnte ihn davor, mit der Goldmacherei allzuweit zu gehen, die Versuche seien kostspielig und gefährlich. Er solle in erster Linie trachten, seinen finanziellen Verpflichtungen nachzukommen ${ }^{16}$. Auf weitere Klagen über Geldschwierigkeiten ging Stucki nicht mehr ein, die eine Bürgschaft belastete ihn wahrscheinlich genug. Der Briefwechsel nahm bereits $1594 \mathrm{ab}$.

Aber seit Brunos Besuch war Heinzel besessen von der Idee, die Versuche würden ihm gelingen. Auf einzelne Menschen wirkt Gold wie ein Rauschmittel. Der Dämon hält sie gefangen, alles muß für die Sucht dienen. Während Heinzel für diese das Letzte aufs Spiel setzte, zeigte er sich in anderer Beziehung höchst kleinlich und geizig. Von Waser verlangte er beispielsweise die regelmäßige Zustellung der Abrechnungen für Studien und Auslagen seines Zöglings. Stets fand er diese zu hoch. Dagegen mußte Waser immer wieder die neuesten Werke über Chemie senden und diese aus dem Geld des jüngsten Bruders, Johann Peter, bezahlen. Waser wurde beauftragt, mit Professor Theodor Zwinger in Basel wegen der versprochenen Beiträge für die Versuche zu sprechen und den jungen, reichen IsELIN gefällig zu machen. «Fortunato eignet sich als gewandter Geschäftsmann gut zum Unterhändler. Ich werd' ihn nach Basel schicken für Einkauf von Eisen, Salz und Salpeter*. Sei ihm behilflich, nenn ihm

* Für Scheidwasser wurden Salz und Salpeter verwendet. Das Ergebnis hing von der richtigen Zusammensetzung ab.

15 UnB BS G I 47.

16 ZB ZH: S 279 Nr. 46. 
den rechten Mann und gib ihm die Werke mit, die ich in Zürich bei Stucki abhole. Ich bin vollauf beschäftigt mit chemischen Studien und Experimenten.» Er empfiehlt den Überbringer des Briefes, RaYmond Weiss aus Wien, besonders freundlicher Aufnahme, da er ein guter Alchemist und zudem ein Verwandter der Heinzel sei ${ }^{17}$.

Wie aber kam es, daß die Heinzel in der Lage waren, 1593 Schloß Haldenstein* zu erwerben? Für diesen Kauf setzte sich sogar die zürcherische Obrigkeit bei den Bündnern mit einem Empfehlungsschreiben vom 23. Juni 1593 ein: «Unser getreuer lieber Landsässe Junker Hans Heinrich von Degerstein, Gerichtsherr zu Elgg teilt uns mit, daß in Euren Landen und Gebieten ein Landgut als freier Edelsitz für ihn und seinen Bruder zu kaufen sei. Er bittet uns, ihm dabei behilflich sein zu wollen. Die Herren in Bünden mögen ihr Möglichstes tun. Die Junker waren früher in der Landschaft Thurgau ansässig **, weswegen sie Zürich gerne als Landsässen aufgenommen hat und jedes ihrer Begehren unterstützen wird» ${ }^{19}$. Es war den Heinzel gelungen, die Obrigkeit in Zürich ganz für sich einzunehmen, und wir dürfen ruhig bemerken, für ihre Zwecke zu gewinnen.

Schloß Haldenstein diente natürlich den Ansprüchen der Junker besser als die kalte Burg Elgg. Die größte Anziehungskraft dürften jedoch die bündnerischen Erzbergwerke ausgeübt haben, und Haldenstein war eine der am intensivsten betriebenen currhätischen Münzstätten. Münzmeister war Hans Jаков Wegerich, der wiederum die verschiedenen Geldaufnahmen vermittelte. Persönlich streckte er selbst 2000 Gulden vor, weitere Darlehen wurden aufgenommen bei Herrn von Rhäzüns (Johann von Planta) mit 2200 Gulden, bei Franz Vertemate mit 2000 Gulden, bei den Gantnerschen Erben mit 4000 Gulden und bei Heinrich Menhard mit 2000 Gulden ${ }^{20}$.

* Haldenstein unterhalb Chur am Fuße des Calanda gelegen. Inhaber war Gregor CARL von Hohenbalken. Das Schloß erhielt seinen Namen von der Familie Haldenstein. Es gelangte in den Besitz des Mailänders CAstion oder Castiglione. "Castion ließ hie in Haldenstein dies Schloß für Kind und Kindeskinder umbauen. Er war König Franzens Gesandter in Italien, ein tapferer Held, durch Glücksgunst und durch Taten berühmt. » (Тн. Монв, Archiv für Geschichte der Republik Graubünden, 1853) ${ }^{18}$.

** Es kann sich nur um einen vorübergehenden Aufenthalt auf dem Gute von Felix Schmidt handeln. Ansässig waren diese Brüder vorher nicht im Thurgau.

17 StA ZH: S. 279, Nr. 46.

18 Тн. Монг, Archiv für die Geschichte der Republik Graubünden, Chur 1853.

19 StA ZH: B IV 49, 5 (1593).

20 Ebenda, A 116,2. 
Für diesen vornehmen Sitz sollte das Bergwerk am Gonzen aufkommen, das daher in vollen Betrieb gesetzt werden mußte. Heinzel ersuchte Felix Schmidt, der sich am besten im Fache verstehe, sich nach einem tüchtigen Schaffner und Werkmeister umzusehen. «Dieser muß jedoch ein Alchemist und Goldmacher sein», lautete das Begehren. Schmidt empfahl als Schaffner Hans CaSpar Spleiss von Schaffhausen, der als Salzhändler über zahlreiche Verbindungen verfüge, zudem bei der schaff hausischen und zürcherischen Obrigkeit in gutem Ansehen stehe. Dagegen müsse Heinzel für einen ihm passenden Werkmeister selbst besorgt sein, da Schmidt mit Goldmachern nichts zu tun haben wolle.

In Württemberg lernte Heinzel Hans Јаков Оснs von Schaffhausen kennen, der ihm als besonders erfahren in der Goldkunst empfohlen wurde. Gestützt auf frühere Erfahrungen weigerte sich Spleiß mit Ochs zu arbeiten, ließ sich dann aber von Heinzel zur Annahme des Postens in Flums überreden. Schmidt leistete für ihn Bürgschaft unter der Bedingung, daß Heinzel beim Klosteramt in Schaffhausen 8000 Gulden hinterlege mit der schriftlichen Verpflichtung, die Summe je zur Hälfte innerhalb drei Jahren an Spleiß und Ochs auszuzahlen nebst gebührendem Gewinnanteil. Heinzel fand Schmidt reichlich mißtrauisch, fügte sich aber den gestellten Forderungen mit der Bemerkung: «Ich halt meine Verpflichtungen auch für den Fall, daß Hans Jakob Ochs die ihm gestellte Aufgabe nicht erfüllen kann.» Spleiß stellte Schmidt einen Schadlosbrief aus*21.

Die Bedenken von Schmidt und Spleiß zeigten sich in der Folge als durchaus berechtigt. Die tirolischen Bergknappen verlangten guten Lohn und Vorausbezahlung. Heinzel aber fehlte es sowohl an Geld wie an Kenntnissen und Verständnis für den Betrieb eines Bergwerkes.

Zuerst reiste er mit Ochs nach Straßburg. Dieser sollte noch mehr Erfahrungen in Lothringen sammeln, wo man mit der Goldmacherei bereits schöne Erfolge erzielt hatte. Heinzel selbst begab sich in die Niederlande. Da es ihm auf der Rückreise in Straßburg an Geld fehlte, beauftragte er Ochs, für ihn bei Herrn von TürкhEIM und bei dem Freiburger Schultheißen, die beide gute Alchemisten und mit Heinzel befreundet waren,

* Schadlosbrief: Das schriftliche, vermutlich pfandgesicherte Versprechen des Hauptschuldners, den Bürgen für alles schadlos zu halten, was er auf Grund der Bürgschaft für den Hauptschuldner leisten muß (gefällige Mitteilung von Herrn Oberrichter Dr. A. BAUHOFER).

${ }^{21} \mathrm{StA} \mathrm{ZH}:$ A 116,2 . 
Darlehen aufzunehmen ${ }^{22}$. Voller Zuversicht kehrte er mit Ochs zurück. Nun sollte tüchtig gearbeitet werden. Bei einigen Versuchen gewann Ochs etwas Goldstaub, aber nach zwei Jahren war noch kein richtiges Resultat erzielt. Heinzel drohte ihm mit Entlassung, falls er sich nicht in absehbarer Zeit als Goldkünstler bewähre.

Wahrscheinlich zirkulierten bereits 1594 in Zürich unerfreuliche Gerüchte über das Treiben und die wirklichen Verhältnisse der Junker. Jedenfalls wünschte die zürcherische Obrigkeit Einsicht in den Kaufbrief von Haldenstein zu nehmen. Heinrich Heinzel befand sich in Paris. Als Ludwig die Aufforderung erhielt, beauftragte er Ochs, den Kaufvertrag nach Zürich zu bringen. Dieser begab sich vorerst nach Stammheim zu seiner Frau, die dort ein kleines Gütchen besaß. Beim Abendtrunk im Wirtshaus machte er sich wichtig, prahlte mit seiner Kunst und ließ Äußerungen fallen, er besitze in seiner Tasche Papiere, die etliche große Herren nicht nur in größte Verlegenheit, sondern sogar an den Galgen bringen könnten. Dies wurde in derselben Nacht der Obrigkeit in Zürich hinterbracht. Bereits am nächsten Tag erhielt der Obervogt durch einen Überreiter die Weisung, von Ochs unter Androhung der Gefangennahme die Herausgabe der Papiere zu verlangen. Vorerst solle er ihm ein Schweigegeld verabfolgen und vorsichtig mit ihm umgehen, da er schaffhausischer Bürger sei. «Die Angelegenheit ist von höchster Wichtigkeit, denn bei Haldenstein sind auch zürcherische Ratsherren beteiligt. Der jüngere Gerichtsherr zu Elgg befindet sich wegen des Kaufvertrages, den er unvorsichtigerweise nicht selbst nach Zürich gebracht, in höchster Aufregung. ${ }^{23}$

Ochs gab die Papiere freiwillig heraus, fühlte sich aber auf zürcherischem Gebiet nicht mehr sicher. Er begab sich eilends nach Schaffhausen, um beim Klosteramt das für ihn deponierte Geld entgegenzunehmen. Zu seinem Erstaunen teilte ihm Klosterschreiber HaNS Jаков HÜNerwadel mit, Junker Heinzel habe die 8000 Gulden längst zurückgezogen mit der Erklärung, die Auszahlung an Spleiß und Ochs werde von ihm persönlich sofort vorgenommen, da diese Geld benötigten. Hünerwadel hatte keine Veranlassung, den Worten Heinzels zu mißtrauen und händigte ihm Geld und Verschreibung aus. Bei der Reklamation von Ochs aber wurde er stutzig und verständigte den Rat. Dieser zitierte Ochs und Spleiß und verlangte Aufklärung über den Sachverhalt. Das Verhör ergab, daß weder Spleiß

22 StA ZH.

23 Ebenda, B IV 50, 107. 
noch Ochs irgendeine Entschädigung von Heinzel erhalten, trotzdem sich dieser zu einer jährlichen Abzahlung von 400 bis 500 Gulden verpflichtet hatte ${ }^{24}$.

Durch das Verhör wurde verschiedenes aufgedeckt. Hünerwadel machte der zürcherischen Obrigkeit Mitteilung, welch großen Schaden die beiden Männer durch Heinrich Heinzels unbegreifliches Vorgehen erlitten. Zur Rede gestellt, suchte sich dieser bei der zürcherischen und schaffhausischen Obrigkeit schriftlich zu rechtfertigen. Spleiß sei für die Schaffnerei eines Bergwerkes nicht geeignet, Ochs* aber hätte die Aufgabe, zu der er angestellt worden, überhaupt nicht verstanden, so fühle er sich keineswegs verpflichtet, das getroffene Abkommen innezuhalten ${ }^{25}$. Dies brachte den Stein ins Rollen.

\author{
Das Treiben der Elgger Schloßherren \\ «Der, dem die Alchemie ist hold, \\ Gewinnt gar leicht aus Quecksilber Gold, \\ Und verleiht ihm den Glanz und der Schwere Kraft, \\ Durch Zutaten, die er sich billig verschafft'.»**
}

Felix Schmidt, der sich seit 1594 als Bergherr in Eisenbach befand, hörte erst später von diesem Ränkespiel der Heinzel. Zwischen 1591 bis 1595 leistete er den Junkern «um der alten fründschaft willen » unzählige Dienste. Darüber unterrichtet uns sein Bericht eingehend!

«Es wäre viel zu ausführlich, Euch zu berichten, was sie alles von mir verlangten und wohin sie mich überall sandten, ich will mich nur an die Hauptsache halten. Zuerst war es Anton Hinterhoffer zu Ravensburg, der als Goldmacher bekannt war. Sie luden ihn ohne mein Wissen nach Stain ein. Zu den Versuchen erschien auch Graf von Sulz mit dem Fürsten von Bayern. Es war kein Spaß, täglich für so viele Herrschaften und dazu noch

* Hans Jakob Ochs führte allerdings kein einwandfreies Leben. Er machte sich verschiedener Veruntreuungen in Schaffhausen schuldig, floh wieder nach Württemberg und erhielt eine Anstellung in den Laboratorien des württembergischen Hofes. Dort verleumdete er die schaffhausische und zürcherische Obrigkeit. Schaffhausen verlangte seine Auslieferung. Ochs' Appellation an das Hofgericht wurde abgewiesen. Am 5. November 1595 wurde er mit dem Schwert gerichtet. Klosterschreiber Hünerwadel erklärte als Vogt der Witwe, der Mann sei durch Heinzel ins Unglück getrieben worden und hätte sich nachher aus Rachsucht gehen lassen.

** Ed. Lippmann, Entstehung und Ausbreitung der Alchemie, Bd. I, S. 502.

24 StA ZH: A 252, 2 (1594).

25 Ebenda, A 116, 2-B V 36. 
die Bedienten und Pferde sorgen zu müssen. Mein Haus war überfüllt und die reinste Herberge. Zum Glück hatten wir die Kinder in Stammheim. Bis tief in die Nacht hinein wurden die Probleme besprochen und tapfer gezecht. Wegen Ruhestörung erhielt ich vom Rat einen Verweis, und ich hatte viele Unannehmlichkeiten. Meiner Hausfrau gefiel das Treiben ganz und gar nicht, aber die Junker verstanden ihre liebste Frau Gevatterin immer wieder zu beschwichtigen mit dem Hinweis, was für berühmte Männer sie beherbergen dürfe und wie alle Unkosten drei- und vierfach bezahlt würden.

Eines Nachts aber entwischte Hinterhoffer, nicht ohne einiges Silberzeug mitgenommen zu haben. Dazu hinterließ er eine Rechnung von 2500 Gulden, die ich den Junkern voller Abscheu übergab. Zufällig sah ich den Schwindler später in Straßburg, ließ ihn arretieren und seine Kleider und das Pferd mit Beschlag belegen. Mit Hilfe seines Bruders aber gelang es ihm, durchzubrennen.

$\mathrm{Zu}$ unserer nicht geringen Überraschung kam Heinrich bereits nach einigen Wochen mit seiner Frau und Veronika, welcher Elgg nicht bekomme, und baten um unsere Gastfreundschaft. Ich stellte die Bedingung, dies Mal wünsche ich keine weitern Besuche und Belästigungen. Aber plötzlich erschien ein Dr. Albinus Weiß von Sulgen eines Tages, mit dem Heinrich schon lange in Verbindung stand. Dieser sei berühmt, verstehe sich auf die Materie und habe sogar von den Brüdern Heinzels in Ulm Geld zu Versuchszwecken erhalten. Nun aber erklärte meine gute Elsbeth energisch, im «Schwarzen Horn » würden keine Experimente mehr geduldet, dafür eigne sich Schloß Elgg besser. Sie zogen verstimmt ab, doch entpuppte sich auch Weiß als Abenteurer. Einige Zeit hatten wir Ruhe. Dann tauchte Heinrich wieder auf mit der Bitte, ihn nach Basel zu begleiten, ich müsse unbedingt an dem großen Erfolg teilnehmen, der ihm nun in Aussicht stehe. Da ich in Basel Geschäfte zu erledigen hatte, willigte ich ein. Nachdem er mir das Versprechen abgenommen, alles, was ich sehe und höre, geheimzuhalten, führte er mich in das Laboratorium eines Baslers, Ludwig Apfel, der mit seinem Gesellen Hans Ruch arbeitete. Ein Experiment, dem wir beiwohnten, ergab einen überraschend feinen Goldstaub. Aus einer Mischung bereitete er echtes Silber.

Heinrich war begeistert. Nach einer zweiten Probe, die ebenfalls gelang, versprach er Apfel 40000 Gulden für das Rezept, sofern er die Experimente nochmals in Stain vornehme. Nach Elgg könne er aus gewissen Ursachen nicht mit ihnen. Zuerst weigerte ich mich - aber schließlich wurde ich wie- 
derum weich. Heinrich war auf der Reise ganz übermütig und fröhlich. ,Endlich, endlich sind wir am Ziel ${ }^{6}$ - sang und jubelte er. Bei der Einkehr in Augst zog er mich in den Garten hinaus, umarmte mich und gab mir strahlend ein Obligo von 8000 Gulden als Abzahlung an all meine Auslagen. Ich war höchst erstaunt und gerührt, denn natürlich hatte ich keine Ahnung, daß diese Summe vom Klosteramt zurückgezogen worden und eigentlich Spleiß und Ochs gehörte.

Zufällig belauschte mein Diener das Gespräch. Er kam zu mir und meinte, ich könnte ihm die 80 Gulden, die er mir schulde, nun füglich schenken, da ich selbst so reich beschenkt worden. Heinrich lachte und sagte: ,Das ist nur billig, steht es doch schon im Evangelium, warum sollst du deinem Bruder nicht die kleine Schuld erlassen, wenn dir so viel tausend Pfund geschenkt werden? Zeige dich also großmütig, du willst ja doch immer andern helfen!

Auf einem prachtvollen weißen Hengst zog Apfel wie ein Fürst in Seide und Samt, feiner Wäsche und viel goldenen Ringen und Ketten, in Stain ein. Zu seiner Linken ritt der strahlende Junker, hinten der Begleiter Ruch und unsere Diener. Bereits auf dem Wege fing ich mich zu schämen an. Ich ritt voraus, angeblich, um unsere Ankunft mitzuteilen, in Wirklichkeit scheute ich mich vor meinen Mitbürgern in einer solchen Gesellschaft gesehen zu werden. Welch erbärmlicher Schwächling war ich, den Überredungskünsten nicht widerstehen zu können. Auf Erfolg hoffte ich ja nie. Aber meine kluge Frau lief heimlich auf das Rathaus. Der Bürgermeister kam persönlich und teilte den Junkern mit, es wäre ihm lieber, sie würden ihre Lustbarkeiten an einem andern Ort betreiben, da sich die Bürger wegen des häufigen Nachtlärms beklagt hätten. Heinrich murrte und war sehr ungehalten über unsere Spießbürgerlichkeit. Nach Elgg könne er nicht. Schließlich schlug ich unsere Behausung in Stammheim vor. Während ich in Eisenbach meiner Arbeit oblag, hielt sich die Gesellschaft viele Wochen in Stammheim auf. Ihr wißt am besten, wie mancher Ratsherr von Zürich, Schaffhausen und Basel kam, um dem Laborieren und Experimentieren beizuwohnen. Mein Weinkeller wurde vollständig ausgepumpt, aber auch das Wissen des Apfel, der schließlich mit weniger Pracht abzog, als er gekommen*.

* Eine Bemerkung von Felix Schmidt in seinem Familienbuch betreffend Alchemie lautet: Welch großen Schaden mir diese Erzbetrüger Weiß und Apfel mit ihrer Goldkunst angerichtet, ist gar nicht zu ermessen. Gott möge mir Kraft verleihen, daß ich fortan den Versuchungen der Junker Widerstand leisten kann. 
In dieser Zeit (8. Februar 1593) gebar meine Frau einen Sohn. Heinrich Heinzel offerierte sich zum dritten Mal als Pate, denn aller guten Dinge seien drei. Am 16. Februar kam er mit Ludwig angerückt. Nach dem Essen bat er um Erlaubnis, die Kindbetterin besuchen zu dürfen. Er machte ihr viel Komplimente über den strammen Buben, den er sich selbst schon lange gewünscht, versicherte die liebste Frau Base seines steten Dankes, für alles, was wir für ihn und seine Familie getan. Nun wolle auch er sich erkenntlich zeigen und ihr eine Freude bereiten. Wie sie wisse, habe er mir bereits in Augst 8000 Gulden als Abzahlung übergeben. Als Patengeschenk gedenke er ihr nun den Schuldschein für die Summe von 12500 Gulden zu senden, welche sie in die Kommanditgesellschaft eingelegt hätten. Derselbe befinde sich allerdings noch in Verwahrung der Schwiegermutter. Sobald sie von Ulm nach Elgg zurückkehre, werde er ihn verlangen. Vorläufig bestätige er die Zusage schriftlich. Dabei legte er einen Zettel folgenden Inhalts in die Hände meiner Frau:, der erbaren, tugendhaften, Elisabeth Hürussin in Stain, miner günstigen liben fründlichen unnd edlen frouw basen, wünschen wir Gottes richen segen. Ich Johann Heinrich Heintzel von Tegerstain, versprech bi verlust miner seeligkeit, den schin von 12500 Gulden, so Felixen Schmidt ist, unnd von mir unnd Ludwigen Heintzel unterschriben worden. Also von unserer Frouw Mutter, euch sofort zu schiken. Johann Heinrich Heintzellin von Tegerstain, Herr zu Elgöuw und Ludwig Heintzellin sin brueder (Datum 16. Februar 1593).

Aber mit diesem Versprechen war es widerum nichts. Meine Frau erinnerte ihn zwar anläßlich jedes Besuches, doch fand er stets eine Ausrede. Als dann Frau Neidhart 1595 zurückkehrte, standen die Sachen in Elgg bereits sehr schlimm*. Zu meinem Erstaunen erhielt ich von ihr durch Vogt Zinggeler ein Schreiben mit der Aufforderung, meine Schulden zu bezahlen, sie sei gezwungen, nun Abrechnung zu halten. Ich begab mich nach Elgg und versuchte sie über den wahren Sachverhalt aufzuklären, daß ich ja in ihrem Auftrag die Einkäufe in Nürnberg und Nördlingen gemacht, seither aber ihren Schwiegersöhnen wiederholt Darlehen verabreicht, welche die Einlage von 12500 Gulden bereits überschritten hätten. Ich wies

* Frau Neidhart scheint über die Umtriebe der Schwiegersöhne gar nicht unterrichtet gewesen zu sein. Offenbar schämten sich die Töchter, der Mutter Mitteilung von den herrschenden Zuständen auf Schloß Elgg zu machen. Als sie dann zur Geburt des Enkels von Ulm zurückkehrte, waren die Verhältnisse bereits unhaltbar geworden, doch verstand Heinrich Heinzel ihr gegenüber den Verführten und Betrogenen zu spielen, wie wir noch sehen werden. 
ihr auch den Zettel an meine Frau nebst allen Belegen vor. Aber Frau Neidhardt lehnte alle Erklärungen ab. Was ihre Schwiegersöhne während ihrer Abwesenheit geborgt, gehe sie nichts an. Sie hätten nun lange genug auf ihre Kosten gelebt. Dabei klagte und jammerte sie dermaßen, daß ich trotz ihren Beschuldigungen Mitleid mit der alten Frau empfand. Obschon ich mich keineswegs verpflichtet fühlte, stellte ich ihr an Stelle von Geld mein Gut in Nußbaumen zur Verfügung, das sie durch Vogt Zinggeler an Junker Covatz zu Lindau verkaufen ließ. Nachträglich fand sie die von ihm erhaltene Summe nicht hoch genug und gelangte mit neuen Forderungen an mich. Schließlich wurde ich so wütend, daß ich voller Ingrimm, trotz den Einwänden meiner Frau, das Silber in Stammheim verpackte. Dazu ließ ich ihr noch 25 Fuder Wein nach Elgg schicken in der Meinung, ihr damit meine Hilfsbereitschaft beweisen und sie von ihrem Wahn befreien zu können*26.

Hans Ludwig Heinzel stand vollständig unter dem Einfluß seines ältesten Bruders. Einige Male hatte er an dessen Stelle Gerichtsfälle zu erledigen, ließ sich jedoch stets in Streitigkeiten verwickeln, namentlich mit Landvogt Holzhalb von Kyburg, der sich genötigt sah, ihm wiederholt Bußen aufzuerlegen. Auch beklagte sich Holzhalb über das anmaßende und hochmütige Benehmen der Junker ${ }^{27}$.

Am 24. März 1595 gebar Ludwigs Gattin einen Knaben Hans Dietrich**. Sie starb aber bereits acht Tage nach der Geburt. Magdalena Neidhart, ihre Mutter, kam um diese Zeit von Ulm nach Elgg und überbrachte dem Schwiegersohn als Geschenk von seiner Mutter 5000 Gulden $^{+}$. Bei «etlichen Herren in Zürich» war er mit 2000 Gulden verpflichtet, der Stadt Baden, wo er öfters zur Kur weilte, schuldete er 1000 Gulden, Frau Amalia von Hohensax 9000 Gulden, Wirt Denzler «Zum Rothen Haus» in Zürich 1000 Gulden, einigen Wirten zu Elgg 400 Gulden und Verzasca in Basel 2000 Gulden $^{28}$. Letzterem übergab Ludwig als Unterpfand für Herrn Riva, Faktor der Ronco-Gesellschaft in Zürich, ein «gülden Kleinod mit einem

\footnotetext{
* Die Belege wurden von Schmidt dem Bericht beigelegt.

** Paten: Johann Meiß und Beatrix Funk geborne von Hinwyl.

+ Veronica Im Hof († 1599).

${ }^{26}$ ZB ZH: Mscr. 279, Nr. 210 und Konzept in Privatbesitz.

27 StA ZH: A 116,2.

28 Ebenda.
} 
großen orientalischen Granaten samt dem dazu passenden Ring und etlichen andern sunderbaren Ringen. ${ }^{29}$

VERZASCA schöpfte Verdacht und war nicht zu weitern Darlehen gewillt, da für die frühern Geldaufnahmen außer 500 Gulden noch keine Abzahlungen erfolgt waren. Für einige von Heinrich Heinzel erhobene Anleihen war Hans Lux Iselin Bürge, für andere stellten Hans Ulrich Wolf und Heinrich Krieg mit seiner Frau Dorothea Zoller ein Obligo als Unterpfand aus ${ }^{30}$.

Ende 1595 traten die Junker mit den Gläubigern in Chur in Unterhandlung wegen des Verkaufs des Bergwerkes am Gonzen, wahrscheinlich von diesen gezwungen. Zürich erhielt Kenntnis von der Absicht und schrieb an Ludwig Heinzel: «In Abwesenheit Eures Bruders machen wir Euch aufmerksam, daß ein Verkauf des Bergwerkes ohne unser Wissen und unsere Bewilligung nicht geschehen darf. Er hat sich diesbezüglich zu Handen unserer Stadt mit 2000 Gulden verschrieben nebst dem jährlichen Zins zahlbar jeweilen auf den 26. Oktober laut seiner Unterschrift an unsern Seckelmeister. Trotz dessen widerholter Mahnung ist weder eine Schuldbezahlung noch der fällige Zins erfolgt. Dies muß nun ohne Verzug geschehen, Ihr wollt umgehend Bericht erstatten. $)^{31}$

Aber Heinrich Heinzel befand sich wieder einmal in den Niederlanden auf der Suche nach Gold. Als er bei seiner Rückkehr verschiedene Mahnbriefe von der zürcherischen Obrikeit vorfand, schrieb er sehr hochmütig, die Junker brauchten sich einen derartigen Ton nicht gefallen zu lassen und seien kein Drängen gewohnt ${ }^{32}$. Da jedoch von allen Seiten Klagen einliefen, verlor Zürich endlich die Geduld. Heinzel wurde aufgefordert, ein genaues Verzeichnis seines Vermögens und seiner Schulden aufzustellen, ansonst man ihn fürderhin nicht mehr in Schutz nehmen könne. Aber auch damit ließ er sich Zeit. Zuerst wurde fieberhaft gearbeitet, teils mit Egli, Nüscheler, dann wieder mit Krieg und Freuler in Bellikon. Von NikLaus WasserHUN *, Salzschreiber in Basel, ließ man sich Salz und Salpeter liefern. Wasserhun, mit Iselin und Zwinger verwandt, hatte mit diesen die Versammlungen auf Bellikon und Zuffikon besucht. Freuler wurde nach Freiburg

* Wasserhun NikLaus, 1555 bis nach 1602, Schaffner beim Salzamt, S. v. Franz Ulrich, Salzschreiber zu Basel, $\infty$ vor 1580 Catharina Rüdin (Base zu Professor Theodor Zwingers Frau).

${ }^{29} \mathrm{StA} \mathrm{ZH}$.

30 Ebenda.

31 Ebenda, BIV 53,136/137.

32 Ebenda, A 116,2. 
im Breisgau zu Goldschmied UlRICH Muelich* geschickt, der sich hauptsächlich mit Metallgewinnung beschäftigte. Nach der Rückkehr überbrachte der schlaue Glarner Benedict Muelich, Propst zu Schönenwerd, Grüße von dessen Bruder in Freiburg, wobei es dem gewandten Scharlatan gelang, den Propst zu einem Besuch auf Schloß Bellikon zu veranlassen. Dort könnte er auch den berühmten Pistorius treffen. Dabei schmeichelte er ihm ein Darlehen ab. Dies wurde ruchbar. Der Vikar beschuldigte seinen Propst des Goldmachens. Die Sache gelangte bis vor den Bischof in Konstanz und vor die Tagsatzung. Glarus wurde ersucht, Freuler strenge Weisung zu erteilen, er möge Propst Benedict Muelich in Schönenwerd** nicht weiter belästigen. Seine Schuld habe er sofort abzuzahlen ${ }^{34}$. In einem Schreiben an Bürgermeister Keller vom 11. November 1595 berichtet Heinzel, er habe des Propsten Bruder Ulrich in Freiburg 6000 Gulden als Lehrgeld für Ochs und Freuler bezahlt, dem Propst selbst 60 Gulden für seine Kirche übergeben, «von Muelich hab ich außer einigen Büchern sehr wenig erhalten, die kann er auf Begehren zurück haben ». ${ }^{35}$

Als Heinzel die Herrschaft Elgg übernahm, hatte er Schmid ersucht, ihm einen tüchtigen, zuverlässigen Beamten zu empfehlen, der sich auch in Gerichtssachen auskenne. Dieser fand sich in der Person von Hans Conrad TANNER, einem jungen Verwandten Schmids. Er hatte sich als Schulmeister ausgebildet, wurde dann aber von Schmid als Schreiber und Buchhalter beschäftigt. Da um diese Zeit die Lehrerstelle in Elgg frei wurde, entschloß sich Tanner zu deren Übernahme, da damit das Amt als Gerichtsschreiber verbunden war. Er ersuchte den Rat in Stein um Aufrechterhaltung seines

* Ulrich Muelich, Goldschmied zu Freiburg und Goldmacher am württembergischen Hof.

** Benedic Muelich, $\dagger$ 15. Mai 1605, aus Freiburg im Breisgau, Pfarrer zu Balsthal, dann Chorherr in Rheinfelden, hierauf Propst zu Schönenwerd, erwarb nach seiner Propstwahl das Bürgerrecht von Olten. (Mitteilungen des Historischen Vereins Solothurn, Heft 5, 1910; Leu, Bd. 16, 446; Helvetia sacra, S. 156). Der Gesandte Petermann von SuRY brachte anläßlich der Tagsatzung vor, Freuler und Heinzel hätten den Vikar bearbeitet, den Propst beim Nuntius zu beschuldigen. Der richtige Sachverhalt sei dem Bischof in Konstanz in aller Form mitgeteilt worden. Man wünsche, daß Freuler und Konsorten streng angehalten würden, den Propst nicht weiter zu belästigen. Den Betreffenden sei das solothurnische Gebiet bei strenger Strafe verboten.

${ }^{33}$ Mitteilungen der Historischen Gesellschaft Solothurn, Bd.II, 66.

34 StA ZH: A 116,2.

35 Ebenda, A 116, 2. 
Bürgerrechtes für sich und seinen ältesten Knaben*. Tanner berichtete am 10. April 1586 an Schmid: "Ich war in Schaffhausen bei Benedict Stokar, um bei ihm Bäldi aus Glarus zu treffen. Auf Grund der Verhandlungen beauftragte mich Benedict, mich anläßlich der Tagsatzung in Baden aufzuhalten, um mit den Gesandten von Glarus wegen Deiner Bürgschaft für Bäldi gegenüber Guldinast in Konstanz Rücksprache zu nehmen**. Die Glarner hätten für diese Schulden aufzukommen. Mit den Elggöuwern steht es sehr schlecht. Die Basler verlangen dringend eine Abzahlung der Darlehen, welcher Forderung die Junker nicht entsprechen können, weil es ihnen vollständig an Mitteln fehlt. Dein Vetter Stokar ärgert sich über Dein immer noch allzu großes Vertrauen in sie. Auch beschwerte er sich über das Verhalten der Zollikofer in den Handelsangelegenheiten. Du tust gut, eine Vermittlung zu versuchen, um ihn wieder zufriedenzustellen. Er beanstragt eine Zusammenkunft mit Ulrich Zollikofer in Baden anläßlich der Tagsatzung. Du sollst unbedingt dabei sein. Benedict gab mir ein Geheimschreiben mit an Herrn Ulrich Dorer in Baden betreffend Abhaltung der Zusammenkunft, zu welcher einige Alchemisten von Basel und Zürich und natürlich Johann Conrad Meyer eingeladen werden. ${ }^{36}$

Wohl auf wiederholte Vorstellungen von Bürgermeister Keller sandte ihm Heinzel im November 1596 ein vertrauliches Schreiben mit einer teilweisen Aufstellung der Schulden. Die fortwährenden Reklamationen Harschers als Beistand von Verzaska in Basel, deren Beschuldigung, die zürcherische Obrigkeit protegiere die Junker in unverantwortlicher Weise, nötigte Zürich zu energischem Vorgehen ${ }^{37}$.

Im Namen von Hans Lux Iselin setzten sich die Basler für ihren durchaus ehrenwerten Mitbürger Niklaus Wasserhun ein, der von Heinzel der Unterschlagung beschuldigt worden war. Die Schaffhauser ihrerseits beschwerten sich über den Wortbruch Heinzels in der Angelegenheit von

* Tanner Hans Conrad, Verwalter bei Felix Schmid, dann Schreiber der Heinzel und Schullehrer zu Elgg, $\infty$ Stein 1. November 1590 Anna Richlin von Neunforn. Der Sohn Bonaventura Tanner $(\dagger 1684)$ war Barbier und Wundarzt in Stein, wurde Obervogt zu Wagenhausen und 1658 Bürgermeister.

** GuldiNAST war Waffenhändler in Konstanz. Unter den Agenten für Söldnerwerbung befand sich der Glarner Bäldi, welcher für den Tampiskrieg Waffen bezog. Heinzel hatte anfänglich die Bürgschaft übernommen, diese dann auf Schmidt übertragen da er häufig landesabwesend sei und Schmidt zudem bessere Beziehungen mit Konstanz unterhalte.

36 StA ZH: B IV 49, 110.

37 Ebenda, A 116, 2. 
Spleiß und Ochs und verlangten entsprechende Entschädigung für diese ${ }^{38}$. Die Entgegnung Heinzels auf die Mahnungen Zürichs lautete: «Ich bin im Begriff nach Frankreich und Italien zu verreisen. Ich ersuche Euch, Harscher und Verzaska um Geduld zu bitten bis zu meiner Rückkehr. Wasserhun habe ich 5214 Gulden versprochen und ihm vorläufig 1666 Gulden übergeben. Er hat mir Salz und Eisenabfälle geliefert, welche Waren damit genügend bezahlt sind. Von Alchemie versteht er nichts. Was Spleiß und Ochs angetrifft, bewilligte ich ihnen zusammen 8000 Gulden nebst einem Gewinnanteil von 2000 Gulden. Beide erfüllten ihre Aufgabe nicht. Ochs hat mich betrogen, er wurde von Muelich als Goldmacher empfohlen und ich nahm ihn mit nach Lothringen und Württemberg, um sich weitere Kenntnisse anzueignen - aber er kann nichts, warum sollt ich dan zalen ? ${ }^{39}$ Heinzel bekannte sich also der zürcherischen Obrigkeit gegenüber offen als Goldsucher und Goldmacher.

Während seiner Abwesenheit schien das Glück Ludwig Heinzel hold zu werden. Felix Schmidt empfing von ihm ein Schreiben nach Eisenbach: «Ich schreibe Dir als unserm liebsten und ältesten Freund und Gevatter. Du darfst es aber bei Deiner Seele Seligkeit niemanden verraten, auch nicht der Frau Basen, noch dem Sohn oder Schwiegersohn. Ich habe von einem höchst zuverlässigen Herrn in $W_{y l}$ gehört, Schultheiß N. (Hans Rudolf) Sailer* soll die wahre Goldkunst kennen und ausüben. Hans von Klingen teilte mir dies mit. Der Schultheiß macht aus Quecksilber Silber, und auch Gold sei ihm schon gelungen. Ich selbst darf nicht hingehen. Da Du aber in Augsburg bei Jeronimus Sailer gewesen bist, kannst Du Dich als Verwandten von St. Gallen ausgeben und ihm in dieser Eigenschaft einen Besuch abstatten. Bei einem guten Schlaftrunk teilst Du ihm dann mit, Du seiest selber Alchemist und interessierest Dich für alle Experimente. Suche das Geheimnis aus ihm herauszulocken. Sailer soll zwar sehr gescheit sein, doch Du bist auch nicht auf den Kopf gefallen und gewandt genug.»

Dazu bemerkt Schmidt in seinem Bericht: «Dies Mal aber weigerte ich mich entschieden und verrichtete ruhig meine Arbeit in Eisenbach. Als ich dann nach Stain reiste, um mit meiner Familie die Festzeit zu begehen, mußte Ludwig dies in Erfahrung gebracht haben. Ganz aufgeregt kam er

\footnotetext{
* Sailer Hans Rudolf ... † 1607, Schultheiß zu Wyl 1594, Alchemist, $\infty$ 1) ... 1583 Anna Krieg v. Bellikon 2) ... Anna Müller.

${ }^{38}$ StA ZH: A116,2.

39 Ebenda, A 116, 2.
} 
am 12. Januar 1596 zu uns. Er erzählte mir, nun verstehe er die Kunst gründlich. Er habe mit Egli und Nüscheler in Zürich experimentiert. Bei ihren Fehlschlägen sei ihm plötzlich ein Gedanke gekommen. Sofort machte er zu Hause einen Versuch. Es glückte ihm, aus Blei Quecksilber und dann portugiesische Dukaten herzustellen. Nun reise er in der Angelegenheit nach Portugal und hierauf zu seinem Bruder Heinrich nach Italien. Mir aber falle eine andere Aufgabe zu, die ich diesmal aus Freundschaft nicht umgehen könne, wie bei Sailer. Er bedürfe eines vertrauenswürdigen Vermittlers, der sich in der Alchemie auskenne. Ich müsse nach Lothringen zu Herzog Carl. Dieser Fürst sei stets gewillt, Rezepte zu erwerben.

Ich wollte durchaus nicht in neue Verbindungen hineingezogen werden, erklärte, ich verstehe nichts von der Goldmacherkunst, interessiere mich auch nicht dafür, wie er längstens wisse, und hätte die ganze Sache satt. Er ließ jedoch nicht ab mit Bitten und Vorstellungen, sprach von den drängenden Geldschwierigkeiten, von dem Verlust der Gattin und suchte mein Mitleid für den kleinen mutterlosen Knaben zu erwecken. Als alles nichts nützte, nahm er einen andern Ton an, ich sei zu diesem Dienst aus Rücksicht auf die Schwiegermutter und in Anbetracht meiner Schulden ihr gegenüber einfach verpflichtet. Diese Beschuldigung empörte mich, denn nicht ich, sondern sie waren die Schuldner. Meine bezüglichen Vorstellungen beachtete er überhaupt nicht, sondern drängte und drängte. Schließlich unterlag ich wie immer. Ich bereue auf diese Stund, daß ich mich um der alten Freundschaft willen stets überreden ließ, aber noch immer betrachtete ich die Junker als Ehrenmänner, denen man Glauben schenken dürfe.

Ich verlangte jedoch ein Muster seiner Dukaten mitnehmen zu können und stellte die Bedingung, Ludwig müsse mir alle seine Versprechen schriftlich geben, ebenso mich ermächtigen, nach freiem Ermessen zu handeln. Damit hoffte ich, ihn loszuwerden. Aber er ging auf alles ein. Vogt Zinggeler brachte mir ein Päckchen nebst einem versiegelten Schreiben an Herrn von Bettstein, für mich selbst ein Beglaubigungsschreiben und einen Vertrag über die getroffenen Abmachungen. Sofern der Verkauf gelinge, sollten mir 30000 Gulden ausgezahlt werden. Er selbst verlangte von Herzog Carl für das Rezept 100000 S.Kr., oder 160000 Gulden.

Die Sache ließ mir keine Ruhe. Ich war froh, daß die Abreise durch andere Angelegenheiten verzögert wurde. Anläßlich eines Besuches in Schaffhausen bei Vetter Benedict Stokar begab ich mich auch zu meinem lieben Freund Johann Conrad Meyer. Glücklicherweise traf ich den Bürgermeister zu Hause. Ihm vertraute ich den mich quälenden Auftrag an, der mir wie 
ein neuer Schwindel erschien. Conradus warnte mich denn auch dringend, mich weiter in die Machenschaften der Junker einzulassen. Obschon wir ihnen alle, er inbegriffen, verfallen seien, müsse diese fortwährende Ausnützung aufhören. Ich sei genügend belastet und verpflichtet, in erster Linie für meine große Familie zu sorgen. Diese Unterredung mit meinem vertrauten Vetter tat mir gut, aber sein schlechtes Aussehen beunruhigte mich innerlich stark.

Ich traf alle Vorbereitungen, um mich wieder nach Eisenbach zu begeben, fest gewillt, die Reise nach Lothringen nicht anszuführen. Da erschien Ludwig in Stain, sehr erzürnt und überhäufte mich mit Vorwürfen. Bürgermeister Meyer habe ihn anläßlich eines Besuches bei Stülz in Schaffhausen auf der Straße getroffen und ihn zur Rede gestellt. Es sei ein schweres Unrecht von mir, ihm von unsern Verhandlungen Mitteilung gemacht zu haben. Ich hätte Verrat geübt, da seine Erfindung eine Vertrauenssache betreffe, welche geheim gehalten werden müsse. ,Entweder Du hältst die Abmachung, wirst ein reicher Mann, während wir das Risiko tragen, oder ich weiß schon, wie ich Dich und Deine Familie ins Verderben stürzen kann', drohte er immer wieder. Ich quälte und quälte mich und ließ mich doch nochmals verleiten. Meiner Frau und Tochter fiel meine Niedergeschlagenheit und Unruhe auf. Sie wünschten, der Schwiegersohn solle mich zurück nach Eisenbach begleiten. Aber Ludwig blieb beharrlich in Stain und erklärte, er komme mit mir, da er persönlich in Straßburg Geschäfte zu erledigen habe. Dort besuchte er einen Herrn von Adel, der ihm 50000 Gulden versprochen, sofern er ihn nur mit der Kunst vertraut mache. Damit könne er Schulden abzahlen, die ,Alte ${ }^{6}$ zufrieden stellen und würde wieder in Gnaden angenommen, ebenso Heinrich und ich. Mir tat diese Sprache in der Seele weh, denn ich liebte und schätzte unsere alte Freundin. Aber ich schwieg und begab mich sofort nach Nancy. Hier übergab ich Herrn von Bettstein das Päckchen mit dem versiegelten Schreiben. Am nächsten Morgen wurde ich aufgefordert, vor dem Herzog* und dem Geheimen Rat einen Vortrag zu halten über alles was ich über Alchemie wisse. In bezug auf das Goldmachen war dies allerdings wenig, und ich erklärte nur im Montanwesen bewandert zu sein. Von dem Inhalt des Schreibens hatte ich keine Ahnung. Es wurde mir von Herrn von Bettstein vorgelesen, denn

* Carolus II, Herzog von Lothringen, verheiratet mit Claudia, Tochter von Heinrich II von Frankreich. Seine Schwester Renata war mit Wilhelm von Bayern vermählt, Dorethea mit Herzog Julius von Braunschweig, alles fanatische Alchemisten ${ }^{40}$.

40 J.HüBNER: Genealogische Tabellen, 1712, Tabelle 281. 
ich sollte Auskunft geben über einige ihnen unverständliche alchemistische Zeichen. Um die Neugierde zu erwecken, war Ludwig sehr geheimnisvoll vorgegangen: ,Mercuris Saturni wird in 14 Tagen gemacht (Zeichen S und Z). Dann benötigt es weitere 10 bis 12 Tage (gnostische Figuren). Ein Mann kann in einem Jahr 20 bis 30 Zentner Gold hervorbringen, zwei Personen in einem Jahr 768000 Gulden. Was würde dies für eine Summe einbringen, wenn, man beispielsweise in Klöstern ein Laboratorium einrichten und dort laborieren würde! Diese Kunst kann demnach nicht genügend bezahlt werden.

Dies von einem wegen seines evangelischen Glaubens Flüchtigen! Ich schämte mich vor Herrn von Bettstein, der Überbringer eines derartigen Schreibens zu sein. Herzog Carl ließ mich nochmals zu sich rufen und übergab mir einen Brief, worin er unsere Unterhandlungen bestätigte, und seine Zufriedenheit über meine Auskunft ausdrückte. Junker Heinzel bewilligte er 160000 Gulden oder die Grafschaft und Schloß Hanberg mitsamt der Stadt Avolt* mit Flecken und Dörfern, sowie 30000 Gulden an den Überbringer Felix Schmidt von Stain mit der Bedingung, der Junker müsse die Proben in Gegenwart des Fürsten und des Geheimen Rates persönlich in Nancy ausführen.

Ludwig war hocherfreut über diese Botschaft. Von Straßburg aus, wo er mich erwartete, reiste er sofort mit seinem Verwandten Raymund Weiß, der sich als Goldkünstler im Elsaß aufhielt, nach Nancy. Trotz wiederholten Versuchen mißlangen die Experimente. Sie erhielten kein Geld, ich natürlich nie eine Entschädigung für meine Auslagen. Aber ich danke Gott, daß Er mich endlich zum Verstand kommen ließ und mich aus diesem Labyrinth der Lügen und des Betruges herausgeführt hat. Dies ist das Bekenntnis der wahren Begebenheiten an meine Gnädigen Herren und Oberen in Zürich von Felix Schmidt, Bürger zu Stain, derzeit Bergherr zu Eisenbach auf dem Schwarzwald.**41

Nach seiner Rückkehr aus Italien versuchte Heinrich Heinzel nochmals seine Überredungskunst bei Schmidt. Er erinnerte ihn an die Kommanditgesellschaft, in welche seine Schwiegermutter eine große Einlage gemacht hätte, ohne etwas dafür zu erhalten. Sie lasse den Vertrag mit dem Schuld-

* Avolt: Kreis Forbach, Lothringen, an der Linie Metz-Saarbrücken.

** Diesem Bericht, der wahrscheinlich ein Entwurf des Originals ist, wurden die jeweiligen Belege der Versprechungen Heinzels, mit dessen Unterschrift beigefügt.

${ }^{41}$ ZB ZH: Mscr. 279, Nr. 210, und Konzept in Privatbesitz. 
schein nicht aus den Händen, bis die Rückerstattung der Summe erfolgt sei und betrachte Schmidt als Verführer ihrer Schwiegersöhne. Trotzdem sie nicht mehr ganz zurechnungsfähig sei, drohe sie stetsfort, gegen Schmidt vorzugehen, was Heinrich verhindern möchte. Endlich erkannte der allzu vertrauensselige Schmidt die wirkliche Gesinnung der Junker. Seine Frau verbat sich jeden weitern Besuch der Heinzel. Der Schwiegersohn Hanold unterbreitete der zürcherischen Obrigkeit eine Aufstellung der Darlehen, die Schmidt den Heinzel verabfolgt hatte. Er klärte sie auch über die weitgehende Gastfreundschaft auf, welche die Flüchtlinge im Hause «Zum Schwarzen Horn » in Stein genossen hatten ${ }^{42}$.

Aber trotzdem die Beistände, Seckelmeister Johannes Escher und Hans Ulrich Wolf, sich bemühten, Frau Neidhart die Tatsachen klarzumachen, scheint diese lediglich der Verlust ihres Vermögens beeindruckt zu haben. Zur Ordnung der Angelegenheit beauftragte sie Achilles Keerer*, Fürsprecher, der auch mit Schmidt prozessieren sollte.

Sofort fand der Verkauf des Bergwerkes am Gonzen statt. Münzmeister Hans Jakob Wegerich in Chur übernahm es mit allen Zugehörigkeiten, Wohnhaus, Kornschütten, Stallung, Schmelzofen, drei Schmieden, vier Kohlhütten, nebst «Schiff und Geschirr», dazugehörigem Holz und Wald um die Summe von 11000 Gulden ${ }^{43}$. An der nächsten Tagsatzung erstattete Bürgermeister Meyer Bericht über den Verkauf und ersuchte um Genehmigung des Lehens für Wegerich ${ }^{44}$.

\section{Der Schwindel wird aufgedeckt}

Dem Rat in Zürich fiel nun die schwere Aufgabe zu, die Verwandten der Heinzel von den Vorgängen in Kenntnis zu setzen, vorab Hans Jakob Heinzel, welcher zu dem Erwerb der Herrschaft Elgg einen Beitrag geleistet hatte. «Zwar haben Euch die Vormünder Eurer Frau Schwieger bereits berichtet, daß Eure Brüder durch allerlei Sachen in große Schulden geraten sind. Da sie aber keine Antwort erhalten, sind wir genötigt, Euch amtlich anzufragen, ob Ihr den Junkern beistehen wollt. Sonst muß alles Hab und Gut auf die Gant gebracht werden. Auf unsere Für-

* Keerer Achilles ... 1618, Fürsprecher, S. v. Felix Keerer, Schaffner des Klosters St. Georgen zu Stein, $\infty$ 1) 1.10.1575 Anna Bygel; 2) ... Anna Lewerer v. Stein. Die Schwester Felicitas heiratete am 14. 12. 1581 Hans Heinrich Gutenson.

${ }^{42}$ ZB ZH: Msr. 279, Nr. 210, und Konzept im Privatbesitz.

${ }^{43}$ StA ZH: A 116, 2 (1596).

44 Eidgenössische Abschiede, Bd.V 1b, S.1434, Art. 102. 
sprache hin wurde ein Rechtstag nochmals verschoben, doch ersuchen wir um der vielen Gläubiger willen um Euren baldigen Bericht.» ${ }^{45}$

Hans Jakob Heinzel aber lehnte anfänglich jede Hilfe schroff ab. Seine Brüder sollten für ihr unverantwortliches Vorgehen und Treiben selbst aufkommen. Auf alle Fälle verlange er seine Einlage von 15000 Gulden bei Erwerb der Herrschaft Elgg zurückerstattet. Von dem Kauf des Palastes Haldenstein hätte er erst nachträglich Kenntnis erhalten. In einem persönlichen Schreiben suchte Bürgermeister Keller eine Verständigung zu erzielen «um Eures Namens und guten Ansehens Willen». Das Erscheinen Hans Jakob Heinzels an dem Rechtstag sei dringend notwendig. Keller erklärte sich bereit, inzwischen mit den Bündnern zu verhandeln ${ }^{46}$.

Ludwig Heinzel war bereits im Frühjahr 1597 verschwunden. Einige Zeit hielt er sich in Stuttgart auf. Durch den Schwiegersohn Hanold ließ ihm Schmidt mitteilen, zu seinem Schmerz sehe er sich nun genötigt, wegen der Verleumdungen, die Frau Neidhart über ihn verbreite, gegen sie vorzugehen. Da Heinrich und Ludwig Heinzel ihre Schwiegermutter im Glauben ließen, Schmidt sei ihr Schuldner, beharre sie eigensinnig auf Rückerstattung der Einlage und erkläre, von einem Vertrag nichts zu wissen. Durch Herrn von Bettstein vernahm Schmidt, daß Ludwig Heinzel für sein Rezept und die Bemühungen in Lothringen 12000 S. Kr. erhalten, ihm dies aber verheimlichte ${ }^{47}$.

Ob sich Heinrich Heinzel beim Tode seiner Gattin am 22. August 1597 noch in Elgg befand, ist unbestimmt. Jedenfalls flüchtete auch er. Die Burgherren waren so häufig wochen- und monatelang abwesend, daß $\mathrm{ihr}$ Verschwinden vorerst nicht auffiel. Als aber Flucht und Sachlage bekannt wurden, herrschte in Elgg große Aufregung und Empörung. Die vielen kleinen Gläubiger, Handwerker und Geschäftsleute drängten den Rat, die zürcherische Obrigkeit um den Schutz ihrer Forderungen zu bitten. Metzger und Bäcker wiesen monatelang ausstehende Rechnungen vor.

Der erste Rechtstag wurde auf den 8. März 1598 angesetzt, da die Abklärung der ganzen Angelegenheit viel Zeit in Anspruch nahm. Eine U̇bersicht der Gläubiger, die lange nicht alle zu erfassen waren, zeigt folgende Aufstellung: Zins

Jakob Martin Stöcklin in Basel ． . . . . . . . . . . . 1000 Gulden 100 Gulden

Mathias Harscher in Basel anstelle seiner Gattin Esther

Verzasca. . . . . . . . . . . 2000 Gulden 200 Gulden

Harscher und Verzasca zu Handen von Riva . . . . . . 9100 Gulden 910 Gulden

Hans Heinrich Menhard in Chur* . . . . . . . . 2000 Gulden 200 Gulden

* Friedrich Menhard (Bruder oder Sohn?) ersucht ebenfalls um Abzahlung seiner Darlehen an die Heinzel (StA ZH: A 116,2).

45 StA ZH: B IV 54, 222.

46 Ebenda, B II 271, 10; A 202,2.

47 ZB ZH: S 279, Nr. 210 und Konzept. 
Hans Jakob Wegerich, Münzmeister in Chur . . . . . . 1800 Gulden Johann von Planta, Herr zu Rhäzüns* . . . . . . . . 1100 Gulden Herr von Sonnwig und seine Schwäger . . . . . . . . 2000 Gulden Gantnersche Erben . . . . . . . . . . . . . 4000 Gulden 180 Gulden 110 Gulden 573 Gulden Francesco Vertemate, Chur . . . . . . . . . . $200 \mathrm{S.Kr}$. Graf Martinengo, Venedig . . . . . . . . 100 S.Kr. Bürgschaft Carl von Hohenheim ． . . . . . . . . . . . 800 Gulden

Folgen die Darlehen der Familienglieder :

Hans Jakob Heinzel bei Erwerb Elggs . . . . . . . . . 15000 Gulden Hans Jakob Heinzel für Ludwigs Sohn . . . . . . . . . 2200 Gulden Maria Walther, Frau von Johann Friedrich Heinzel . . . . 2600 Gulden von der Frau Mutter (Veronica Im Hof) . . . . . . . . 6200 Gulden von der Schwester unserer Frau Schwieger (Maria Steben-

haber verheiratet mit David Weiß) . . . . . . . 3000 Gulden von unserer Base Jakobina (verheiratet mit dem Vetter

David Heinzel . . . . . . . . . . . . . . . . . 6000 Gulden

Für Haldenstein wurden aufgenommen bei:

Gantnersche Erben in Chur . . . . . . . . . . . 4000 Gulden

Heinrich Menhard . . . . . . . . . . . . . . . 2200 Gulden

Hans Jakob Wegerich . . . . . . . . . . . . . 2000 Gulden

Herrn von Planta** . . . . . . . . . . . . . . . . 1600 Gulden

Alchemistische Schulden:

Caspar Spleiß in Schaffhausen . . . . . . . . . . . . . 4490 Gulden samt Zins

Niklaus Wasserhun in Basel . . . . . . . . . 2000 Gulden samt Zins

Felix Nüscheler in Zürieh . . . . . . . . . . . . 100 Gulden

Hans Jakob Nüscheler in Zürich . . . . . . . . . . . 600 Gulden

Jakob Denzler zum «rothen Haus» Zürich . . . . . . . 500 Gulden

einigen zu Elgg . . . . . . . . . . . . . . . 470 Gulden

Bettsteins Erben in Lothringen . . . . . . . . . $300 \mathrm{~S} . \mathrm{Kr}$.

Michael Bäldi in Glarus . . . . . . . . . . . . $3000 \mathrm{S.Kr}$.

Fridlj Freuler in Glarus . . . . . . . . . . . . . . . . $6000 \mathrm{S.Kr} \cdot{ }^{48}$

Wie sich am Rechtstag zeigte, war diese Aufstellung höchst mangelhaft. Nicht erwähnt wurden die Schulden an Pfarrer Egli, Hans Jakob Bürkli, Gerold Escher, Johannes Meiß, Hans Rudolf Rahn, Johann Caspar Waser, Hans Ulrich Wolf, Bürgermeister Keller, Frau von Fleckenstein und ihre Tochter, Hans Jakob Kyd, Bürgermeister Meyer, Benedict Stokar und Felix Schmidt.

Der Kaufpreis der Herrschaft Elgg betrug 68000 Gulden, der Verkauf an Bonaventura von Bodegk ergab nur mehr 57500 Gulden, da sich die Räumlichkeiten

* Herr von Rhäzüns wünscht sofortige Abzahlung seiner Darlehen an Heinzel (15. Juni 1598, StA ZH: A 116,2).

${ }^{48}$ StA ZH: A 116, 2, B IV 54, 222. 
sowohl in der Burg selbst, wie in den Nebengebäuden in vernachlässigtem Zustand befanden.

Nur wenige Gläubiger konnten befriedigt werden. Für Harscher und Verzasca sandte Hans Jakob Heinzel an den Seckelmeister in Zürich 4000 Gulden, seine Schwester Euphrosina Rechlinger 9000 Reichstaler (15.4.1598). Hartnäckig weigerten sie sich, für den Kauf von Haldenstein aufzukommen. Auch wiesen sie alle alchemistischen Forderungen zurück mit der Begründung, ihre Brüder seien in der Eidgenossenschaft das Opfer von Betrügern und Wucherern geworden ${ }^{49}$.

Interessante Aufklärungen, besonders was die Goldmacher anbetrifft, ergaben die Verhöre. So schildert Bäldi seine Beziehungen zu Heinzel und brachte den Beweis, wie oft er diesem Darlehen verabfolgt habe, unter anderem mehr eine Summe in Paris. 1595 waren Bäldi, Freuler und dessen Schwager Caspar Pfyffer* von Luzern nach Frankreich gereist in allerhand «geschäftlichen Dingen». In Paris trafen sie Junker Heinzel. Sie führten zusammen ein flottes Leben, Heinzel vornehmlich auf Kosten der andern. Dann ging ihnen das Geld aus. Freuler kannte den Faktor der Ulrich Zollikoferschen Gesellschaft, Michael Lange, in Paris. Dieser zögerte, ihnen ohne Bewilligung seiner Vorgesetzten einen Geldbetrag von 400 Gulden zu verabfolgen, aber die gewandten Herren wußten sich ein Empfehlungsschreiben von dem in Paris weilenden Ambassadoren Herr von Sillery zu beschaffen. Bäldi unterschrieb den Empfangsschein und verlangte von Heinzel 200 Gulden, die er nie erhielt ${ }^{51}$. Sodann war Bäldi im Auftrag der Heinzel verschiedene Male in den Niederlanden, in Lothringen und Württemberg gewesen, teils allein, teils mit Freuler oder Heinzel selbst. Für diese Reisen forderte er Vergütung der Auslagen. Freuler wurde sogar nach Spanien und Portugal geschickt, um nach neuen Mitteln zu forschen und den Stein der Weisen zu entdecken. Er wies ein schriftliches Versprechen von Heinzel vor, laut welchem ihm bei der Rückkehr 6000 Gulden verabfolgt werden sollten. Bei der Abreise erhielt er nur ein Reisegeld von 100 Gulden. Es sah sich genötigt, im Namen Heinzels bei den Alchemisten Lienhard Kasthofer in Aarau und Diethelm Rüssi in Rapperswil Geld aufzunehmen ${ }^{52}$. In Frankreich mußte er für Egli Chemikalien im Betrage von 470 Gulden besorgen, für welche sich Heinrich Heinzel verbürgte ${ }^{53}$. Anläßlich des Prozesses bestritt Hans Jakob Heinzel jeden Anspruch Bäldis und Freulers.

* Caspar Pfyffer betrieb mit seinen Brüdern neben dem Tuchhandel alle möglichen Geschäfte. 1585 hatte er beispielsweise einen langen Prozeß mit Apotheker Conrad Pretelli in Bern wegen illegalen Lieferungen von Chemikalien, aus welchem hervorgeht, daß er ebenfalls der Sucht nach Goldmachen huldigte (StA LU: Personalien) ${ }^{50}$.

49 StA ZH: A 116,2.

50 StA LU: Personalien.

51 StA ZH: A 116, 2.

52 Ebenda, A 116, 2.

53 Ebenda, A 252,2. 
Die Unterschrift seiner Brüder verpflichte ihn selbst nicht: Zudem hätten die Mitglieder der alchemistischen Gesellschaft für einander gutzustehen ${ }^{54}$.

Über das Treiben Freulers, der zu den eigentlichen Scharlatanen gehörte, erhalten wir interessanten Aufschluß durch das Verhör von Offrion RutschmanN von Rafz. Dieser diente als Müllerknecht im Gotteshaus Rheinau. In seiner freien Zeit leistete er auf dem Gute von Christof vom Grüt kleine Dienste in dessen Laboratorium. Eines Tages besuchte ihn ein Verwandter, Caspar TANnegger, der längere Zeit als Söldner in den Niederlanden unter Leutnant Freuler gedient hatte. Tannegger berichtete, wie er von diesem mancherlei über die Goldmacherkunst gelernt habe. Freilich gelinge es nicht immer, aber man müsse etwas wagen. Nun befinde er sich bei einem guten Lehrmeister, dem Goldschmied Hans Stülz in Schaffhausen. Sofern ihm Rutschmann 100 Gulden gebe, werde er dieselben doppelt oder dreifach zurückerhalten, er solle ihn nach Schaffhausen begleiten ${ }^{55}$.

Stülz* versprach, 6000 Gulden herzustellen, sofern man ihm die benötigten Mineralien, namentlich Erz, verschaffen könne. Tannegger war bekannt, daß Fridlj Freuler sich in den Bündner Bergwerken am besten auskenne. Dieser zeigte sofort Bereitschaft, die benötigten Mineralien, namentlich Erze, zu beschaffen, welche von Rutschmann und Tannegger nach dem Schlößchen Zuffikon gebracht werden sollten, da man dort am ungestörtesten arbeiten könne. Aber Stülz weigerte sich, außerhalb des eigenen Laboratoriums zu experimentieren. Tannegger könne ihm als eingeweihter Gehilfe zur Hand gehen, Rutschmann die Öfen bedienen, Freuler dürfe zusehen. Zufolge einer Unvorsichtigkeit mißlangen die ersten Versuche. Stülz nahm die entstandenen Unkosten freiwillig auf sich. Bei einem neuen Experiment wurden angeblich dritthalb Tausend Gulden gewonnen. Stülz beantragte, den Gewinn in vier Teile zu teilen, aber Freuler beanspruchte die Hälfte wegen Beschaffung der Mineralien. Er hatte das von Stülz angewandte Verfahren genau beobachtet, verkaufte das Rezept an Frau von Fleckenstein und behielt den Erlös für sich $^{57}$.

1605 erkrankte Freuler auf einer Reise nach St. Gallen in Schmerikon. Er wurde von seinem Bruder Gabriel nach Glarus gebracht, wo er starb. Dieser hatte für die zahlreichen Schulden aufzukommen, prozessierte jahrelang und reichte noch 1606 Klagen wegen der Heinzel ein ${ }^{58}$.

\footnotetext{
* Als Stülz noch 1600 mit seinen Versuchen Silber erzeugte, erhielt er eine Buße von 100 Gulden ${ }^{56}$.

54 StA ZH: A 116,2.

55 Ebenda, B V 6, 36, 476; A 27, 160.

56 Ebenda, E I 16.

57 Ebenda, B III 17, 20.

58 Ebenda, B V 361, 306.
} 
Am meisten geschädigt durch die Heinzel, neben Felix Schmidt, wurde Hans Caspar Spleiß. Er hatte nicht nur seinen guten Salzhandel in Schaff hausen aufgegeben, sondern auch den unbescholtenen Ruf verloren. Deshalb hegte er einen tiefen Groll gegen Schmidt, der ihn zu der Annahme der Stellung bei Heinzel ermunterte. Als er nach einiger Zeit der Tätigkeit als Schaffner in Flums Einblick in die Verhältnisse erhielt und ihn Heinzel um ein Darlehen ersuchte, wurde er unruhig ${ }^{59}$. Wahrscheinlich fühlte er sich zufolge des Abkommens gebunden und trachtete, den eingegangenen Verpflichtungen nachzukommen. Dann wurde er zu seiner Bestürzung von Hans Jakob Hünerwadel nach Schaffhausen vor den Rat beordert und erhielt die Mitteilung von dem durch Heinzel erfolgten Rückzug des deponierten Geldes. Er weigerte sich, nach Flums zurückzukehren. Trotz wiederholter Aufforderung erschien Heinzel nicht zu der Einvernahme, sondern beschuldigte Spleiß schriftlich beim Rate des Betruges. Er habe ihm zweimal mit je 1500 Gulden als Abzahlung zu Schmidt gesandt, die dieser jedoch nie erhalten. Nachträglich stellte es sich heraus, daß Heinzel diese 3000 Gulden zu einer seiner Reisen in die Niederlande verwendet hatte, wo er mit allen Goldmachern im Verbindung stand ${ }^{60}$.

Als Schaffner von Flums stand Spleiß unter zürcherischem Recht und Schutz. Er ersuchte um Beistand und Hilfe. Da er beweisen konnte, daß er sich nie mit Goldmachen beschäftigt hatte, erhielt er die Erlaubnis, auf der Landschaft einen kleinen Handel zu betreiben, um seine Familie durchbringen zu können. Als er von der Flucht der Junker hörte, wurde er sowohl in Schaffhausen als auch in Zürich vorstellig, man möge deren Verbleib ausfindig machen. Aber beide Obrigkeiten hatten unzählige solcher Gesuche entgegenzunehmen. Zürich wünschte die verschiedenen Angelegenheiten genau abzuklären, um alles auf den zweiten Rechtstag festzulegen, der am 1. Mai 1599 stattfinden sollte. Spleiß war in einer höchst unglücklichen Lage. Seine Existenz war ruiniert. Von den Verwandten gemieden, in Schaffhausen alles konfisziert, führte er mit seiner Familie ein kümmerliches Dasein. Nachdem er sich in Schaffhausen jahrelang einer geachteten und angesehenen Stellung erfreut hatte, schämte er sich in eine derartig unsaubere Sache verwickelt worden zu sein.

Er wurde schwer krank, trotzdem ihn einige Freunde zu unterstützen versuchten und sich für ihn verwendeten. Jahrelang hatte er auszuharren, bis seine Sache abgeklärt und seine Ehre wiederhergestellt war.

Zu den Verhören hatte auch der Elgger Vogt VYT Zinggeler zu erscheinen, denn man wünschte über die Geldgeber in Elgg unterrichtet zu werden. Zinggeler befand sich in wenig beneidenswerter Lage. Von jeher war die Amtstätigkeit eines Vogtes zu Elgg eine schwierige Aufgabe. Einerseits hatte er die Interessen

59 StA ZH: A 116,2, A 252,2.

${ }^{60}$ Ebenda, A 252, 2. 
der Gemeinde zu wahren, anderseits diejenigen des Gerichtsherrn zu berücksichtigen. Zinggeler trachtete zu vermitteln und kümmerte sich anfänglich nur um seine Amtspflichten. Erst als das Treiben auf dem Schlosse, namentlich durch die Teilnahme des neugewählten Pfarrherrn HaNs JАков KolLer* im Flecken Unwillen erregte, wurde er neugierig. Während der Vogt ein gutes Verhältnis mit dem Gerichtsschreiber und Schullehrer Hans Conrad Tanner pflegte, konnten sich beide nicht mit Pfarrer Koller verstehen. Wahrscheinlich klärte Tanner den Vogt nach und nach über die Goldmacherkunst und die wahren Interessen Heinzels auf. Natürlich lockte ein Mehrverdienst auch den Vogt. Er wußte, daß der Gerichtsherr ihn benötigte, denn nur durch die Vermittlung Zinggelers gelang es, von den Geschäftsleuten ohne Barzahlung die benötigten Lebensmittel zu erhalten. Auch mußte der Vogt Holz und andere Materialien für die Experimente beschaffen. Um ihn vollständig für seine Zwecke zu gewinnen, übergab ihm Heinzel gemeinsam mit Tanner die Bedienung der Öfen. Unter der Bedingung strengster Verschwiegenheit wurde beiden Männern zukünftiger Gewinnanteil versprochen.

Pfarrer Koller war ein Anhänger und Verehrer von Raphael Egli und von diesem dem Gerichtsherrn empfohlen worden. Er interessierte sich namentlich für Naturwissenschaft. Wahrscheinlich fühlte er sich anfänglich fremd und ausgeschlossen in Elgg. Er machte daher viel Besuche auf den umliegenden Gütern, was der Bürgerschaft nicht gefiel. Bald nahm er solch leidenschaftlichen Anteil an den Experimenten auf dem Schloß, daß er einige Zeit verwirrt wurde. Er geriet auf Abwege, fing an in der Nacht Gräber auszugraben, um etwa vorhandene Schmuckstücke der Toten zum Einschmelzen verwenden zu können. Dem entsetzten Sigristen, der ihn eines Nachts bei diesem Tun überraschte, erklärte er, der Pfarrer habe über den Kirchhof zu bestimmen. Seine Arbeit diene der Wissenschaft, von welcher die Bauern natürlich nichts verstünden. Der Elgger Rat war jedoch anderer Meinung, betrachtete dieses Treiben als Totenschändung und wurde trotz dem Zureden des Vogtes bei der Obrigkeit in Zürich vorstellig. Die gesamte Bevölkerung Elggs befand sich in Aufregung und weigerte sich zum Besuch des Gottesdienstes. Nach der Vorladung erhielt Koller einige Monate Urlaub. Dann bat er wieder nach Elgg zurückkehren zu dürfen. Er söhnte sich mit Vogt Zinggeler und Lehrer Tanner aus, nahm aber mit diesen wieder teil an den Versammlungen im Schloß, die allerdings weniger häufig stattfanden. Da Koller ein guter Prediger war, auch seine Amtspflichten getreulich erfüllte, hatte die Gemeinde ein Einsehen, um so mehr, als die Pfarrfrau wegen ihrer steten Hilfsbereitschaft geschätzt und geachtet wurde.

Ein vierter im Bunde gesellte sich zu ihnen, Pantle Mantel, der Krämer. Als geriebener Handelsmann, der gerne auch Wechselgeschäfte übernahm, freute er

* Koller Hans Jakob, 1560 bis 1612, VDM Pfarrer zu Elgg 1591, von Zürich, $\infty$ 23. Januar 1583 Elisabeth Lavater. 
sich, den Junkern borgen zu können und dafür etwas von dem geheimnisvollen Tun auf dem Schlosse sehen zu dürfen. Er betrieb weitgehende Maklergeschäfte für die Heinzel, besorgte ihnen auch welsche Münzen und stand diesbezüglich mit italienischen und französischen Gaunern auf gutem Fuß. Bei seinem Falliment wurden eine Unzahl Betrügereien von den eigenen Schwiegersöhnen aufgedeckt $^{61}$.

Auch Felix Nüscheler gestand in den Verhören, durch Pantle Mantel von den Heinzel ein Liechtgeld (Trinkgeld) im Betrage von 140 Gulden erhalten zu haben mit dem Versprechen, der Betrag werde verdoppelt, sofern er Gold beschaffen könne ${ }^{62}$. Durch Mantel war Goldschmied Conrad Schellenberg, der spätere Schultheiß in Winterthur, in den Kreis der Heinzel gelangt. Er nahm an den Versammlungen und Experimenten in Elgg teil, zog sich aber rechtzeitig wieder zurück.

Anläßlich der Vorladung bekannte Vogt Zinggeler, das «Müllimünzwerk»* sei auf Befehl Heinzels in seinem Hause verborgen worden. Seckelmeister Escher wurde beauftragt, dies schleunigst mit dem Stadtbott zu holen und in Zürich in Gewahrsam zu bringen. Zinggeler erhielt eine harte Buße und mußte sein Amt niederlegen ${ }^{64}$.

Hans Jakob Heinzel erschien weder zum ersten, noch zum zweiten Rechtstag. Die Schulden beliefen sich auf über 100000 Gulden. Obschon nichts mehr vorhanden war, berief sich Hans Jakob auf sein Recht. Die Obrigkeit sei haftbar, da sich die ganze Sache auf zürcherischem Gebiet abgespielt und man die Goldmacherei geduldet habe. Umsonst machte ihn Bürgermeister Keller auf das große Vertrauen und Entgegenkommen aufmerksam, das seine Brüder jahrelang mißbraucht hätten ${ }^{65}$. Im Oktober vernahm man, Hans Jakob Heinzel sei in Schaffhausen gesehen worden. Spleiß wurde angehalten, mit ihm eine Verständigung zu suchen. Dieselbe Aufforderung erging an Heinzel mit dem Gesuch, den Aufenthalt seiner Brüder bekanntzugeben und diese zu veranlassen, vor der zürcherischen Obrigkeit zu erscheinen. Aber um solche Zuschriften bekümmerte sich Heinzel nicht ${ }^{66}$. Nun trachtete Zürich, wenigstens Caspar Spleiß eine kleine Entschädigung zukommen zu lassen. Junker Hans Heinrich Funk wurde beauftragt, das gesamte Hab und Gut im Schloß zu Elgg zu beschlagnahmen und Spleiß die

* Dieses Müllimünzwerk (Idiotikon, Bd. IV, $189^{63}$ ) wurde in Stammheim durch den Goldmacher Apfel angefertigt und nach der Burg Elgg gebracht. Es wurde mit Wasserkraft betrieben.

${ }^{61}$ Gemeindearchiv Elgg IV A 1.

${ }^{62}$ StA ZH: A 27, 161.

${ }^{63}$ Schweizerisches Idiotikon, Bd.IV, S. 189.

64 StA ZH: A 116, 2.

65 Ebenda, A 116,2, B II 271, 33.

66 Ebenda, A 116,2 (1599). 
vorhandenen Kleinodien zu übergeben mit Ausnahme der Waffen. Diese sollten in einem $\mathrm{Faß}$ verborgen aufbewahrt werden. Bei der Durchsuchung der Burg zeigte sich jedoch, daß außer viel zerschlagenen Retorten, Tiegeln, demolierten Öfen gar nichts mehr vorhanden war als einige von Stucki, Meyer und Werthenstein entlehnte Bücher. Die Junker hatten verstanden, alles Wertvolle rechtzeitig wegzuschaffen ${ }^{67}$.

Welche Rolle Junker Funk in der ganzen Angelegenheit spielte, lassen die Quellen nicht erkennen. Dank seiner Beziehungen kam der Verkauf der Herrschaft Elgg an Junker Bonaventura von Bodegk* zustande ${ }^{68}$.

Nach eingehenden Beratungen wies Zürich die Ansprüche von Hans Jakob Heinzel entschieden und endgültig ab. Der Rat erklärte sich zu einem Ausgleich bereit durch Anweisung von 1500 Gulden, abzüglich 500 Gulden als Entschädigung an Seckelmeister Escher, Statthalter Ziegler und Stadtschreiber Grebel für deren große Mühewaltung. Damit gab sich jedoch Hans Jakob Heinzel nicht zufrieden. Er verlangte von der Schwiegermutter für die Kinder seiner verstorbenen Gattin Sabina Neidhart die Auszahlung der ihm laut Heiratsbrief verschriebenen 14000 Gulden, da er bei Erwerb der Herrschaft Elgg diese Summe nebst einem Zuschuß von 1000 Gulden den Brüdern als Darlehen gab. Nach all der geübten Nachsicht und den gebrachten Opfern entrüstete dies Ansinnen Zürich. Heinzel wurde kurz mitgeteilt, daß man auf keine Forderungen mehr eingehe, er möge mit seiner vollständig verarmten Schwiegermutter vor Augsburger Gericht treten $^{69}$.

Dem Vormund des Knaben von Ludwig Heinzel bewilligte man für sein Mündel 5000 Gulden, für die erwachsene Tochter Veronika von Heinrich konnte nichts erübrigt werden. Ihr Beistand, Hans Jakob Bürkli, sah sich genötigt, ihr Rechnungen von Geschäftsleuten zuzustellen, welche befriedigt werden mußten. Er erhielt von Hans Jakob Heinzel einen maßlos zornigen Brief: Nach allem, was man in Zürich seinen Brüdern zugefügt, trachte man nun noch darnach, das Leben der jungen Tochter zu vergiften und den Vater herabzuwürdigen ${ }^{70}$.

Noch 1602 wurde die zürcherische Obrigkeit von den Gläubigern bestürmt. Bäldis und Freulers Forderungen schenkte man kein Gehör. Dagegen wurde Caspar Spleiß Hilfe zugesichert, sobald sich eine Gelegenheit biete. Wiederholt

* Bonaventura von Bodegk, $\dagger$ Elgg 4. Januar 1629, Handelsherr und Bankier, Gerichtsherr zu Elgg, $\infty$ 1) Augsburg, Catharina Rechlinger; 2) Ursula von Bärenfels. Die Schwester der ersten Gattin verheiratete sich mit dem Neffen von Junker Heinrich Funk.

67 StA ZH: B IV 58, 160, B II 269, 36.

68 Ebenda, A 208, 1. Rueger-Chronik E 55.

69 Ebenda, A 202,1. B II 269, 36 .

70 Ebenda, A 160,2. 
richtete dieser Schreiben nach Ulm und Augsburg, ohne je eine Antwort zu erhalten. 1605 vernahm er, Veronika Heinzel sei durch den Tod ihres jüngsten Oheims Johann Peter eine ansehnliche Erbschaft zugefallen. Er setzte Zürich davon in Kenntnis und Bürkli wurde angewiesen, mit der Tochter, wegen Erstattung der Schuld an Spleiß, in Unterhandlung zu treten. Als er ohne Antwort blieb, drohte er, sich direkt an den Rat in Augsburg zu wenden ${ }^{71}$. Kurz darauf erschien Heinrich Heinzel heimlich in Laufen, wo Bürkli als Obervogt der Herrschaft amtete. Auf seine Mitteilung erhielt er den Befehl von Zürich, Heinzel sofort in Haft setzen zu lassen. Hauptmann Holzhalb wurde beauftragt, zwischen Spleiß und Heinzel zu vermitteln. Die Vorschläge von Zürich und Schaffhausen lauteten: «Sofern Junker Hans Heinrich Heinzel schwört, seine Schulden an Caspar Spleiß innert einem Jahr in drei Raten abzuzahlen, wird er der Haft entlassen und freigesprochen. Die Zahlungen sollen regelmäßig an den Zahlmeister Felix Ramsauer in Schaffhausen erfolgen. ${ }^{72}$ Spleiß war einverstanden, Heinzel reiste ab, hielt aber wiederum nicht Wort. Als die auf Neujahr festgesetzte erste Anzahlung ausblieb, reklamierte Bürkli bei Hans Jakob Heinzel. Dies Mal erfolgte die Antwort umgehend: Es sei eine Schande, wie Fremde in der Eidgenossenschaft behandelt würden. Durch die unwahren Gerüchte, seine Brüder hätten in drei Herrschaften Schulden gemacht und seien nachher geflüchtet, würden die Junker in ihrem eigenen Land verhöhnt und verfolgt. Zürich und Schaffhausen, wie alle Orte, hätten die Alchemisten nicht nur geduldet, sondern sie im Gegenteil noch unterstützt. In dieser Gesellschaft, in welcher alle verpflichtet worden, einander beizustehen, habe man die Fremden von den Vereinbarungen ausgeschlossen und sie nur ausgenützt. Sämtliche Betrüger, zu denen auch Spleiß zähle, seien Schweizer, weshalb die Familie Heinzel allen weitern Belästigungen kein Gehör schenken werde ${ }^{73}$. Dazu beklagte sich noch der Kurator der Heinzel, LamberT Baumgartner in Augsburg, über die Arrestlegung und Behandlung des hochwohlgebornenen Junker Hans Heinrich Heinzel von Degerstein, die den Ständen Zürich und Schaffhausen wenig Ehre einlege!!*74

Damit war das Maß voll. Zürich und Schaffhausen wandten sich gemeinsam an die Behörden von Augsburg. Diese beauftragten Stadtpfleger Markus

* Unterschrieben war dieses Schreiben vom 8. Dezember 1606 von Veronika Heinzel als Tochter, Euphrosina Heinzel als Schwester, Hans Baptist Heinzel für sich und seine abwesenden Brüder Hans Jakob und Hans Friedrich Heinzel, Hans Joachim Pechmair, Daniel Welser, Jakob Fentsch, Daniel Oesterreicher, Daniel Schad, alles Vettern, der Letztere ein Schwager zu Adolf Occo.

71 StA ZH: A 202,1.

72 Ebenda, B II 229, 40.

73 Ebenda, A 202,1.

${ }^{74}$ Ebenda, A 202, 1. 
WELSER * sich in den beiden Städten eingehend über die Vorkommnisse während des Aufenthaltes der Heinzel in der Eidgenossenschaft zu erkundigen. Der ausführliche Bericht Welsers setzte Bürgermeister Schad in Augsburg, einem Vetter der Heinzel, in nicht geringe Verlegenheit. Er entschuldigte sich im Namen aller Familien bei den Ständen Zürich und Schaffhausen. Um der Ehre und des Ansehens der Stadt Augsburg willen würden alle berechtigten Ansprüche befriedigt, das unverantwortliche Treiben der beiden Brüder hart gerügt, welches allerdings nur einigermaßen durch Entschädigung der Gläubiger gutgemacht werden könne. Heinrich Heinzel hatte sich bei der Familie, wie vorher bei der Schwiegermutter, als ungerecht Betrogener und Verfolgter darzustellen gewußt.

Die Brüder Heinrich und Ludwig Heinzel wurden in Zürich und Schaffhausen schuldig erklärt der vorsätzlichen Täuschung über ihre Vermögensverhältnisse, der fortwährenden Bestechungen und Betrügereien zum Zwecke der Goldmacherei, des wiederholten Wortbruchs, der planmäßigen Ausbeutung ihres Wohltäters Felix Schmidt, der Verarmung und des Ruins zahlreicher Familien. Daraufhin wurden sie auch aus dem Gebiet von Augsburg und Ulm verwiesen, welche Städte sie nie mehr betreten durften. Felix Ramsauer erhielt eine Anweisung zur Begleichung der Schulden, an Caspar Spleiß, Zürich, wurde eine Summe für die übrigen Gläubiger zur Verfügung gestellt, den Kindern von Felix Schmidt 1000 Gulden zugesprochen, eine kleine Entschädigung für die vielen Opfer, welche der Vater aufgewandt hatte! ${ }^{75}$

Vornehmer als sein Bruder Hans Jakob benahm sich Johann Peter Heinzel. Im Dezember 1599 beklagte er sich zwar in einem Schreiben an Waser, daß er als vollständig Unbeteiligter durch das unverantwortliche Treiben der Brüder leiden müsse. Auch falle es ihm schwer, zu verstehen, wie sein so hochanständiger und gelehrter Lehrer und Freund an den Experimenten der Goldmacher, die er nicht zur wirklichen Alchimey zähle, habe teilnehmen können. Statt Heinrich stets mit neuen Werken zu versehen, hätte er ihn warnen sollen. Im übrigen sei ihm bekannt, daß sein Bruder bereits in Augsburg wegen der Sucht zur Goldmacherei und verbotenen Experimenten Bußen erhalten habe. Es liege ihm ferne zu richten, er selbst werde seinen Teil zur Abzahlung der Schulden beitragen, mit Ausnahme der Forderungen der Schwindler Bäldi und Freuler. Als Waser ihm den Sachverhalt klarstellte, sandte Johann Peter am 11. Juni 1603 die Summe von 325 S.Kr. für Freuler als Abzahlung eines von diesem gemachten Darlehens an

* Markus Welser 1558-... einer der bedeutendsten Wissenschafter, betrieb ebenfalls alchemistische Studien und stand durch Occo in regem Briefwechsel mit Bürgermeister Meyer, dessen Gesinnung wie die Kellers und Schmidts zu vornehm war, um die Heinzel bloßzustellen ${ }^{75}$. Und doch, wie viel Unglück wäre verhindert worden bei rechtzeitigem Eingreifen in das Tun dieser Junker, welche durch ihr Auftreten nicht nur zwei Obrigkeiten, sondern unzählige ehrliche Bürger zu beschwindeln vermochten.

75 StA ZH: A 202,1. 
Heinrich Heinzel, ebenso für Landammann Bäldi 300 S.Kr. Eine Entschädigung für die Reisen der beiden nach Lothringen, den Niederlanden und Spanien lehnte er $\mathrm{ab}^{76}$.

Wieviel Unheil und Unfrieden stifteten diese Junker in der Eidgenossenschaft! Gewiß verfügten sie über reiche Geistesgaben, aber wie verwendeten sie ihre Talente! Umsonst bemüht man sich, auch nur ein gutes Werk, die kleinste Hilfeleistung zu finden. Stets waren sie die Fordernden und nahmen die gebotene Gastfreundschaft als selbstverständlich an. Heinrich Heinzel fehlte jede Herzensbildung. Er war besessen vom Dämon Gold, der Sucht nach Reichtum und Genuß, ein anmaßender, hochmütiger Egoist. Dies äußert sich in der Respektlosigkeit, mit der er die Großmut der Freunde und Gönner lohnte, der vollständigen Gleichgültigkeit über bewußte Unterschlagungen und Fälschungen, jedem Mangel an Pflichtgefühl und Verantwortungsbewußtsein gegenüber der Schwiegermutter, der Gattin, der Familie. Frau Neidhart hatte nicht nur Hab und Gut geopfert, sondern auch ihre drei Töchter verloren *. Was wußte sie, was wissen wir von den Leiden und Kämpfen, welche die jungen Frauen in ihrer Einsamkeit durchmachten? Heinrich Heinzel erwartete und beanspruchte wohl Hilfe von jedermann, der seinen Zwecken dienen konnte, er selbst aber gewährte keine. Seine herrische Natur kommt besonders im Verhalten gegenüber den Landleuten zum Ausdruck. Zum Beispiel brachte Baschi Steinemann einmal den Pachtzins für die untere Mühle zu Elgg nicht rechtzeitig auf das Schloß. Heinzel betrieb den Bürgen Hans Buechi, worüber im Flecken große Aufregung herrschte. Umsonst versuchte Vogt Zinggeler, ihn von derartig strengem Vorgehen abzuhalten. Beim kleinsten Vorkommnis ließ er die Bauern in den Turm bringen, bis sie die oft übersetzten Bußen bezahlten. Verschiedene Male sah sich der Landvogt von Kyburg gezwungen, einzugreifen, um Unruhen unter der Bevölkerung zu vermeiden. Die Schloßherren selbst aber waren bei den Geschäftsleuten über und über verschuldet ${ }^{77}$.

Die zürcherische Obrigkeit wurde finanziell schwer belastet, ganz abgesehen von den unzähligen Schreiben und Verhandlungen. Einige der Ratsherren** verzichteten zugunsten der bedauernswerten Frau Neidhart auf ihre Ansprüche ${ }^{78}$.

In seinem Schreiben an Simmler ${ }^{+}$beklagt sich Hans Jakob Heinzel über das Verhalten von dessen Schwager, Apotheker Hans Ulrich Wolf. Dieser sei zwar

* Jede der drei Schwestern brachte ihrem Gatten 6000 Gulden in die Ehe, dazu erbten sie von einem Oheim je 2000 Gulden.

** Hans Jakob Bürkli, Seckelmeister Hans Escher, Statthalter Hans Meiß, Hans Rudolf Rahn und Hans Caspar Waser.

+ Hans Rudolf Simmler, Dr. med., Professor 1568-1611, $\infty$. . 5-1599 Cleophea Stucki, T. v. Wilhelm Stucki.

${ }^{76}$ StA ZH: A 202,1.

77 Ebenda, A 202,1.

78 Ebenda, B V 34, 314, F II 383. 
einer der eifrigsten Vertreter der Alchemie, wolle aber für den entstandenen Schaden weder aufkommen noch verantwortlich gemacht werden. Wolf schrieb eine Erklärung an Caspar Waser, welche er seinem ehemaligen Zögling, Johann Peter Heinzel, übermitteln könne, mit Hans Jakob Heinzel werde er sich jedoch nur vor dem Gericht einlassen. Wolf hatte Heinrich Heinzel 1593 ein Darlehen von 3000 Gulden mit $5 \%$ verzinsbar gemacht. Als Unterpfand verschrieb Heinzel das Bergwerk am Gonzen. Ohne Wolf zu verständigen, trat er dann zwecks Verkauf des Bergwerkes in Unterhandlungen mit Münzmeister Hans Jakob Wegerich. Die zürcherische Obrigkeit machte Heinzel darauf aufmerksam, sie könne dies nicht dulden, solange das Darlehen an Hans Caspar Wolf nicht zurückerstattet sei. Dieser gab dann mit Zustimmung des Rates doch seine Einwilligung, damit einige Hauptgläubiger befriedigt werden konnten. Hans Jakob Heinzel aber verlangte von Wolf völligen Verzicht auf seine Ansprüche, da er einer der meistbeteiligten Alchemisten sei, oder dann mindestens Stundung seiner Forderung. Wolf schrieb: «auf das erste Ansinnen gehe ich natürlich nicht ein. Hans Jakob Heinzel kann als sehr reicher Handelsherr für die Schulden seiner Brüder einstehen. Unter Umständen und auf höfliche Bitte bin ich mit einer Stundung einverstanden, aber nur zu $8 \%$ Zins. Es ist genügend bekannt, daß Heinzel als Geldverleiher 15 bis $20 \%$ fordert und seinen Schuldnern gegenüber wenig Geduld zeigt. Bei Herrn von Graeplang wird er nicht so leichten Kaufs davon kommen* Wie und in welcher Weise ich selbst mein Geld anlege, geht die Herren in Augsburg nichts an. Ich habe Heinrich Heinzel leider wie so viele andere in freundschaftlicher Weise aus der Klemme geholfen, und wir haben nichts als Undank und nun dazu noch Hohn geerntet. Nebst den Darlehen ist zudem eine Schuld für gelieferte Chemikalien und Instrumente im Betrage von 2200 Gulden mit 220 Gulden Zins ausstehend. Sofern mir Hans Jakob Heinzel ein Obligo von 4000 Gulden ausstellt, will ich mir die Sache überlegen**80.

Wie aus den Verhören eindeutig hervorgeht, trug Heinzel die größte Schuld an dem Unglück von Pfarrer Raphael Egli. Obschon dieser wie Wolf zu den eifrigsten Alchemisten zählte, würde er ohne das stete Drängen der Heinzel nie Versuche zur Goldgewinnung unternommen haben. Er beschäftigte sich allerdings sehr viel mit naturwissenschaftlichen Studien. Bereits 1592 wurde ihm vom Rat der Vorwurf gemacht, sich mehr mit Alchemie als seinen Pflichten als Seelsorger

* Graeplang: Ludwig Tschudi, Herr zu Graeplang, war bei Haldenstein beteiligt und hatte ebenfalls Forderungen zu stellen ${ }^{79}$.

** Hans Ulrich Wolf war demnach noch nicht Besitzer des Bergwerks am Gonzen, wie dies in die Literatur eingegangen ist, sondern das Werk mußte über Hans Jakob Wegerich von Harscher und Verzasca in Basel zurückerworben werden und gelangte erst nach 1600 in den Besitz von Hans Ulrich Wolf.

79 Kubli-Müller, Die Tschudi von Glarus, in IHVG 1920.

80 ZB ZH: A 116, 2. A. 27, 160. 
abzugeben. Seine Liebhaberei passe nicht zu dem Stande eines Geistlichen, besonders nicht in der Stadt. «Wenn die Experimente woanders stattfinden können, muß man es wohl geschehen lassen »! ${ }^{81}$

In einem ausführlichen Schreiben teilte Egli dem Rat mit: er habe, auf Grund der Beobachtungen und Erfahrungen von Paracelsus und Geßner aufbauend, stets nur reine wissenschaftliche Alchemie für Heilzwecke betrieben. In vielen Fällen sei Krankenlinderung, ja Heilung von langjährigen Leiden zuteil geworden, was für alle seriösen Gesellschafter einen Ansporn bedeutete. Namentlich Hans Ulrich Wolf und Bürgermeister Meyer hätten in dieser Hinsicht Bedeutendes beigetragen, dieser durch seine Forschungen mit Schobinger, die Studien mit Platter und Cysat, den Anweisungen von Occo und Wirsung. Beispielsweise habe er Landesseckelmeister Sebastian Bueler und Oberst von Reding Erleichterung von dauernden Beschwerden verschaffen können. Auch habe er gemeinsam mit seiner Frau einer großen Anzahl hilfsbedürftiger Armen geholfen, ohne daß ihm je ein Opfer zu groß gewesen wäre. Egli selbst hätte einige Schwerkranke durch Mittel von Schmerzen befreien dürfen, die aus pflanzlichen Stoffen in der Apotheke zum Kranz durch Wolf persönlich hergestellt würden. Nach Eglis Erklärung interessierte ihn die Metallgewinnung nie besonders. Erst anläßlich des Besuches von Giordano Bruno nahm er auf dessen und Heinzels Wunsch eigene Versuche mit dem am Bergwerk Gonzen gewonnenen Erzkies vor. Die Säuberung allein aber benötigte acht bis zehn Tage, die weitere Behandlung nahm jeweilen längere Zeit in Anspruch, wodurch Heinzels Ungeduld sich immer mehr steigerte, so daß er dann die Goldmacher zu Rate zog*. Die meisten der Versuche wurden durch Hans Jakob Nüscheler in seinem Häuschen vorgenommen, der auf dem Gebiet der Metallgewinnung mit Apotheker Felix Bluntschli und dessen Schwager Ludwig Löw aus Lindau auf Veranlassung der Zollikofer arbeitete ${ }^{82}$.

Ganz entschieden wehrte sich Egli gegen die ihm gemachten Vorwürfe, durch häufigen Verkehr mit den Katholiken, namentlich Pistorius ${ }^{83}$, nicht voll und ganz zu seinem evangelischen Glauben zu stehen. Seiner innersten Überzeugung sei und bleibe er stets treu, was er in verschiedener Hinsicht bewiesen habe.

«Überhaupt kam man von Anfang an überein, anläßlich der Zusammenkünfte weder politische, noch religiöse Fragen zu erörtern, sondern es solle lediglich ein

* Eglis Befund lautete: Aus dem verfeinerten Stahlkies lasse sich mit Schwefel ein Öl herstellen, das, im Scheidewasser geläutert, zu Heilzwecken verwendet werden könne. Goldspuren ließen sich nur in unbedeutenden Mengen finden.

81 StA ZH: A 116, 2.

82 StA ZH: A 116,2, E II 238.

Mscr. 159, 10, 19, 130.

Mscr. $161,31,59$.

Mscr. J 306.

83 Ebenda, Mscr., S. 153,95. Allgemeine deutsche Biographien, Bd. 26,197. 
Austausch von Beobachtungen und Erfahrungen über naturwissenschaftliche Probleme stattfinden. Diese Vereinbarung wurde von allen Mitgliedern der Gesellschaft strikte innegehalten. Ein einziges Mal versuchte Pistorius eine Anspielung zu machen, wurde jedoch sofort von katholischer Seite scharf zurechtgewies en. »

Auf Ansuchen von Hans Jаков KуD in Schwyz begleitete Egli Pistorius zu einer Besprechung nach Wollerau. Kyd hatte auf dem Heimritt von Zürich ein Bülgli* verloren, worin sich ein gebundenes Büchlein befand, über natürliche und übernatürliche Dinge handelnd, ein Wörterbuch in sechs Sprachen, ein Memorial von Conrad Dreyer in Prag mit neun Briefen, an Heinzel gerichtet, sowie drei verschlossene, jedoch unversiegelte Schreiben an Pistorius. Dieser Verlust versetzte Kyd in große Aufregung, wodurch sein Steinleiden wieder zum Ausbruch kam. Da ihm Egli bereits einmal Erleichterung durch ein Mittel verschaffen konnte, erbat er dessen Hilfe. Pistorius aber wollte er den Verlust des Bülglis und dessen Inhalt mitteilen und sich bei ihm gebührend entschuldigen ${ }^{84}$.

Auf Anordnung der zürcherischen Obrigkeit fand in Eglis Wohnung «Zum Silberschild» eine Hausdurchsuchung statt. Man fand im Waschhaus einen großen Brennofen, zwei kleine Destillieröfen und drei weitere kleine Öfen. In einem davon war ein großer Kolben, enthaltend etliche «Sachen», die man nicht zu definieren wußte. In einem Waschraum lagen «Gutteren» nebst einem großen weiten Gefäß mit allerlei unbekannten Dingen, viele Tiegel und Werkzeuge aller Art. Auch im Studierstübli standen etliche Flaschen, gefüllt mit «klarem und mit trübem Wasser », einige in dunkles Papier eingewickelt. Auf einer derselben enthielt ein Zettel die Angaben: « 7 Lot 1 Dukaten Silber, Gewicht 15 Lot Wasser. » Bei ihrer Einvernahme erklärte Frau Egli, durch ihren Vater sei sie an wissenschaftliche Experimente gewöhnt, um die Liebhaberei des Gatten habe sie sich nie bekümmert. Wenn er einem Kranken helfen könne, freue sie sich mit ihrem Mann. Junker Heinzel hätte ihr Haus allerdings öfters aufgesucht, sei auch manchmal ungeladen zu Tisch erschienen, was ihr nichts besonders paßte, da er große Ansprüche stellte, die sich ein Pfarrhaus mit vielen Kindern nicht leisten könne. Eine Entschädigung für die Mahlzeit oder ein Batzen an die Jungfrau für seine Bemühungen wurde nie verabreicht. Als sorgliche Hausfrau habe sie allerdings das Kostgeld aufgeschrieben und eine Rechnung gestellt. Nüscheler habe hin und wieder Sachen geliefert, Krieg und Freuler kenne sie nicht, Junker Topfer und Junker Zollikofer hätten Egli, wie viele fremde Wissenschafter, besucht ${ }^{86}$.

* Bülgli = lederner Sack für Wertsachen (Idiotikon, Bd. IV, 1214). Die Tasche wurde in der Nähe von Wädenswil von einem Bauern gefunden, der sie der zürcherischen Obrigkeit überbrachte (StA ZH: BV 36/269, 289) ${ }^{85}$.

${ }^{84}$ Frau Egli war die Tochter von Sebastian Schmidt, Pfarrer und Mathematiker in Oberwinterthur.

85 StA ZH: A 267, 166.

85 Ebenda, B V 36,269, 289, Bügli = Sack für Wertsachen. Idiotikon Bd. IV/1214.

86 Ebenda, A 27, 166. 
Eglis größter Fehler lag in der Schwachheit und Nachgiebigkeit gegenüber Heinzel. Vor dem Aufenthalt der Junker in Zürich befaßten sich die Alchemisten nie mit Experimenten für Goldgewinnung. Heinzel aber besaß bereits einige Kenntnisse. Der Besuch Brunos erfüllte ihn mit einer Leidenschaft, der alles geopfert werden mußte. Eglis Interesse bei den Versuchen des Nolaners, seine offen bezeigte Begeisterung für dessen Lehren, diente den Junkern. Sie standen bei der Obrigkeit in hohem Ansehen, verkehrten in den Kreisen der meisten Ratsherren, man bezeigte ihnen größtes Entgegenkommen, und so fühlte sich auch Pfarrer Egli verpflichtet, ihren Wünschen zu entsprechen, und zwar durchaus nicht im geheimen ${ }^{87}$.

Leider ließ sich Egli gutmütigerweise auch in Bürgschaften ein. Pfarrer Samuel Gruner* in Seengen, Mitglied der Gesellschaft, gab Caspar Krieg in Bellikon ein Darlehen im Betrage von 200 Gulden. Egli übernahm die Bürgschaft, ebenso eine solche für Heinzel, welchem Hans Jakob Kyd 800 Gulden zu einer Reise in die Niederlande vorstreckte. Ferner hatte Egli für die durch Diethelm Rüssi in Rapperswil an Freuler gelieferten Mineralien und Chemikalien nachträglich aufzukommen. Nach dem Falliment Heinzels meldeten sich viele seiner Gläubiger bei Egli. Schließlich stand er wegen der übernommenen Bürgschaften selbst vor dem Konkurs und war zur Flucht gezwungen. In seinem Schreiben an Hans Rudolf Rahn beteuert er, wie sehr er seine Schwachheit bereue - «an allem Unglück, welches das Land betroffen, tragen allein die Heinzel schuld. Trotzdem sie nie ein Versprechen gehalten, ist doch jedermann auf ihre Überredungskunst hineingefallen. Ich bin ein armer elender Sünder, aber kein Schelm und Betrüger.» ${ }^{88}$

Noch 1608 schuldete Heinzel Pfarrer Egli nebst den Darlehen und den Bürgschaften für ihn 87 Reichstaler für Kostgeld! Umsonst hoffte Egli, durch die Tochter Veronika nach ihrer Erbschaft entschädigt zu werden. Dabei hatte Heinzel die Unverfrorenheit, Egli nach Marburg, wo dieser als beliebter und geschätzter Professor und Schloßprediger amtete, zu schreiben: Er schätze seinen lieben alten Freund immer noch und wisse, dieser habe ihn nie zu Schaden bringen, sondern ihm die echte Kunst der Alchemie beibringen wollen!!

Allerdings scheint Egli doch einige Zeit die Experimente zu weit getrieben zu haben, was besonders bei der Geistlichkeit Anstoß erregte. So schrieb Rüeger nach einem Besuch Eglis 1598 in Schaffhausen an Stucki: «Du wunderst Dich, was Pfarrer Egli bei uns treibt. Auch wir wundern uns und staunen, nicht ohne über sein Verhalten verletzt zu sein. Er war schon zum zweitenmal hier in der Stadt, aber nie hat er einen der Pfarrherren begrüßt. Ich glaube, er besucht die Alchemisten. Dir sei es ins Ohr geflüstert, ,daß der Tüfel nur unsern Bürgermeister

* Gruner Samuel $\dagger 1625$ VDM von Bern, Pfarrer zu Seengen 1568 bis 1619, $\infty$ 1) ... Margareta Zeender; 2) .... 1569 Elisabeth Glar.

87 StA ZH: A 22,61.

88 Ebenda, E II 358. 
nit beschieß', welcher zum Glück abwesend ist. Wenn das, was ich hörte, wahr ist, soll beider Lage äußerst betrüblich sein, aber ich kann nichts behaupten. ${ }^{89}$

Ähnlich antwortete Rüeger am 7. März 1598 auf eine Mitteilung Stuckis: «Ich bin erstaunt, daß Du es so schwer nimmst, wegen Heinzel und wenn einer jener Störer der christlichen Kirche (Pistorius) versuchte, Dich Eurem Egli gleichzustellen. Fürwahr eine ausgezeichnete Gesellschaft von Juden, Götzendienern, schwankenden Sehern, wie sich unsere Gegner auszudrücken belieben, die jedoch so eifrig mitmachen. Vielleicht hat ihnen ein Theologieprofessor von unserer Seite noch gefehlt und deshalb hat Dich jener Apostat zuzuzählen versucht. Vermöchte ich doch nur unsern Conrado (Bürgermeister Meyer) davon abzubringen. Ich habe solchen Kummer um ihn.»*90

Mit keinem Gedanken befaßte sich Heinzel mit dem Leid, dem Kummer und den Sorgen, welche er über die Familie des Pfarrers gebracht, welchen die Sehnsucht nach dem Vaterland nie verließ. Raphael Egli starb zu Marburg den 20. August 1622, nachdem ihm dort ein schönes und segensreiches Wirkungsfeld beschieden gewesen.

Guten Einblick in die Begebenheiten gewährt auch WiLPERT ZoLLERs Verhör. Als junger Mann fand er bei der Handelsgesellschaft Zollikofer Anstellung. JАков und Sigmund Zollikofer** waren eng befreundet mit Bartholome Schobinger und interessierten sich für seine Studien. Ein begeisterter Alchemist wurde Sigmunds Sohn Ulrich, der zudem ein großer Gönner von Wissenschaft und Kunst war. Er besaß ein Bergwerk im Gotthardgebiet, wo Eisen- und Erzfunde gemacht wurden. Nun suchte er einen Sachverständigen, der ihm in der Person von Junker Topfer in Meißen empfohlen ward. Dieser weilte längere Zeit auf Nengensberg, dem Gute der Zollikofer, und erteilte dem Hauslehrer der Kinder, Wendel Irmel, einem aus Durlach vertriebenen Geistlichen, Anleitung in der Metallgewinnung. An den Versuchen nahm auch die Schwester Unsula ZolLIKofer mit ihrem Gatten Hans Lochmann öfters teil. Durch diesen Schwager erfuhr Ulrich Zollikofer von den Experimenten Eglis im Auftrage von Heinzel. Mit Junker Topfer besuchte er Egli in Zürich und bat ihm um Prüfung der in

* Dies, nachdem Stucki wiederholt an Zusammenkünften teilgenommen, wobei auch Pistorius, Kyd, Bueler wie Zollikofer anwesend waren.

** Zollikofer (schwarze Linie) Sebastian gründete mit seinem Bruder Ludwig und Lienhard Keller eine Handelsgesellschaft. Seine Nachkommen betrieben diese weiter. Der Enkel Ulrich erwarb 1591 die Gerechtigkeit des Erblehenhofes Nengensberg und Karrersholz (Gemeinde Steinach), von dem Spital in St. Gallen ertauscht gegen Rent und Gülten ${ }^{91}$. Ulrich Zollikofer 1561 bis 1608, Handelsherr, Stadtammann zu SG 1597-1603, $\infty \ldots$ 1590 Agnes Reichling von Meldegg.

${ }^{89}$ StA ZH: E II 358.

90 ZB ZH: Mscr. 151, 18.

91 Stiftsarchiv St. Gallen, L. A. 12,89. Pfalzgrafprotokoll 1084, 82. 
seinem Bergwerk gefundenen Erze. Gemeinsam wurde ein Experiment im Häuschen von Hans Jakob Nüscheler beschlossen. Das erstemal arbeitete Topfer mit Nüscheler, wobei Wendel Irmel Handlangerdienste leistete. Zoller fiel die Aufgabe zu, das Erzkies zu zerstoßen. Egli war lediglich Beobachter und notierte die Vorgänge.

Beim zweiten Mal im Frühjahr 1597 wurde eine größere Gesellschaft eingeladen*. Irmel und Zoller halfen. Jakob Baumann** bediente die Öfen, Egli gab hin und wieder Anleitung. Für die Ausführung dieses Versuches war Zoller von Ulrich Zollikofer beauftragt worden, in Italien eine bedeutende Summe Sonnenkronen einzuwechseln. Das Experiment ergab etliches Gold, doch lange nicht genügend, um den Kostenaufwand zu decken. Das von Egli aufgeschriebene Rezept lautet ähnlich wie dasjenige, mit welchem Bragandino arbeitete ${ }^{+}$. Auf seiner Flucht 1605 fand Raphael Egli bei Ulrich Zollikofer Unterkunft. Dessen Beziehungen verhalfen ihm auch zu der Stelle in Marburg ${ }^{++92}$.

Den weitestgehenden Aufschluß über das Treiben der Goldmacher erhalten wir jedoch durch die Aussagen von HaNs Heinrich Nüscheler*+, der als

* Es waren dies Bürgermeister Keller mit seinen Brüdern, Wilhelm Stucki, Hans Caspar und Hans Ulrich Wolf, Caspar und Hans Lochmann, die beiden Heinzel, Hans Lux Iselin von Basel und andere mehr. Bürgermeister Meyer wurde ebenfalls eingeladen, war jedoch nicht abkömmlich.

** Jakob Baumann war ein Findelkind, im Spital erzogen, dann jung als Söldner in Kriegsdiensten. Hierauf diente er bei einem Chirurgen und Alchemisten in Sachsen, kam zu Junker Topfer und begleitete diesen und verrichtete Handlangerdienste ${ }^{93}$.

+ Rezept: 1 Pfund Quecksilber in einen Schmelztiegel legen, auf ein Kohlenfeuer setzen, von einem orangefarbenen Pulver soviel wie ein gemahlenes Hirsekorn nehmen, es in rohes Wachs einhüllen, ein anderes Körnchen eines schwärzlich-grünen Stoffes ergreifen, in gleich viel Wachs. Zwei Kügeli davon werden in einen Tiegel geworfen, wo das Quecksilber kocht. Frische, sorgfältig angezündete Kohlen darauf gelegt, so daß das Ganze rings herum brennt. Eine Viertelstunde drinnen gelassen, dann behutsam herausgenommen und in ein Gefäß mit einer bläulichen Flüssigkeit gestellt. Ist der Tiegel erkaltet, kann daraus ein Klumpen genommen werden, der ein Pfund wiegt und wie Quecksilber aussieht.

++ Nach E. GöTZINGER: Die Familie Zollikofer verlaborierte Ulrich Zollikofer $30000 \mathrm{Gul}$ den und soll in großer Armut um 1608 gestorben sein. Laut Pfalzratsprotokoll, Bd. 1081, S. 24f., Stiftsarchiv St. Gallen, besaßen jedoch seine Angehörigen noch Nengensberg und Karrersholz, denn sie befanden sich in einem Streit mit dem oben erwähnten Hans Wilpert Zoller, der Anspruch auf diesen Besitz geltend machte.

*+ Hans Heinrich Nüscheler kann nur ein Sohn des Glasmalers Heinrich Nüscheler und der Barbara Wolf gewesen sein. Jedenfalls werden Felix und Hans Jakob Nüscheler als seine Oheime bezeichnet. Wie aus allen Akten hervorgeht, war er ein liederlicher, arbeitsscheuer Bursche, der den Eltern viel Kummer bereitete. Wahrscheinlich wurde er deshalb von seinem Vater früh weggeschickt. Bei Caspar Krieg konnte er allerdings auch nicht viel Gutes lernen.

92 StA ZH: E II 358, 648.

${ }_{93}$ Ebenda, A 27, 161, A 116, 2. 
junger Bursche in die Dienste von Caspar Krieg gelangte und ihn nach Italien begleitete. Da er jedoch die Sprache schwer erlernte, sandte ihn Krieg zu Stülz nach Schaffhausen, der ihn in die Anfänge des Goldmachens einführen sollte. Später nahm ihn Krieg nach Lothringen und Württemberg mit. Hier trafen sie Heinzel mit Ochs, welch letzterer Nüscheler zu einer Anstellung bei Ulrich Muelich in Freiburg verhalf. Der Bursche erwies sich als sehr geschickt und durfte nach einiger Zeit in den Laboratorien des württembergischen Hofes die Öfen bedienen. Dabei belauschte und beobachtete er vieles. Krieg wünschte nun, daß Nüscheler ihm mit den gewonnenen Kenntnissen in der «Kunst» diene und ließ ihn nach Zürich kommen. Hier sollte er Pfarrer Egli über seine Beobachtungen bei Muelich und am württembergischen Hofe Bericht erstatten. Bei seinem Besuch war zufällig Junker Heinzel im Pfarrhaus anwesend, der furchtbar aufgeregt und verärgert schien. Als nun Nüscheler erzählte, wie Muelich aus Quecksilber und geringem Metall Silber herstellte, verlangte Heinzel, der junge Mann solle im Hause seines Oheimes Hans Jakob Nüscheler die erworbenen Kenntnisse zeigen und eine Probe vorführen. Diese fand in Gegenwart von Heinzel, Egli, Krieg und Hans Jakob Nüscheler statt. Es stellte sich jedoch bald heraus, daß der junge Mann geprahlt und reichlich übertrieben hatte. Er wußte nicht mehr, als was man bereits kannte. Heinzel tobte, aber auch Krieg war erbost, denn er vernahm am selben Tag, Heinrich Nüscheler werde wegen wiederholten Diebstahls von der schaffhausischen Obrigkeit gesucht. Er ließ ihn sofort in Gefangenschaft setzen. $\mathrm{Ob}$ aus Bosheit und Rachsucht oder aus Furcht vor Strafe machte Heinrich Nüscheler bei dem Verhör folgende Aussagen: Anläßlich der Errichtung des Laboratoriums auf Schloß Bellikon sei er von seinem Dienstherrn Caspar Krieg beauftragt worden, Geld zu sammeln. Als Spender nannte er den reichen Iselin* in Basel, Frau von Fleckenstein mit Frau von Sax (je 100 Gulden), Felix Platter und Theodor Zwinger, die Brüder Krieg mit ihren Schwägern Zoller, Hans Caspar und Hans Ulrich Wolf, Hans Jakob Fries, mehrere Escher, die Brüder Lochmann, Johannes und Georg Keller, Johann Conrad Meyer und zwei Stokar in Schaffhausen, Pfarrer Samuel Gruner in Seengen, Sulpitius Haller und andere Berner, Lienhard Kasthofer in Aarau, Münzmeister Hans Jakob Wegerich und seine Brüder in Bünden und noch einige Herren, Landammann Sebastian Bueler, Hans Jakob Kyd, Statthalter Jost Schilter von Schwyz, Stadtschreiber Johann Jakob Stocker von Zug (je 50 Gulden), Pistorius (30 Gulden) und noch viele, deren Namen er nicht aufgeschrieben habe. Die Junker auf Schloß Elgg hätten zur Zeit kein flüssiges Geld besessen. Außer diesen Beiträgen mußten für Einrichtung und Betrieb des Laboratoriums auf Bellikon wie auf Schloß Elgg zusätzliche Mittel aufgenommen werden, die Verzasca durch Vermittlung Iselins zur Verfügung stellte.

* Durch dessen Vermittlung Verzaska und Harscher für die Darlehen gewonnen wurden. 
Nüscheler fügte seinen Angaben höhnisch bei: «Die großen Herren lasse man laufen, aber die kleinen Diebe wolle man hängen. ${ }^{94}$ Diese Aussagen müssen die Richter in nicht geringe Verlegenheit versetzt haben, wurden doch die Namen höchster Magistraten genannt. In aller Eile stellte man dem Burschen einen Mannrechtsbrief aus zur Niederlassung in Württemberg und sandte ihn unter Bewachung an die Grenze ${ }^{95}$. Er fand wiederum Anstellung, betrog jedoch den Herzog auf schändliche Weise und wurde schließlich auf dessen Befehl hin am 30. Januar 1606 am Galgen gehängt ${ }^{96}$.

Bei Hans Jakob Nüscheler fand ebenfalls eine Hausdurchsuchung statt. Man entdeckte merkwürdige Vorrichtungen in den Öfen, auch einen geheimnisvollen Kolben. Alle vorhandenen Sachen wiesen auf Goldmachen hin, auch Münzen wurden gefunden. Der angebliche Physikus und Quacksalber war geflohen ${ }^{97}$.

Hans Caspar Waser erhielt noch einige unerfreuliche Briefe von Heinrich Heinzel. Am 3. Juni 1599 schrieb er ihm: «Ich bin ausgestoßen von der ganzen Familie und von allen Freunden verlassen. Es ist schon so : nimmer Geld, nimmer Gsell. So habe ich nirgends mehr eine Heimat und irre herum, bald da, bald dort. Die Alt meint, was Großes sie tue, wenn sie Veronika veranlaßt, mir hie und da 100 Gulden zu senden. Wohin reichen diese!? Ich hab' keine Arbeit und keinen Verdienst, bin auch nicht dazu geschaffen, so kann ich nicht das von mir verlangte Versprechen ablegen, mich nie mehr mit der Goldkunst zu befassen, wie dies meine Brüder fordern. Im Gegenteil bin ich mehr denn je darauf angewiesen. Einmal wird und muß es gelingen. Dann lach' ich über sie und Euch alle. Egli tut mir ja leid, er ist aber besser dran als ich. Felix hat den besten Teil erwählt. Ich soll zwar die Schuld an seinem Tode tragen - aber er hat nun Ruhe, während Ludj und ich herumirren müssen und heimatlos geworden sind. Er ist zu Raymond Weiß nach Lothringen gegangen, wo dieser ihn beschäftigen kann. Ich selbst suche mein Glück wieder in Venedig. Heinzellius. ${ }^{98}$

Dieses Schreiben kennzeichnet Heinzel am besten. In seiner Berichterstattung schrieb Schmidt: «Heinrich ist ein Mann, der nicht imstande ist, seine Sucht zu überwinden und ein neues Leben zu beginnen. Auf meine wiederholten Vorstellungen erklärte er mir, die Goldmacherkunst sei das Geheimnis des ewigen Lebens. Ihr diene er, gleich wie jener Alchemist, dem es geglückt, einen Homunkulus zu schaffen und der dann gezwungen war, nach dem Diktat dieses künstlichen Wesens zu handeln. ${ }^{98}$

94 StA ZH: A 27,161, A 116,2.

95 Ebenda, A 116,2.

96 Ebenda, A 27, 161. E 163, 116.

97 Ebenda, A 27, 161.

${ }_{98}$ ZB ZH: Mscr., S.279, Nr.210. (28.1. und 3.6.1599). Rueger Chronik: E 47. 
Die griechische Sage erzählt von einem König, der alle Dinge, die er mit seinem Zepter berührte, in Gold verwandelte. Einen solchen Zauberstab suchte Heinzel und verschrieb dafür seine Seele dem Teufel Mammon. Heinrich Heinzel soll um 1608 an einem einsamen Ort gestorben sein, sein Bruder Ludwig bereits 1603.

«Wie sich Verdienst und Glück verketten Das fällt den Toren niemals ein.

Wenn sie den Stein der Weisen hätten, Der Weise mangelte dem Stein.

(GoETHE, Faust II, 1)

Von der gleichen Autorin wurden früher veröffentlicht:

Felix Schmid, Bergbauingenieur von Stein am Rhein

Die Herren von Schönau und Hürus 


\section{Stammtafel}

Die Heinzel von Degerstein, von Augsburg

Wappen: in rot ein silbernes Schwert mit goldenem Knauf, schräg rechts gestellt.

Stammeltern zu Augsburg:

1 Hans Heinzel, Junker,Handelsherr in der 1478-1543 Welsergesellschaft $\infty$... 1506 Catharina Welser $1487-1550$ Bürgermeister zu AugsT. v. Anton und Cath. Vöhlin burg. S. v. Heinrich von Lindau

2 Paul, Junker 1527-158 .

Gelehrter, Astronom $\infty$ 13.12.1558

Elisabeth Rhem 1536-1603
3 Johann Baptist, Junker 1524-1581, Handelsherr, Gelehrter

$\infty 23.1 .1549$

Veronika Im Hof 1530-1599
4. Daniel, Junker 1529-1607

Handelsherr in der Welsergesellschaft 1 1) 24.10.1554 Barbara Welser; क 2) 30.10 .1585 Regina von Stetten

1 Johann Heinrich 1553 bis um 1608, $\infty$ 17.7.1575 Barbara Neidhart, eine Tochter Veronika Augsburg † Elgg 22.8.1597. T.v. Gabriel

2 Johann Baptist 1554-.... $\infty$ 26.10.1579 Barbara Hainkofer

3 Johann Friedrich $1557-\ldots .$. $\infty$ 1) 25.4.1580 Maria Buroner $\infty$ 2) vor 1597 Maria Walther

4. Johann Jakob 1558-.... $\infty$ 1)12.11.1582 Sabina Neidhart, $\dagger$ vor 1597, T. v. Gabriel und Magdalena Stebenhaber

5 Johann Ludwig 1560 bis um 1602, $\infty$ 12.11.1582 Susanna Neidhart, $\dagger$ Elgg 30.3.1595. T. v. Gabriel und Magdalena Stebenhaber

ein Sohn Dietrich $\quad \infty 1618$ Regina Welser. T. v. Friedrich und Maria Puller

6 Johann Peter 1572-1608 ledig, Gelehrter, Altertumsforscher

7 Euphrosina ........ $\infty 27.2 .1582 \quad$ Wolfgang Rechlinger

8 Veronika ........ $\infty 27.2 .1590 \quad$ Hs. Joachim Pachmair 